\title{
THE SEARCH FOR ADDITIONAL VALUE FROM FOOD WASTE USING ANAEROBIC DIGESTION AND PYROLYSIS
}

By

\author{
Vanessa Bairos
}

B.Sc., Ryerson University, 2016

A thesis presented by Ryerson University in partial fulfillment of the requirements for the degree of Master of Science in the program of Molecular Science

Toronto Ontario, Canada, 2019

(C) Vanessa Bairos, 2019 


\section{Author's Declaration}

I hereby declare that I am the sole author of this thesis. This is a true copy of the thesis, including any required final revisions, as accepted by my examiners. I authorize Ryerson University to lend this thesis to other institutions or individuals for the purpose of scholarly research. I further authorize Ryerson University to reproduce this thesis by photocopying or by other means, in total or in part, at the request of other institutions or individuals for the purpose of scholarly research. I understand that my thesis may be made electronically available to the public. 


\section{The Search of Additional Value from Food Waste Using Anaerobic Digestion and Pyrolysis}

Vanessa Bairos

Master of Science, Molecular Science, 2019

Ryerson University

Abstract

Rethinking food waste could be an effective means to bridge the gap between local liabilities and finding value from this lost resource. While traditionally biomass has been used as a renewable energy source through combustion, there are more clever solutions. Biomass conversion can undergo both biotechnological (anaerobic digestion) and thermal (pyrolysis) conversion processes to produce end products that could sequester carbon from the environment. To date, both processes are being used independently for a number of energy carriers; however, no research at the moment has focused on converting biomass using anaerobic digestion to produce a fertilizer and extract further value by subjecting the digestate to pyrolysis. In the pyrolysis system, this feedstock is burned creating valuable carbon allotropes used to reshape next-generation energy devices, while removing carbon from the atmosphere. The objectives of this thesis are to determine if the digestate can be a suitable fertilizer as is. Based on N:P:K ratio, the digestate may not be as useful as a fertilizer. The second objective is to use the digestate as a suitable feedstock for pyrolysis in the search of high value nanocarbons. Although, the digestate was successful in being a feedstock, it did not provide insight to high value nanocarbons. Lastly, the solid product from pyrolysis (coke) was exfoliated to retrieve the advanced carbons using electrochemical exfoliation and sonication. 


\section{Acknowledgments}

First, I would like to thank my supervisor Bryan. Without Bryan's ability to see the best in people and capability recognizing their strengths, I would not be writing this thesis today. Thanks to an opportunity Bryan had provided me months prior to my masters, I would not have grown into the researcher, leader and person I am. He's been an astonishing mentor and role model for hard work, generosity, dedication and continuous curiosity. I cannot thank him enough for the impact he has made on me.

A huge thank you to my lab mates and the rest of the Department of Chemistry family, as you have always been supportive of me and my research. I would like to extend my gratitude to Sahana Sritharan, Rob Denning and Shawn McFadden for their continuous support and friendship throughout my masters.

I would like to thank both of my industry partners; CCI BioEnergy and Bio-Techfar for their partnership and continuous exploration to create a better future. Each partnership has flourished in their own ways, but both have undeniably taught me how to bridge the gap between academia and industry. Both have allowed me to grow my project management skills and tap into new disciplines.

I would like to thank my committee members Dr. Hausner and Dr. Bostan for their time and effort reviewing my thesis, making this thesis the best it could be.

I would like to thank my parents, my brother, in-laws and friends for their encouragement and ongoing support during the long path that has led to this thesis. Lastly, I would like to thank my fiancé Jesse. I can't express how much you've helped me keep sane during this process and continue to encourage me. You have always been there for me and I'm eternally grateful. 


\section{Table of Contents}

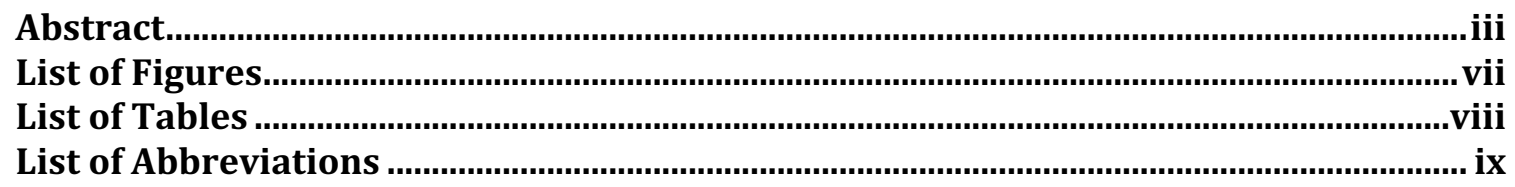

Chapter 1: Converting Waste-derived Biomass into Energy and other value-added

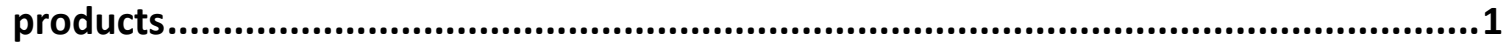

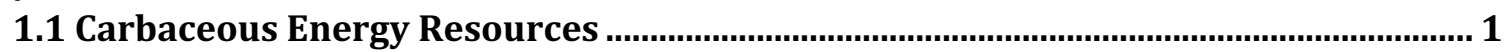

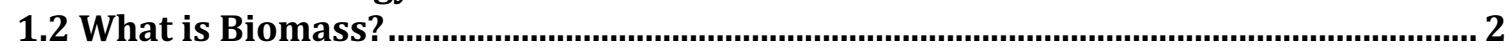

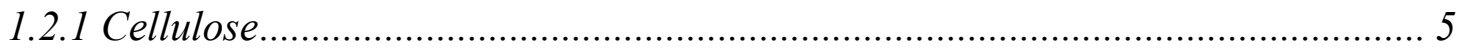

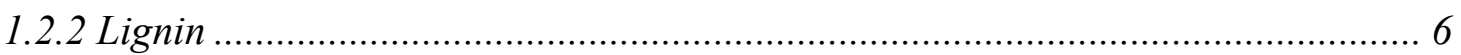

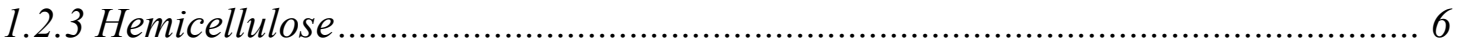

1.3 Traditional Value-added from Biomass Waste ....................................................... 9

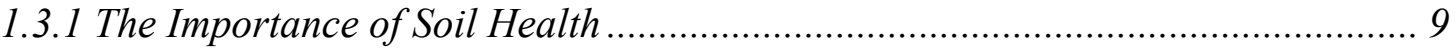

1.3.2 Historical Usage of Waste as a Fertilizer........................................................ 10

1.3.3 Modern Chemically Derived Fertilizers ..................................................... 11

1.3.4 Manufactured Fertilizers .................................................................. 13

1.3.5 More Recent Soil Amendment Strategies with Biomass ................................. 14

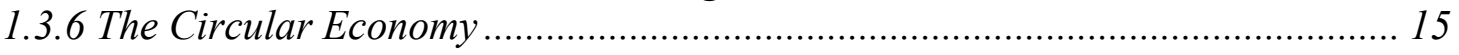

1.4 Relevant technologies for biomass conversion to energy carriers ............................17

1.4.1 Combustion and Cogeneration ...................................................................... 17

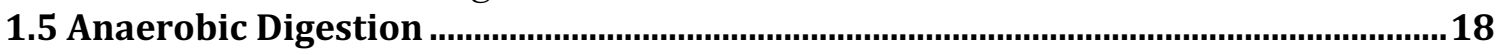

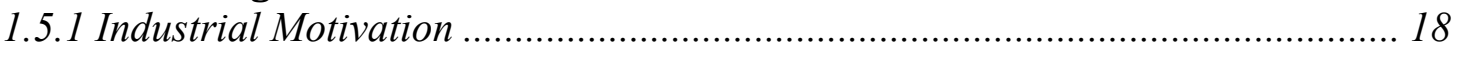

1.5.2 Anaerobic Digestion Technologies used by CCI BioEnergy .......................... 19

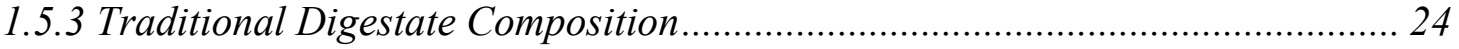

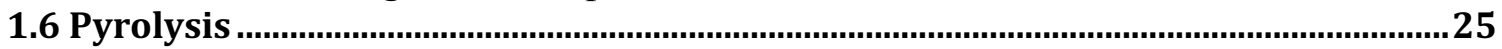

1.6.1 Background of Process ..................................................................................... 25

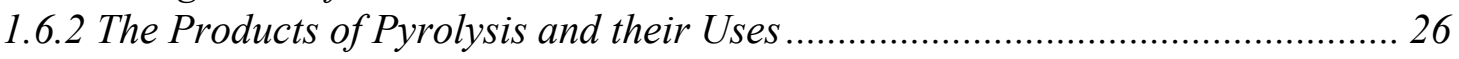

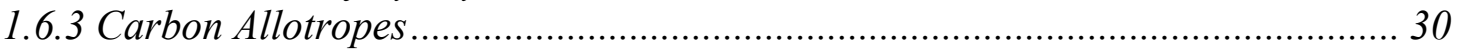

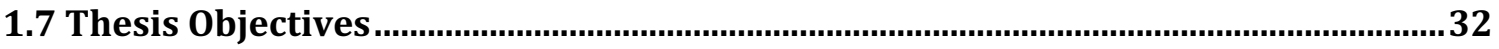

Chapter 2: Methods and Materials .................................................................. 34

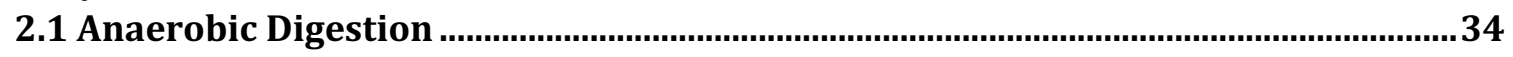

2.1.1 Metal Analysis using Flame Atomic Absorption Spectroscopy ........................ 35

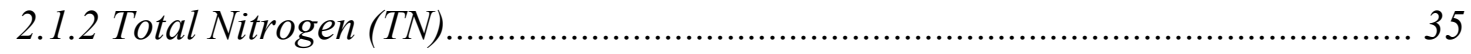

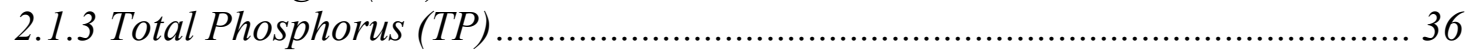

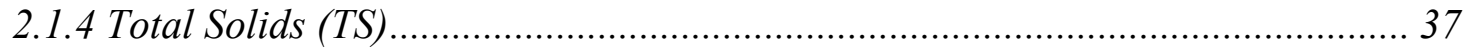

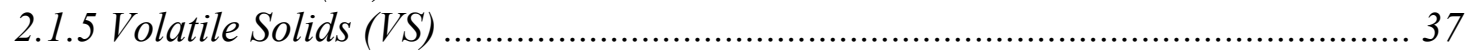

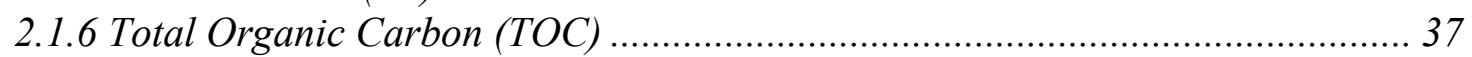

2.1.7 Volatile Fatty Acid/ Total Alkalinity Content (VFA/TAC) ............................... 38

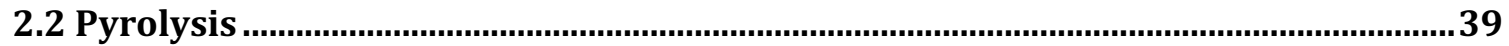

2.2.1 Isolation/ Exfoliation of Carbon Allotropes....................................................... 40

2.2.3 Characterization Techniques for Carbon Allotropes....................................... 42

2.2.4 Operating BT-Lab Prototype ............................................................................ 44

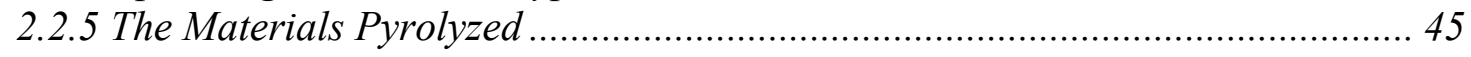

2.2.6 Characterization of Bio-Oil, Biochar and Coke ........................................... 49 
Chapter 3: Results \& Discussion.........................................................................52

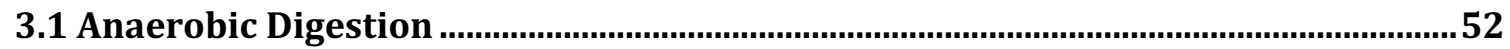

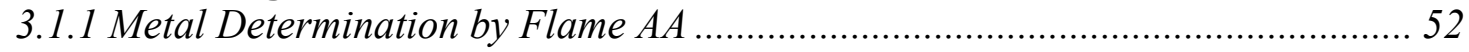

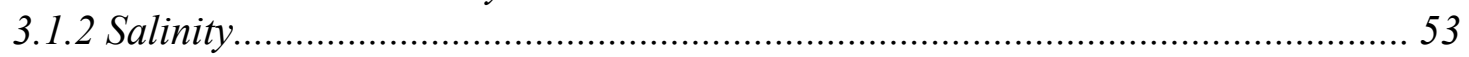

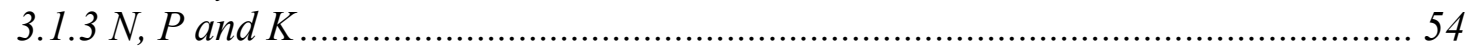

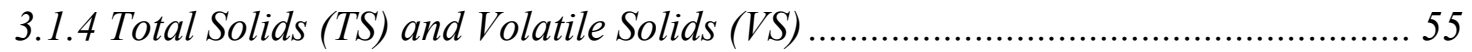

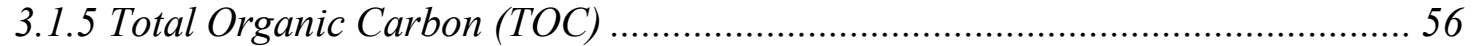

3.1.6 Volatile Fatty Acid/ Total Alkalinity Content (VFA/TAC) .............................. 56

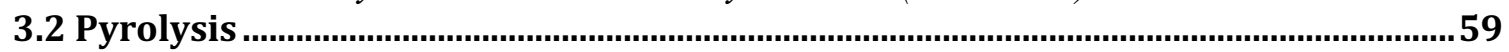

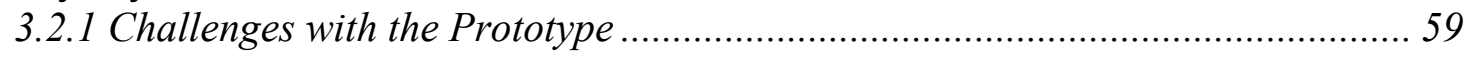

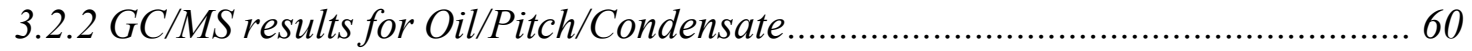

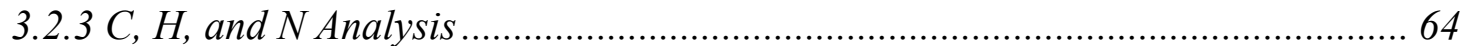

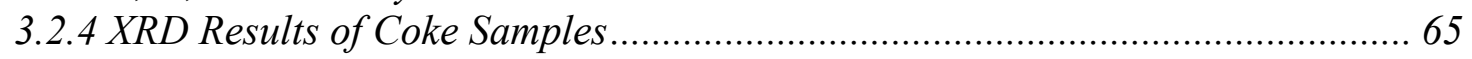

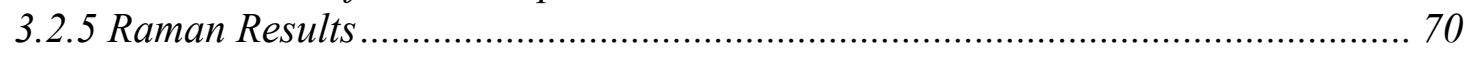

Chapter 4: Conclusions and Future Work ...........................................................72

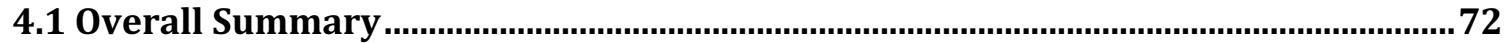

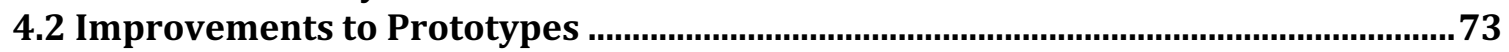

4.3 Future Work with the Carbon Allotropes from Pyrolysis............................................... 74

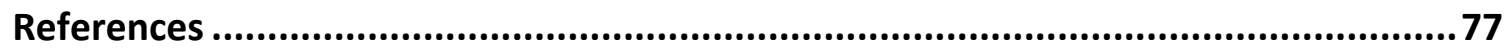




\section{List of Figures}

FIGURE 1.1: BIOMASS SOURCES OF ENERGY: IN DEVELOPING COUNTRIES BIOMASS CONTRIBUTES TO 22\% TO THE TOTAL PRIMARY ENERGY (BECAUSE OF COOKING FOOD). IN INDUSTRIALIZED COUNTRIES, TOTAL CONTRIBUTION OF BIOMASS IS 3\% TOTAL PRIMARY ENERGY.THE USE OF BIOMASS IN HEAT AND INDUSTRIAL ENERGY CONTRIBUTES TO A TOTAL OF 3.3\% BY 2050. TRANSPORT BIOFUELS REPRESENT 2\% OF TOTAL BIOENERGY.4 3

FIGURE 1.2: SCHEMATIC REPRESENTATION OF WOOD CELL WALL, MIDDLE LAMELLA (ML), PRIMARY WALL (P), SECONDARY WALL (S1-S3)

FIGURE 1.3: CELLULOSE STRUCTURE DEPICTED AS POLYMER; LIGNIN ALCOHOL PRE-CURSORS; HEMICELLULOSE STRUCTURE

FIGURE 1.4:THE NEW TAKE ON TRADITIONAL WASTE AND CREATING VALUE FROM ITS DISPOSAL

FIGURE 1.5:SUMMARY OF FOUR MAJOR PROCESSES OF ANAEROBIC DIGESTION 20

FIGURE 1.6:PROCESS OF CCI'S ANAEROBIC DIGESTION 23

FIGURE 1.7:CARBON ALLOTROPES - GRAPHENE (LEFT), GRAPHITE (RIGHT), CARBON NANOTUBE (BOTTOM LEFT) AND FULLERENE (BOTTOM RIGHT) 31

FIGURE 1.8:GRAPHENE AND ITS OTHER RELATED MATERIALS ARE EXPECTED TO INCREASE BY 2025

FIGURE 2.1:DIAGRAM OF ELECTROCHEMICAL EXFOLIATION USING H2SO4 AND HOW THE COKE (GRAPHITE) PARTICLES SUSPEND ${ }^{37}$

FIGURE 2.2:DIAGRAM OF MECHANISM FOR GRAPHENE SONICATION

FIGURE 2.3: X-RAY DIFFRACTION ILLUSTRATION

FIGURE 2.4:BT-LAB PROTOTYPE

FIGURE 2. 5:(LEFT TO RIGHT); EUCALYPTUS (EUC) WOODCHIPS WHICH WERE BALL MILLED AND THEN GROUND FURTHER USING A BLENDER. BARK (DBA) WAS PREVIOUSLY BALL MILLED AND SO WAS THE BARK RESIDUE (DMR)

FIGURE 2.6:(LEFT TO RIGHT); WALNUT (WAN) SHELLS THAT HAVE BEEN GROUND. CELLULOSE

(CUL) IN A FINE POWDER FORM. DISCO ROAD DEWATERED 30\% DIGESTATE (VDI) DRIED 48

FIGURE 2.7:XRD SLIDE WITH AND WITHOUT KAPTON FILM 50

FIGURE 3.1:NPK VALUES FOR EACH DIGESTATE AND THE CORRESPONDING RATIO ON THE RIGHT SIDE OF THE LEGEND.

FIGURE 3..2: XRD PATTERNS OF GRAPHITE, GRAPHENE OXIDE, AND GRAPHENE 66

FIGURE 3.3: XRD PATTERN FOR FULLERENE POWDER 66

FIGURE 3.4: GRAPHITE STANDARD FROM HB PENCIL $\quad 66$

FIGURE 3.5: EUC CHAR (RED) AND COKE (BLUE) SIEVED 67

FIGURE 3.0.6: RAW CELLULOSE PRIOR TO PYROLYSIS (RED), CUL COKE-1 (BLUE), GRAPHITE (GREEN)

FIGURE 3.7: DIGESTATE COKE (2), PRIOR TO SIEVING (BLUE) AND DIGESTATE (2) AFTER SIEVING USING 53 M (RED)

FIGURE 3.8:DIGESTATE (1) COKE AFTER SONICATION IN BLACK TEA (BLUE), DIGESTATE (1) COKE AFTER 0.1 M H2SO4 ELECTROCHEMICAL EXFOLIATION (GREEN) COMPARED TO DIGESTATE SIEVED PRIOR TO EXFOLIATION (RED) 
List of Tables

TABLE 1.1: CONTENTS OF STRUCTURAL COMPONENTS OF 4 LIGNOCELLULOSIC PLANTS IN \% DRY WEIGHT 11

TABLE 1.2: COMMON NUTRIENTS AND UPTAKE NEEDED FOR PLANT HEALTH 12

TABLE 2.1:SUMMARY OF FEEDSTOCK MATERIAL, PRE-TREATMENT ASSOCIATED WITH IT, HOW MANY RUNS AND THE ABBREVIATION

TABLE 2.2: FEEDSTOCK RUNS AND CORRESPONDING PARAMETERS EUC= EUCALYPTUS WOODCHIPS, WAN= WALNUT SHELLS, DMR/DBA= BARK. A) COKE SAMPLES OF SPECIFIC RUNS WITH CORRESPONDING TEMPERATURES AND WEIGHT PERCENTAGE; B) CHAR SAMPLES OF SPECIFIC RUNS WITH CORRESPONDING TEMPERATURES AND WEIGHT PERCENTAGE

TABLE 3.1: EACH LOCATION OF DIGESTATE OVER A 3-MONTH PERIOD AND THE CORRESPONDING ELEMENTAL ANALYSIS FROM FLAME ATOMIC ABSORPTION. SD REPRESENTS STANDARD DEVIATION

TABLE 3.2: AGRICULTURE GROWN IN SPECIFIC SALT TOLERANCE 36

TABLE 3. 3: NITROGEN, PHOSPHORUS AND POTASSIUM CONCENTRATIONS OF EACH DIGESTATE

TABLE 3.4: TOTAL SOLIDS, VOLATILE SOLID COUNTS IN PARTS PER MILLION FOR EACH DIGESTATE AS WELL AS TOTAL ORGANIC CARBON, VOLATILE FATTY ACIDS AND TOTAL ALKALINITY CONTENT

TABLE 3.5: COMPOUND LIST FOUND IN EUCALYPTUS OIL AND PITCH

TABLE 3.6: LIST OF COMPOUNDS FOUND IN EUCALYPTUS CONDENSATE AND CORRESPONDING PERCENTAGE

TABLE 3.7: C, H, AND N ANALYSIS OF COKE AND CHAR FOR DIFFERENT FEEDSTOCKS 


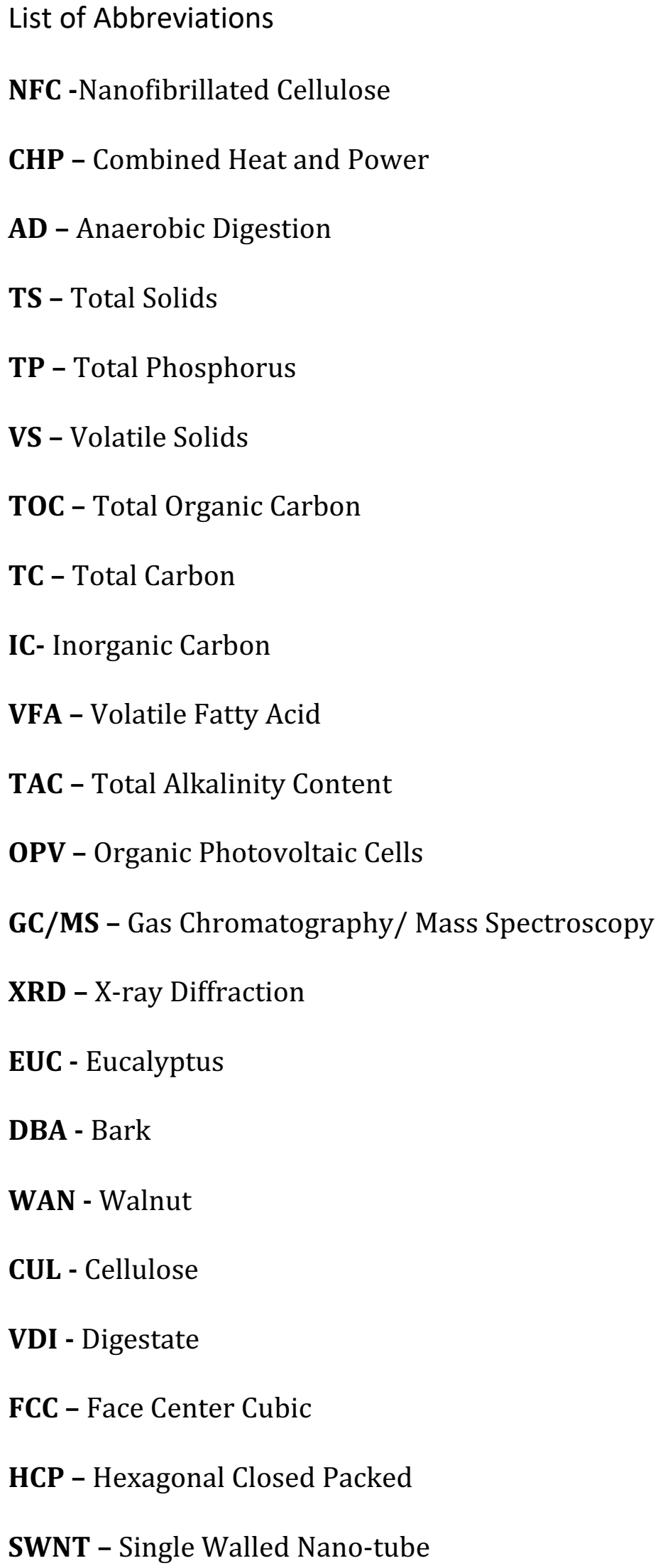




\section{Chapter 1: Converting Waste-derived Biomass into Energy and other value-added products}

\subsection{Carbaceous Energy Resources}

Since the discovery of fire, humanity has been using biomass as a source of energy. However, in the 19th and 20th century, with the industrial revolution and the advent of the combustion engine, there was a seismic shift away from biomass towards petroleum, coal and natural gas as our dominant sources of energy. However, when considering the carbon life cycle, the use of fossil fuel resources is not sustainable, and many questions emerge when we further drill down on the economic, ecological and environmental impacts of its use. Burning of fossil fuels increases the level of $\mathrm{CO}_{2}$ in the atmosphere directly associated with global warming. These greenhouse gases drive climate change and the process cannot be quickly reversed. The adverse effect of greenhouse gas emission and declining fossil fuels reserves has led to a search for sustainable and environmentally benign sources of energy. ${ }^{1}$ To this end, it is vital to the future of fuel and chemical production that we explore environmentally sustainable energy carriers. ${ }^{1}$

While growing crops directly for energy generation is not environmentally sustainable, the conversion of biomass-residues from agricultural or food production waste would effectively lower the carbon footprint. Furthermore, owing to the ability of plants to efficiently sequester carbon dioxide from the atmosphere the conversion of plant biomass would mitigate the carbon footprint if we converted it into additional value, or energy carriers. With the added benefit of diverting organic waste from landfills, which ultimately produces a more harmful greenhouse gas in the form of methane, we would 
move even closer to a circular sustainable loop.

\subsection{What is Biomass?}

According to Biomass Energy Centre, biomass is defined as a biological material obtained from living or recently living organisms, and is often referring to plant derived materials. ${ }^{2}$ The total biomass production per annum on earth is approximately 100 billion tonnes of organic dry matter from land biomass and 50 billion tonnes of aquatic biomass. Food use for human consumption of plant biomass represents $1.25 \%$ of the entire land biomass. ${ }^{2}$ Some biomass material is used directly for heat generation such as wood fuel or processed to different products described further in this thesis. Examples include; dedicated agricultural crops for energy (e.g. corn, sugarcane, rapeseed, etc.); branches and wood residues from forestry activities; and organic waste from municipalities and industrial food activities (dairy, sugar, beer, wine, sewage sludge, etc.). Table 1 shows the current global composition of biomass energy, not including food grown for human consumption. ${ }^{3}$ 


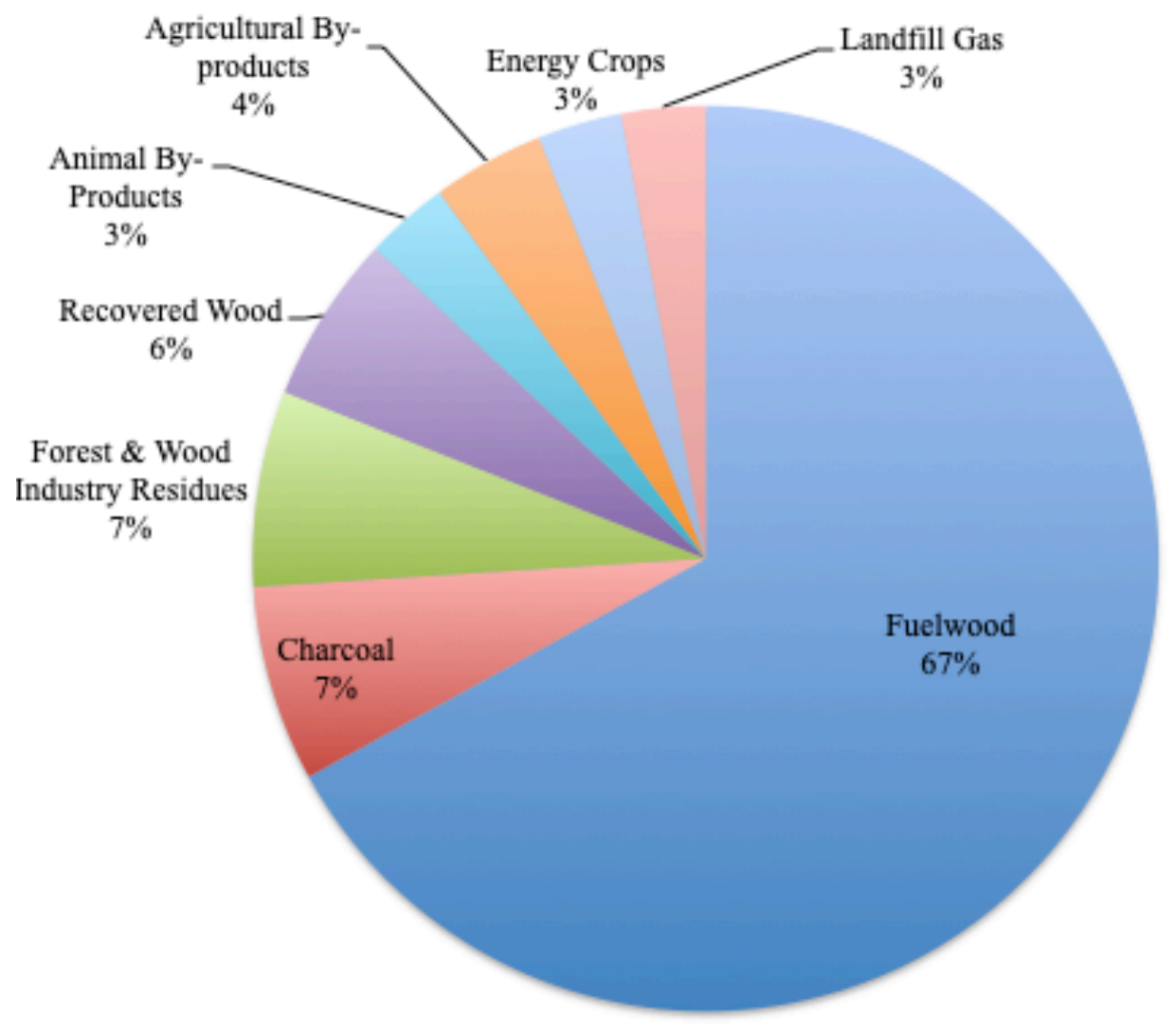

Figure 1. 1: Biomass sources of energy: In developing countries biomass contributes to $22 \%$ to the total primary energy (because of cooking food). In industrialized countries, total contribution of biomass is 3\% total primary energy. The use of biomass in heat and industrial energy contributes to a total of 3.3\% by 2050. Transport biofuels represent $2 \%$ of total bioenergy. 4

In order to appreciate the value of biomass, it is important to understand its chemistry. Plant biomass feedstocks are comprised of lignocellulosic materials that make up most of the plants mass. Biomass is primarily comprised of carbohydrate polymeric materials, extracts (small molecules) and small quantities of inorganics. Through photosynthesis, plants convert carbon dioxide and water into primary and secondary metabolites. Primary metabolites are carbohydrates, lignin and their cellulose/hemicellulose and lignocellulose biopolymers. The secondary metabolites include products such as gums, resins, rubber, waxes, terpenes, steroids, tannin, plant 
acids, alkaloids, etc. are present in low amounts in the plant. The primary metabolites can be converted into biofuels where the secondary metabolites can be used for high value chemicals such as food flavors, cosmetics, pharmaceuticals, etc. ${ }^{2}$ Yet, plant biomass represents one of the most abundant and underutilized biological resources on the planet and can be seen as a promising source of material for fuels and raw materials.

The three main biopolymers that make up the sheathing around the plant cell are; cellulose, hemicellulose and lignin (a cartoon of the cell wall is presented below; Figure 1.2). The primary wall comprised mainly of cellulose, pectin and hemicellulose provides mechanical strength but also expands to allow the cell to grow and divide. The thicker and stronger secondary wall, accounts for more carbohydrate content, and is deposited once the cell has ceased to grow. Secondary walls are the major component of wood and a source of nutrient for livestock who consume plant matter. The secondary walls contain cellulose, hemicellulose and lignin, and have slight different growing stages and compositions as shown in S1, S2 and S3 (Figure 1.2). The cellulose fibrils are embedded in a network of hemicellulose and lignin.

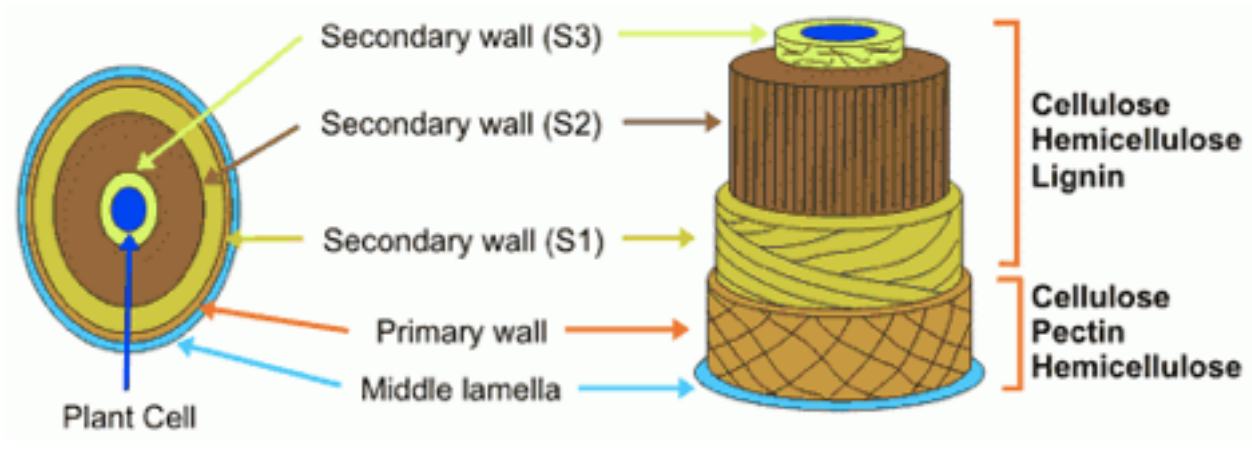

Figure 1. 2: Schematic representation of wood cell wall, middle lamella (ML), primary wall (P), secondary wall (S1S3) 


\subsubsection{Cellulose}

The most abundant organic compound in the biosphere is cellulose (see chemical structure in Figure 1.3), and this is synthesized and degraded at the rate of $\sim 10^{15} \mathrm{~kg}$ annually. ${ }^{5}$ Cellulose is an important structural component in the cell walls of green plants and algae. Cellulose is a polysaccharide consisting of a linear chain of several hundred to thousands of $\beta$-linked D-glucose units (Figure 1.3). The acetal linkage is beta, which makes it structurally different from starch. This leads to the non-digestibility in humans as we lack the appropriate enzymes to breakdown the acetal linkages in cellulose.

The multiple hydroxyl groups on the glucose from one chain form hydrogen bonds with oxygen atoms on the same or on a neighboring chain, holding the chains together side-by-side to form microfibrils with a high tensile strength. In the cell wall, crystalline cellulose is partially aggregated into larger structural units called fibrils, which are more commonly known as microfibrils. These microfibrils combine to form sheets, which form discrete wall layers with a random interwoven network. ${ }^{6}$

Depending on the plant source, cellulose and its properties will differ. Cellulose from wood pulp typically has chain lengths between 300-1700 glucose units. Cellulose exhibits properties such as high moisture absorbency, flexibleness, dyeability and with mechanical properties, cellulose could be used for potential applications such as nanomaterials. Nanofibrillated cellulose (NFC) is composed of nanosized cellulose fibrils. The fibrils are isolated from wood-derived residues. The material is a building block for high-strength composites due to its properties with an elastic modulus. 


\subsubsection{Lignin}

Lignin gives plants shape and stability and is the main binder for cellulosic components. ${ }^{7}$ Lignin has an amorphous highly cross-linked three-dimensional structure consisting of a non-regular arrangement of phenyl propane units. ${ }^{8}$ The composition of lignin in wood varies from species to species. However, the biochemical monomers that make up lignin (See Figure 1.3). include three different phenyl propane monomers: pcoumaryl alcohol, coniferyl alcohol and sinapyl alcohol. ${ }^{9}$ Coniferyl alcohol and sinapyl alcohol are both methoxylated and the methyl monomer content of hardwoods is higher than that of softwoods. The main precursors in softwoods are coniferyl alcohol and minor amounts of p-coumaryl alcohol, and p-coumaryl alcohol is commonly found in grasses. ${ }^{9}$ Of the polymers found in the plant cells, lignin is the only one that is not composed of carbohydrate (sugar) monomers.

Adding to the complexity of lignin is that there are many possible bonding patterns between individual units. Lignin and cellulose work together to provide structural function in plants; the fibrous cellulose components, are primary load-bearing elements while lignin provides rigidity. Consequently, trees grow much taller than grasses before they bend under their own weight. ${ }^{10}$ Lignin plays a crucial part in transporting water to the plants and is more hydrophobic in nature. The presence of cross-linking of polysaccharides by lignin is one of the obstacles for water absorption to the cell wall. It also plays a role in plant disease. Due to the complexity and insolubility of lignin it is resistant to degradation by most microorganisms, which also enhances its persistence in the soil. ${ }^{9}$

\subsubsection{Hemicellulose}

Hemicellulose is a heteropolysaccharide of glycol and is composed of two or more 
monomer units, namely hexoses and pentoses. ${ }^{5}$ Hemicellulose (Figure 1.3) also consists of xylose, arabinose, mannose and galactose. Xylose is the most common of the sugar monomer present in the largest amount, although in softwoods mannose can be the most abundant sugar. Hemicellulose is a cross-linking amorphous glycan that binds together cellulose microfibrils, and this contributes to its structural integrity. ${ }^{7}$ The hemicellulose backbone is usually made up of a single monomer that is hydrogen-bonded to the cellulose microfibrils. ${ }^{7}$ Hemicellulose is classified according to its compositional units, molar ratios and linkages. Hemicellulose also consists of shorter chain sugar units (500 to 3000) and these units can help bind to cellulose with pectin to form a network of cross-linked fibers. In addition, hemicellulose is commonly a branched polymer, while cellulose is unbranched. It is also known that through covalent and non-covalent interactions with cellulose and lignin, hemicellulose contributes to strengthening the cell wall. Unlike cellulose and lignin, hemicellulose can be readily solubilized when treated by different temperatures. The backbone and a protruding short sugars side chains vary with plant species and age. 

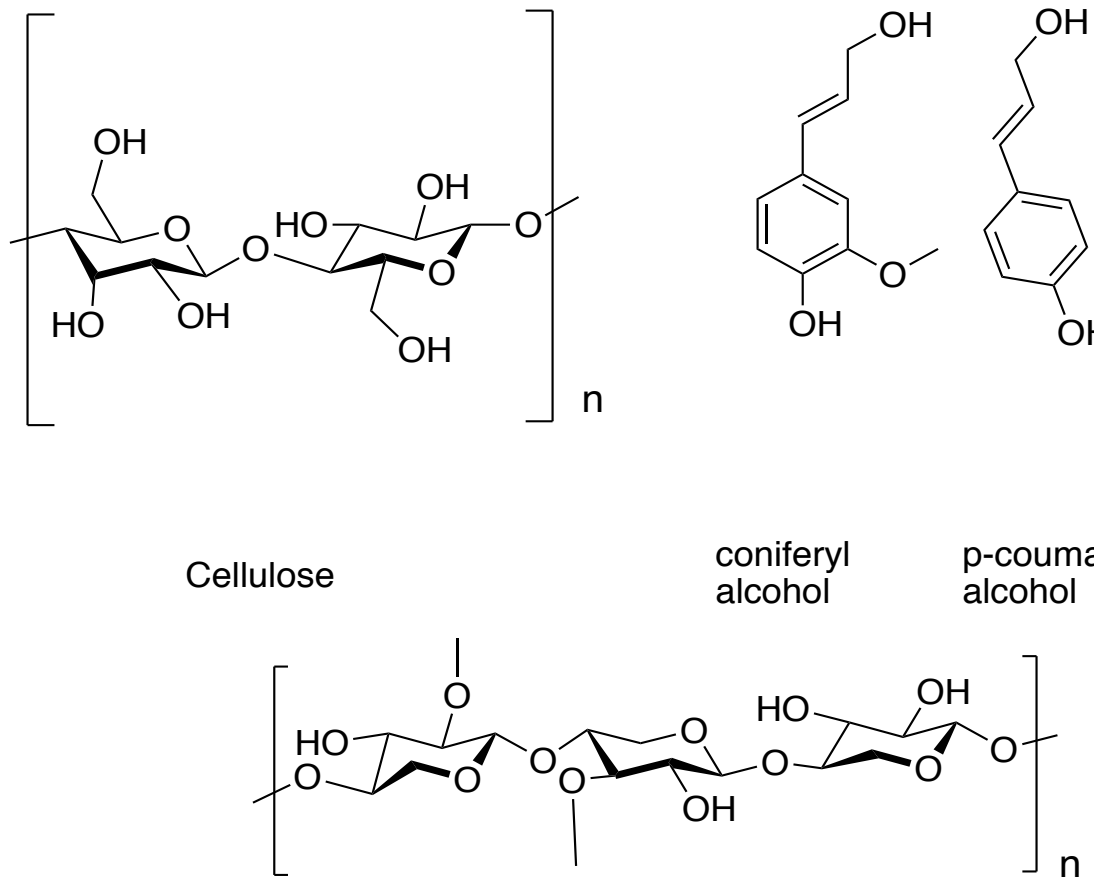

Hemicellulose

Figure 1. 3: Cellulose structure depicted as polymer; Lignin alcohol pre-cursors; Hemicellulose structure

Table 1. 1: Contents of structural components of 4 lignocellulosic plants in \% dry weight ${ }^{11}$

\begin{tabular}{|c|c|c|c|c|c|}
\hline \multicolumn{2}{|c|}{ Plant Type } & Extractives & Lignin & Cellulose & Holocellulose \\
\hline Miscanthus & 20.9 & 14.7 & 30.5 & 29.9 & 60.4 \\
\hline Switchgrass & 16.9 & 21.2 & 35.8 & 21.5 & 57.3 \\
\hline Sorghum & 23.7 & 17.9 & 31.4 & 23.4 & 54.8 \\
\hline Reed & 20.3 & 26.2 & 30 & 23.8 & 53.9 \\
\hline
\end{tabular}

The values shown above are expressed as \% based on dry weight and statistical significance was analyzed by least significant difference $(p<0.05)$. Extractives content ranged from 16.9 to $23.7 \%$, lignin content ranged from 14.7 to $26.2 \%$, cellulose content ranged from 30 to $35.8 \%$, hemicellulose content ranged from 21.5 to $29.9 \%$. The reed collected showed the highest lignin content, whereas miscanthus showed the lowest lignin content. The amount of holocellulose, which consists of cellulose and hemicellulose, was 
higher than the combined number of extractives and lignin, at the 5\% significance level. Although switchgrass was recorded to have the highest polysaccharide content among the crops mentioned, the values were not significantly different at the $5 \%$ significance level. ${ }^{11}$

\subsection{Traditional Value-added from Biomass Waste}

\subsubsection{The Importance of Soil Health}

Soil is a mixture of organic matter, minerals, gases, liquids and organisms that together support life. Body of soil, also referred to pedosphere has four important functions: medium for plant growth; means of water storage, supply and purification; modifier of Earths atmosphere; habitat for organisms. Soil health is the soil quality defined as the continued capacity of soil to function as a vital living ecosystem sustaining plants, animals and humans. Only "living" things can have health, so viewing soil as a living ecosystem reflects a fundamental shift in the way soil should be cared for. ${ }^{12}$ Mechanical cultivation and continuous production of row crops can result in loss of soil, displacement through erosion, and large decrease in soil organic matter with a release of $\mathrm{CO}_{2}$ in the atmosphere. Soils contribution to plant productivity is commonly recognized but soil health also impacts water and air quality. The quality of surface and sub-surface water has been jeopardized due to the imbalance of carbon, nitrogen and water cycling in soil. ${ }^{5}$ Practices such as tillage, cropping patterns, pesticide and fertilizer use influences this imbalance. Soil health can be quantified because soils and their biota provide ecosystems functions that benefit humans. These ecosystems provide value such as storing or releasing water, decomposing plant and animal residues, transforming and recycling nutrients, sequestering and detoxifying organic toxicants, and promoting plant health by suppressing

pathogenic microbes. ${ }^{13}$ Implementation of fertilizers or amendments may balance 
necessity components for soil health. ${ }^{5}$ Healthy balance of available soil nutrients such as $\mathrm{N}, \mathrm{P}, \mathrm{K}$ can conserve soil organic matter and help in plant production. By maintaining soil health, crop growth and yield will increase, resulting in excess waste once crops are tilled, however, by rethinking waste conversion, perhaps we can also find new products can provide addition value for the agricultural sector.

\subsubsection{Historical Usage of Waste as a Fertilizer}

Historically, farm waste (in the form of manure) has been applied to soils in order to provide the necessary nutrients to growing plants. Manure is high in nitrogen and phosphorus, as well as other nutrients that aid in crop growth. ${ }^{14}$ Manure incorporation has been shown to increase soil aggregation, aggregate stability, increase volume of macropores and soil water-holding capacity. ${ }^{15}$ Manure fertilized soils tend to increase soil shear strength in comparison to other fertilizers as well as increasing soil cohesion with decreasing water potential. Manure applications leave the microbial communities in the soil more active, improving soil quality because these communities are important for nutrient and organic matter cycling. ${ }^{15}$ The extra organic matter also helps soil hold water better and also lightens the texture of the soil, enhancing rainfall penetration to roots. It has become increasingly recognized that interactions between root and microorganisms are affected by anthropogenic disturbances, such as agricultural practices and biological modification. ${ }^{16}$ As a result, the rhizosphere (the soils energy powerhouse) requires fertility management for optimal productivity and sustainability of the ecosystem.

While manure is effective in many ways, it also has its limitations. Despite manurebased fertilizers increasing crop growth, there are also some environmental concerns, regarding; soil accumulation, water eutrophication, smell, microbial imbalance and global 
warming. While biosolids (organic matter recycled from sewage) are rich in both nitrogen and phosphorus, these elements have a lower N/P ratio (particularly cattle and hog manure), often resulting in over application of phosphorus (P), specifically when considering the nitrogen $(\mathrm{N})$ needs of crops. $^{12}$ Organic phosphorus adsorption is particularly high with manure application. ${ }^{14}$ This is undesirable in coarse-textured soils, where phosphorus may reach groundwater, especially in areas with low water tables. Phosphorus movement in organic forms from manure enhance movement in deeper soils in comparison to chemical fertilizers (for better or worse depending on soil needs). ${ }^{14}$ In addition to phosphorus there are numerous other minerals present in manure that can also accumulate and contribute to eutrophication, which may result in excessive growth of algae, which can result in fish mortality. ${ }^{17}$ Excessive application of manure, can also lead to heavy metals bioaccumulation in the top layer of the soil, with consequences for plant growth and risks for human and/or animal health. Furthermore, surplus precipitation and leaching of nitrate often exceed tolerable concentrations in fresh water, affecting aquatic life. In addition, animal manure carrier some pathogens that can lead to health risks when using manure as agricultural fertilizer.

\subsubsection{Modern Chemically Derived Fertilizers}

With the increased demand for global food production, the switch from manure to chemical fertilization and the development of novel soil amendment strategies has increased significantly. Fertilizers are any solid, liquid or gaseous substance essential for plant growth as fertilizers are like food for plants. Fertilizers can either be applied to soil, directly on the plant or added to aqueous solutions to maintain soil fertility, development and quality. Plants require 17 essential nutrients (Table 1.2) in soil in order to help 
replenish these nutrients as some may have been removed. ${ }^{18}$ The three most important nutrients for high crop yields and sustainable production (as alluded to earlier) are nitrogen $(\mathrm{N})$, phosphorus $(\mathrm{P})$, and potassium $(\mathrm{K})$.

Table 1. 2: Common Nutrients and Uptake Needed for Plant Health

\begin{tabular}{|c|c|c|c|c|}
\hline Nutrient & Macro/micro & Uptake form & Mobility in Plant & Mobility in Soil \\
\hline Carbon & Macro & $\mathrm{CO}_{2}, \mathrm{H}_{2} \mathrm{CO}_{3}$ & & \\
\hline Hydrogen & Macro & $\mathrm{H}^{+}, \mathrm{OH}^{-}, \mathrm{H}_{2} \mathrm{O}$ & & \\
\hline Oxygen & Macro & $\mathrm{O}_{2}$ & & \\
\hline Nitrogen & Macro & $\mathrm{NO}_{3^{-}}, \mathrm{NH}_{4}^{+}$ & Mobile & Mobile as $\mathrm{NO}_{3^{-}}$, immobile as $\mathrm{NH}_{4}+$ \\
\hline Phosphorus & Macro & $\mathrm{HPO}_{4}^{2}{ }^{2}, \mathrm{H}_{2} \mathrm{PO}_{4-}^{-}$ & Somewhat mobile & Immobile \\
\hline Potassium & Macro & $\mathrm{K}^{+}$ & Very mobile & Somewhat mobile \\
\hline Calcium & Macro & $\mathrm{Ca}^{2+}$ & Immobile & Somewhat mobile \\
\hline Magnesium & Macro & $\mathrm{Mg}^{2+}$ & Somewhat mobile & Immobile \\
\hline Sulfur & Macro & $\mathrm{SO}_{4^{-}}$ & Mobile & Mobile \\
\hline Boron & Micro & $\mathrm{H}_{3} \mathrm{BO}_{3}, \mathrm{BO}_{3-}^{-}$ & Immobile & Very mobile \\
\hline Copper & Micro & $\mathrm{Cu}^{2+}$ & Immobile & Immobile \\
\hline Iron & Micro & $\mathrm{Fe}^{2+}, \mathrm{Fe}^{3+}$ & Immobile & Immobile \\
\hline Manganese & Micro & $\mathrm{Mn}^{2+}$ & Immobile & Mobile \\
\hline Zinc & Micro & $\mathrm{Zn}^{2+}$ & Immobile & Immobile \\
\hline Molybdenum & Micro & $\mathrm{MoO}_{4^{-}}$ & Immobile & Somewhat mobile \\
\hline Chlorine & Micro & $\mathrm{Cl}-$ & Mobile & Mobile \\
\hline Cobalt & Micro & $\mathrm{Co}^{2+}$ & Immobile & Somewhat mobile \\
\hline Nickel & Micro & $\mathrm{Ni}^{2+}$ & Mobile & Somewhat mobile \\
\hline
\end{tabular}

Inorganic minerals/nutrients such as $\mathrm{Ca}, \mathrm{K}, \mathrm{Na}$ and $\mathrm{Mg}$ are commonly found in woody biomass, with smaller or trace amounts of elements such as S, P, Fe, Mn or Al also being seen. These elemental constituents are usually in the form of inorganic minerals, e.g. oxides, carbonates, chlorides and phosphates. ${ }^{19}$ Some of the minerals are macronutrients and others are micronutrients, regarding the plant species. Table 1.2 also discusses which nutrients are more mobile, whether it is in the plant or directly in the soil.

Fertilizers can be found as straight fertilizers, multinutrient and NPK fertilizers. Straight fertilizers contain only one nutrient. Multinutrient fertilizers contain two or more nutrients referred to a compound fertilizer formed by mixing ingredients where they react 
chemically. NPK fertilizers must contain at least $3 \% \mathrm{~N}, 5 \% \mathrm{P}_{2} \mathrm{O}_{5}$ plus $5 \% \mathrm{~K}_{2} \mathrm{O}$ and at least $20 \%$ total nutrients (percent by weight). NPK fertilizers have the important advantage of simplified application, since all nutrients can be distributed in one operation. As human consumption of crops continues to increase, fertilizer application also continues to grow because of the demands for these nutrients.

\subsubsection{Manufactured Fertilizers}

Plants take small molecules such as carbon, hydrogen, oxygen, nitrogen, phosphorus, potassium and other minor nutrients to build large molecules such as sugars, carbohydrates, oils, protein and DNA. Other nutrients are used less often, and in smaller amounts but are critical for building the large molecules. To improve crop yield and production on existing farmland, it is crucial to improve soil health for the targeted cropping. Organic and inorganic fertilizers are important for plant growth. In manufacturing fertilizers, the molecules are made available from petroleum by-products or synthesis. Nitrogen is produced from the Haber process. A method was developed to produce ammonia from air, where natural gas and steam are pumped into a large vessel. The air was then pumped into the system, and oxygen is removed by the burning of natural gas and steam, leaving by-products of nitrogen, hydrogen and carbon dioxide. Carbon dioxide is removed, producing ammonia by introduction of electric current into the system. A catalyst such as magnetite $\left(\mathrm{Fe}_{3} \mathrm{O}_{4}\right)$ is used to improve the speed and efficiency of ammonia synthesis. Any impurities are removed from the ammonia. ${ }^{20}$

Once phosphate rock is mined, it is treated with sulphuric acid and/or nitric acid to produce phosphoric acid. Some of the material is reacted with sulphuric acid and nitric acid to produce solid form of phosphorus. Some of the phosphoric acid is reacted with 
ammonia, resulting in ammonium phosphate, another good primary fertilizer. ${ }^{21}$

The potassium component used in fertilizers begins in the form of potash ore, mined from underground deposits in many parts of the world. Potassium chloride is typically extracted from the potash. The energy inputs of mining the potash is similar to those of mined phosphate rock. Manufacturers typically are supplied potassium chloride but then converted into a useable form by granulating it. Granulating makes it easier as all the other components are blended together. The solid materials are placed into a rotating drum, where pieces of the solid fertilizer take on spherical shapes, passed through a screen to separate sized particles. An inert dust is applied to the particles in order to inhibit moisture retention. The particles are then dried and placed in a mixing drum to produce the best mixture. ${ }^{20}$ Crop intensification, with regards to soil quality, results in lower level soil fertility and inevitably will lead to the negative effects of decreased rate of organic matter, and amount of nitrogen in soil. Fertilizer use is a key element in improving performance, but also increase crop residues (biomass), which help to increase soil organic matter content. $^{22}$

\subsubsection{More Recent Soil Amendment Strategies with Biomass}

Biochar has also emerged as another amendment strategy for soil health and plant yield. Biochar is carbonized organic matter residue after pyrolysis. Recently, biochar has been examined for a myriad of soil remediation strategies and this carbonaceous product is commonly used as in agriculture to improve soil fertility and enhance crop productivity. Biochar addition to soil was found to alter the soils physical structure and air capacity, and improve water holding capacity, water retention and plant available water. Biochar amended soil retains $15 \%$ more moisture content, and therefore in environments that lack 
proper water conditions, biochar amendment could be crucial. Biochar was also studied in oversaturated saline environments. Salinity affects plant growth by influencing plant physiological processes including photosynthesis and transpiration. ${ }^{23}$ Salt stress will decrease soil water potential, leading to ion toxicity and therefore plant death. The use of biochar in high saline environments alleviates plant salt stress through the release of essential macro- and micronutrients such as $\mathrm{Ca}, \mathrm{K}, \mathrm{N}, \mathrm{P}$ and $\mathrm{Zn}$ in soil to offset the adverse effects of salts. The use of biochar as a soil amendment improves nutrient retention and generally plant uptake.

It has also been shown that biochar addition to soil also changes the microbial community composition. Microorganisms adapt immediately to fresh biochar, more specifically the 'r-strategist' microbes, which adapt to and respond quickly to newly available carbon sources, which may be present in the form of volatile organic matter. Microorganisms benefit from improvement of water supply during drought conditions due to the presence of biochar, increasing microbial biomass and microbial activity. Since biochar is a constant available carbon source, biochar addition to soil is beneficial for microbial biomass and activity under drought conditions and that these effects are increasing with time after field exposure. ${ }^{24}$

\subsubsection{The Circular Economy}

The need to transition to more sustainable systems mitigating or removing environmental impacts is becoming more relevant. Economic challenges, such as supply/risk, deregulated markets, and imperfect incentive structures are leading to increasingly frequent financial and economic instability. Currently, linear economic strategies, which focus on 'take-make-dispose', are unsustainable; however, circular 
economies represent an alternative. A circular economy integrates product lifecycle analysis and considered how we can reuse the widget without creating waste. A circular economy is a regenerative system where resource input, waste, emission and energy leakage are minimized by closing energy and material loops. This process can be achieved by reuse, recycling and upcycling. In additions, using less material reduces material extraction costs. The core of circular economy is the closed flow and use of raw materials (Figure 1.4). The figure below shows circular economy does not require changes in the consumers life nor does it require loss of revenues for manufacturers. The circular economy represents a more sustainable way of resource extraction and consumption. In the case of biomass, excess or disposed biomass could be transformed into additional value products or soil amendments.

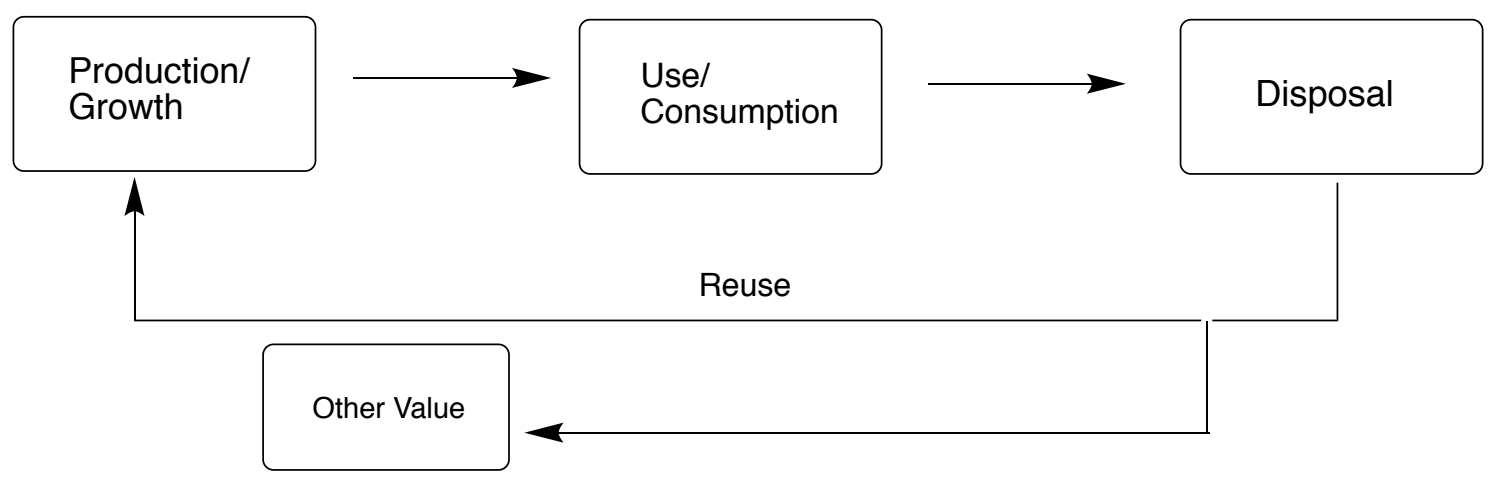

Figure 1. 4:The new take on traditional waste and creating value from its disposal

In terms of sustainability, little regard is given to the waste derived from human food production. Traditionally, this item is placed in a landfill, however, when you consider transportation costs already integrated into the unit price of food, and the biomass energy that could be produced creating value from food waste seems like an untapped potential. Rethinking this waste and seeking to find alternative value, is the focus of this thesis. 


\subsection{Relevant technologies for biomass conversion to energy carriers}

\subsubsection{Combustion and Cogeneration}

Combustion is a high temperature exothermic redox chemical reaction between a fuel (the reductant) and the oxidant, which is usually atmospheric oxygen. Combustion occurs when a hydrocarbon reacts with oxygen to produce carbon dioxide and water (Equation 1). Combustion is often a complicated sequence of elementary radical reactions, but it was the first controlled chemical reaction discovered by humans.

Equation 1: $\quad \mathrm{CH}_{4}+2 \mathrm{O}_{2} \rightarrow \mathrm{CO}_{2}+2 \mathrm{H}_{2} \mathrm{O}+$ heat

Historically, fire was used to provide warmth and cook food, but during the industrial revolution, it was found that it could also be used to heat steam to drive engines and turbines. More recently this has become the cogeneration of heat and electricity. The use of biomass instead of fossil fuels in combined heat and power (CHP) applications can provide advantages such as reductions in carbon dioxide $\left(\mathrm{CO}_{2}\right)$, sulphur and mercury emissions, energy cost savings, waste reduction, and local economic development. Integrated energy systems use waste heat recovery technology to capture heat byproducts and then generate electricity. The simplest way is to burn the biomass in a furnace, exploiting the heat generated to produce steam in a boiler, which is then used to drive a steam turbine. During cogeneration of biomass, 30 to $35 \%$ of its energy content is transformed into electrical power and 55 to $60 \%$ into useable heat. By adding biomass fuels into the energy generation process, substantial efficiency gains have been made in several sectors, including pulp \& paper, and sugar cane \& food-processing plants, where steam or hot water is also produces with electricity. For small cogeneration plants ( 1 to 20 
megawatts of power), biomass or methane produced from landfills can be used as a frontend fuel source but most power plants are still using natural gas as the primary input. ${ }^{25}$

\subsection{Anaerobic Digestion}

Non-anthropogenic anaerobic digestion is one of the oldest modern forms of biological conversion of biomass (e.g., methane generation in swamps). However, modern anaerobic digestion is carried out in an airtight reactor and organic matter in the form of sludge is converted into methane (the energy carrier) and carbon dioxide ${ }^{26}$ The term sludge is used to describe highly mixed biosolids that are suspended in water. Industrial scale anaerobic digesters are heavy users of water; however, after many days, the depleted water suspension known as the biodigestate is removed from the digester, dewatered, and the water recycled back into the digester. This conversion process will be discussed in further detail in Chapter 2, but for the purpose of the thesis objectives biodigestate is the material of interest.

\subsubsection{Industrial Motivation}

CCI BioEnergy is an Ontario-based company who specializes in large-scale anaerobic digestion. CCI delivers an innovative waste management system that sustainably uses the organic fraction of waste to produce clean, renewable energy and a variety of other beneficial products. CCI developed and operates of the City of Torontos (Disco Road) anaerobic digestion (AD) facilities for processing Torontonians green bin waste. $\mathrm{CCI}$ is committed to growth and expansion of $\mathrm{AD}$ technologies to recover inherent value in all organic assets. As such, CCI wanted to investigate the potential value the extracted effluent stream (or digestate) to determine if it could be used as an effective 
fertilizer. CCI BioEnergy has allowed for the following to be discussed without withholding any proprietary information.

\subsubsection{Anaerobic Digestion Technologies used by CCl BioEnergy}

Anaerobic digestion is a microbial-delivered process that converts lignocellulose and sugars into methane. ${ }^{26} \mathrm{AD}$ is carried out in an air-tight reactor and is accomplished through four major processes: hydrolysis, fermentation, acetogenesis and methanogenesis (Figure 2.1). Hydrolysis is when hydrolytic enzymes break down large polymers like carbohydrates in the sludge suitable for being utilized as a source in cellular respiration.

Acidogenic fermentation occurs right after resulting in acetate being the main end product from the conversion of sugars and amino acids into carbon dioxide, ammonia, organic acids and hydrogen. Acetogenesis follows resulting in the breakdown of the products of hydrolysis and fermentation into immediate compounds such as acetate and formaldehyde.

Finally, methanogenesis converts these compounds to methane and water. ${ }^{26}$ Microorganisms, usually bacteria, are involved at each step of the reactions. End products of fermentation like hydrogen and acetate are converted to methane and carbon dioxide by the methanogens, while acidogens produce the hydrogen. ${ }^{26}$ 


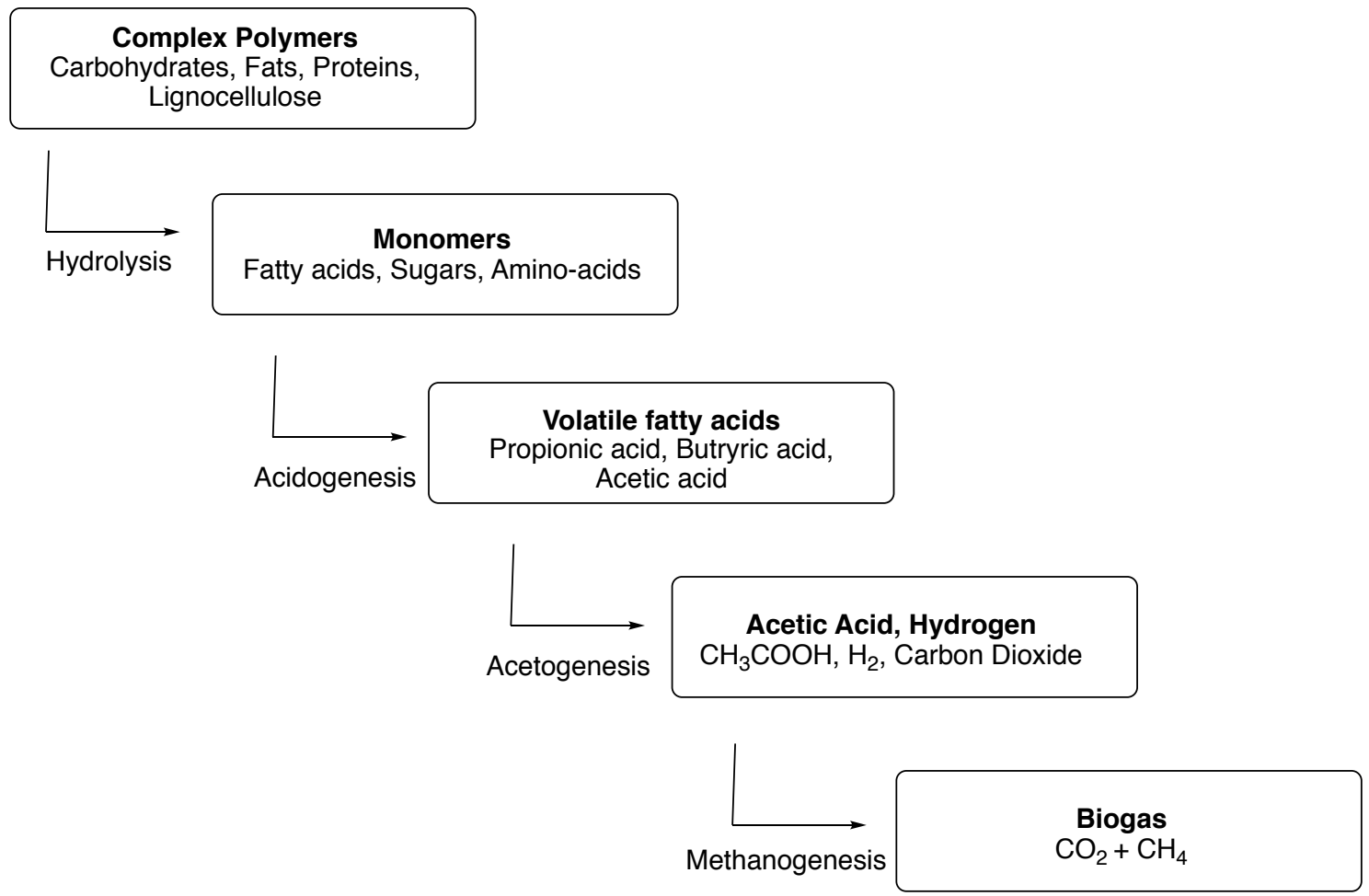

Figure 1.5: Summary of four major processes of anaerobic digestion

There are two main configurations for anaerobic digestion suitable for agri-food systems in Canada: completely mixed and plug flow. Completely mixed systems consist of a large tank where fresh material is mixed with partially digested material. This type of system is suitable for manure or other agri-food inputs with low dry matter content (4\%$12 \%)^{27}$

Plug flow systems typically consist of long channels in which organic waste move along as a plug. This system is suitable for thicker materials such as liquid manure with $11-13 \%$ or higher dry matter content. ${ }^{27}$ It should be noted that $\mathrm{AD}$ is a water intensive technology and all \% are reported by weight when mixed in water.

Anaerobic digestion systems can be employed at 3 different temperature ranges: thermophilic $\left(50-60^{\circ} \mathrm{C}\right)$, mesophilic $\left(35-40^{\circ} \mathrm{C}\right)$, and psychrophilic $\left(0-25^{\circ} \mathrm{C}\right)$. This thesis 
focuses on the anaerobic digestion in a mixed system within the mesophilic range. In this temperature range, the system needs a longer treatment time (retention times of at least 1520 days) in order for the lower temperature micro-organisms to break down organic matter. ${ }^{27}$

CCI BioEnergy's large-scale plant located on Disco Road in Toronto takes a waste feedstock, which is characterized by a high plastic content due to the collection in plastic bags and is directly fed into a pre-treatment system without prior treatment; however a skimmer early in the treatment removes plastic. The configuration includes three waste pulpers and a grit removal system to remove the inert contaminants and other nondigestible elements. The anaerobic digestion process is a wet digestion in the mesophilic range using two $5,300 \mathrm{~m}^{3}$ digesters with full mixing using compressed biogas and $\mathrm{N}_{2}$. The future plan for the biogas is for cogeneration and to create electricity and heat for the facility needs. The digestate is dewatered using two centrifuges and the resulting digester solids are considered the $95 \%$ total solids (TS). Any liquid in the waste is reclaimed and reused as process water in the closed-loop process water system. ${ }^{28}$

As an alternative to the large-scale industrial process, CCI BioEnergy's medium size digesters that have been used to digest apple pomace and grocery food waste can be described using Figure 1.6. The medium size anaerobic digesters are referred to as the Biocube but consist of the same process. Starting from step 1, feedstock organic sources are pre-treated and ground, which is then placed in a blend and feed tank where organic liquids are present. This tank leads to the digester where during mesophilic conditions produces biogas. The biogas is stored and further conditioned to remove sulphur in order to generate electricity for the rest of the system. The effluent from the digester flows into 
the outflow tank where it can either become pasteurized (step 9) for fertilization or it can be stored in a holding tank (step 11) where it is returned to the digester.

The two main digestate products that will be the focus of this thesis are $5 \%$ total solids known as "the digestate" and the $95 \%$ total solids known as "dewatered digestate". The latter looks similar to soil and the former looks like brown pea soup. 


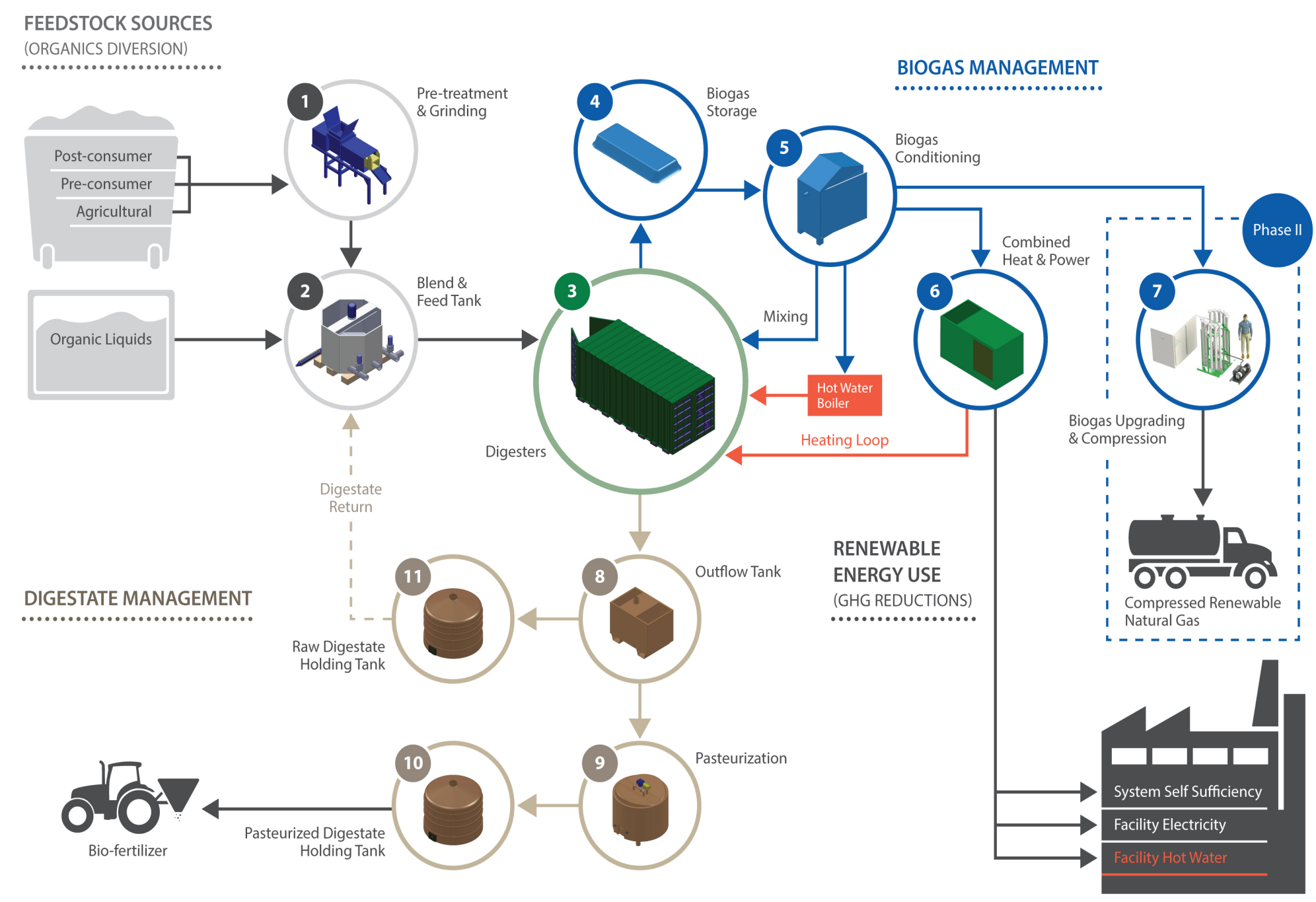

Figure 1. 6:Process of CCI's anaerobic digestion 


\subsubsection{Traditional Digestate Composition}

\section{Nitrogen Component}

Typically, in digestates, the ammonium $\left(\mathrm{NH}_{4}^{+}\right)$content is high, which leads to a higher ammonium $\left(\mathrm{NH}_{4}{ }^{+}\right)$to total nitrogen $\left(\mathrm{N}_{\text {total }}\right)$ ratio. This however is feedstock dependent and digestates from feedstocks with high degradability (i.e. cereal, grains, poultry and pig manures) with high nitrogen content are high in $\mathrm{NH}_{4}{ }^{+}: \mathrm{N}_{\text {total }}$. However, cattle manures or fibrous feedstocks are low in nitrogen and lead to low $\mathrm{NH}_{4}{ }^{+}: \mathrm{N}_{\text {total }}$. In the digester, complex organic nitrogen compounds are mineralized to $\mathrm{NH}_{4}^{+}: \mathrm{N}_{\text {total }}$ and the digester microorganism uses a part of this for growth. ${ }^{29}$

\section{Phosphorus Component}

As a constituent of adenylates, nucleic acids and phospholipids, phosphorus is an important plant macronutrient. The bioavailable supply of phosphorus in most soils is small; however AD has the opposite influence on crop phosphorus. Raising the $\mathrm{pH}$ moves the chemical equilibrium toward the formation of phosphate $\left(\mathrm{HPO}_{4}{ }^{2-} \rightarrow \mathrm{PO}_{4}{ }^{3-}\right)$ and precipitation as calcium or magnesium phosphate. The binding form of other elements such as iron may also affect phosphorus turnover and precipitation processes during AD. ${ }^{29}$ The small fraction of dissolved phosphorus, mineralized during $\mathrm{AD}$ is associated with suspended solids. The probable cause of phosphorus loss in AD is the retention in the digesters due to the precipitation processes and nearly $36 \%$ of phosphorus is lost for the aqueous phase using AD. ${ }^{29}$

\section{$\underline{\text { Potassium Component }}$}

Potassium that is contained in all terrestrial plants at a high level and is retained through the AD process. ${ }^{29}$ As a result, potassium is found at high levels in the digestate aqueous phase. 


\subsection{Pyrolysis}

Aside from anaerobic digestion, another process used to convert organic matter into useful products is an anaerobic thermal conversion process called pyrolysis. While the pyrolysis of organic matter to make charcoal has also been known since ancient times, only in the last 100 years has its potential been realized for the production of energy carriers (biofuels). The products of the anaerobic thermal chemical conversion processes are divided into a volatile fraction (consisting of gases, vapours and tar components) and a carbon-rich solid fraction (biochar and coke). Depending on the operating temperature of the pyrolyzer $\left(300-1200^{\circ} \mathrm{C}\right)$, the ratio of pyrolyzed products can be biased, but generally coke is the sublime-able solid fraction, while biochar is carbonized organic matter. This conversion process will be discussed in further detail in Chapter 3, but for the purpose of the thesis objectives the solid fractions (biochar and coke) are of greatest interest.

\subsubsection{Background of Process}

Pyrolysis of biomass is referred to as the direct thermal decomposition of organics in the absence of oxygen to obtain an array of solid, liquid and gas products. Pyrolysis is one of the most promising methods for the conversion of biomass to bio-oil, which is a potential substitute for non-renewable crude oil. ${ }^{31}$ Solid, liquid and gas product yields are influenced by the conditions of pyrolysis. ${ }^{30}$ Within the pyrolysis reactor there are two pyrolysis reactions: primary and secondary. Primary pyrolysis involves generation of volatiles and biochar, and the secondary reactions involve volatiles at void space and downstream of the reactor. ${ }^{32}$ Primary pyrolysis can be divided into four individual stages: moisture loss, hemicellulose decomposition, cellulose decomposition and lignin decomposition. ${ }^{33}$ 
Hemicellulose is easily degraded, at $220-315{ }^{\circ} \mathrm{C}$, where cellulose is mainly at $315-400{ }^{\circ} \mathrm{C}$, while lignin possesses a large temperature range $\left(150-900{ }^{\circ} \mathrm{C}\right)$. At low temperatures $(<500$ ${ }^{\circ} \mathrm{C}$ ) the pyrolysis of hemicellulose and lignin involved exothermic reactions while those of cellulose are endothermic. Pyrolysis of hemicellulose has higher $\mathrm{CO}$ and $\mathrm{CO}_{2}$ yield, while lignin displays higher $\mathrm{CH}_{4}$ release. Organic ethers, esters and ketones are mainly released at low temperature, i.e. $200-400{ }^{\circ} \mathrm{C}$ and $350-450{ }^{\circ} \mathrm{C}$ from hemicellulose and cellulose. ${ }^{33}$

Secondary pyrolysis involves the cracking of the emerging volatiles, which includes generation of radical fragments by cleavage of chemical bonds and condensation or coupling of radical fragments to form gas and bio-oil. In this process, formation of solid carbonaceous materials (coke) can be observed as a result of radical recombination and/or polymerization reactions. ${ }^{32}$

The fast pyrolysis of biomass is an endothermic process that requires high heating rates, typically between $10-200^{\circ} \mathrm{C} / \mathrm{s}$, in order to meet typical processing conditions $\left(\sim 500^{\circ} \mathrm{C}\right.$, short hot vapour residence time of $\sim 1 \mathrm{~s}$ ). The high heating rate requirement is one of the most significant challenges of pyrolysis equipment but can be reduced by minimizing the feedstock particle size.

\subsubsection{The Products of Pyrolysis and their Uses}

Biochar

Typically, lower process temperatures and longer residence times favour char formation. ${ }^{34}$ On contrary, a raise in temperature leads to a decrease in char yield and increase of gas yield. ${ }^{35}$ The presence of char also catalyzes reactions leading to the increase of viscosity of the oil and eventually formation of $\operatorname{tar}^{36}$ As a result of functional groups 
decompose during pyrolysis, but the initial chemical composition of the material has a negligible effect on the hydrological properties of the biochar pyrolyzed at high temperatures. ${ }^{37}$

Biochar has many potential uses previously described in the literature. Adding biochar to soil can generate agronomic and environmental value through improved chemical and physical properties of the soil and creation of long-term storage for carbon. ${ }^{37}$ Biocharinduced higher crop yields have been attributed to increase in soil $\mathrm{pH}$, cation exchange capacity and availability of nutrients, and to improved nitrogen fertilizer use efficiency and water retention capacity. Biochar is returned to the field as a soil conditioner and for carbon bio-sequestration. $37 ; 38$

\section{$\underline{\text { Biogas }}$}

Biogas contains mainly $\mathrm{H}_{2}, \mathrm{CO}_{2}, \mathrm{CO}, \mathrm{CH}_{4}, \mathrm{C}_{2} \mathrm{H}_{6}, \mathrm{C}_{2} \mathrm{H}_{4}$, trace amounts of larger gaseous organics and water vapour. ${ }^{33}$ In the absence of cellulose, the interaction between lignin and hemicellulose can accelerate decarbonylation by promoting $\mathrm{CO}$ formation, especially above $500{ }^{\circ} \mathrm{C}$. Greater amount of $\mathrm{CO}$ is formed from cellulose than that of hemicellulose, and there is almost no contribution from lignin. ${ }^{34 ;} 35$

$\mathrm{H}_{2}$ generation is strongly correlated with the condensation of aromatic rings during char formation, and the condensation of aromatic subunits also increases the char and coke products formed. ${ }^{33}$ High temperatures and longer residence times within the reactor increase biomass conversion to gas and gas yield increases from temperatures increase from 350 to $550{ }^{\circ} \mathrm{C} .{ }^{36 ;} 37$ 
While not the focus of this thesis, biogas applications have been described at length. Biogas along with bio-oil is most commonly used for possible biofuels and used for smallscale incomplete combustion engines or microturbines. ${ }^{35}$ This product has been investigated less in industry due to the complexity and yield production.

\section{$\underline{\text { Bio-Oil }}$}

Depending on the initial feedstock and the mode of fast pyrolysis, the colour of bio-oil can be almost black through dark red-brown to dark green, influenced by the presence of micro-carbon in the liquid and chemical composition. ${ }^{34}$ Bio-oil is composed of a complex mixture of oxygenated hydrocarbons with an appreciable proportion of water from both the original product moisture and condensation reactions and a maximum yield occurs between $480-520{ }^{\circ} \mathrm{C}$. Heavy bio-oils can be considered as mixtures of water and water-soluble organic compounds combined with waterinsoluble, mostly oligomeric materials. ${ }^{30}$ Bio-oils are usually single-phase liquids because of the presence of polar carboxyl and hydroxyl compounds, that solubilize the water fraction. ${ }^{36}$

The nature of the starting material input can affect bio-oil production. For example, bio-oil production increases with decreasing flow of carrier gas during the pyrolysis of straw at $500{ }^{\circ} \mathrm{C}$, however, bio-oil yield decreases quickly and the gas yield increases with increasing volatiles residence time from 1.3 to $9.4 \mathrm{~s}$ during pyrolysis of grass at $500-600{ }^{\circ} \mathrm{C} .{ }^{32}$ Yield decreases at temperatures above $600{ }^{\circ} \mathrm{C}$, while the water yield increases with increasing the volatiles residence time from 1.5 to $4.7 \mathrm{~s}$, and the gas yield increases in the first $2.9 \mathrm{~s}$ and then remains constant. ${ }^{32}$

Bio-oil quality is improved with an increase in the volatiles residence time at the temperature of $600{ }^{\circ} \mathrm{C}$. Moderate temperatures and short vapour residence time are optimum for producing liquids. ${ }^{34}$ The bio-oil yield reaches a maximum value at about $450{ }^{\circ} \mathrm{C}$ 
and then the bio-oil yield is decreased due to secondary reactions. ${ }^{35}$ Biomass pyrolysis at mid-low temperatures is important for production of liquid fuels (bio-oil). ${ }^{32}$

Bio-oil is a complex mixture of hundreds of chemicals, with a mixture of aliphatic and aromatic organic compounds, as a result, with refinement bio-oils can have multiple applications. Various types of compounds such as phenols, alkanes, alkenes, saturated fatty acids and their derivatives have been identified. ${ }^{35}$ It not only has high acidity and water content, but also shows high thermal instability and polymerization tendency. ${ }^{38}$ Bio-oils have some undesired properties for fuel applications such as high water content, high viscosity, poor ignition characteristics, corrosiveness, instability and others. However, combustion tests performed in boilers, diesel engines and turbines have demonstrated the feasibility of the converting existing or slightly modified equipment to use bio-oils for energy conversion. ${ }^{36}$ Condensate, which is the liquid portion past the condensed bio-oil has properties that can be used as a herbicide, disease combat, acidity promotion in large intestine to inhibit growth of enteropathogenic microbes and detoxification pads for medical applications..$^{36 ; 31}$

\section{$\underline{\text { Coke }}$}

Coking behaviour of organics generally begins during pyrolysis at $540{ }^{\circ} \mathrm{C}$. Starting around 200 (to 450$)^{\circ} \mathrm{C}$ it was found that the coke content in bio-oil increased linearly with radical concentration. ${ }^{32}$ Coke yields decline with increasing reaction time but increase with low temperatures and short reaction time. This occurs due to repolymerization of reactive fragments with aromatic rings combined with the hydrogen formation of larger conjugated fragments. ${ }^{38}$ Some success has been achieved with hot vapour filtration, but problems tend 
to arise with the sticky nature of fine char and disengagement of the filter cake from the filter. ${ }^{34}$ Generally speaking, the formation of coke is highly undesirable in traditional pyrolysis machines for this pragmatic reason.

There is not much focus on coke analysis or production in literature as coke is considered the hinderance in the pyrolysis reactor for production of oil, condensate and gas. Coke is the sublimation product of char, however, it causes clogging and brings the pyrolysis run to a halt. However, as described below, this thesis will focus on studying the potential for reclaiming carbon allotropes from coke.

\subsubsection{Carbon Allotropes}

This thesis focuses on coke and biochar, and the potential to isolate the carbon allotropes that may be present in these carbaceous products. The carbon allotropes of interest are graphene, graphite, carbon nanotubes and/or fullerene shown in Figure 1.7. Since graphene is the mother of all graphitic forms, graphene and graphite may be the most abundant allotropes to be found in the pyrolysis products. ${ }^{39}$ The benefits of searching and isolating carbon allotropes in coke and/or biochar are numerous owing to the variety of applications they can be used for (vide infra), and this represents a method for carbon sequestration. Due to the extended hexagonal lattice of $\mathrm{sp}^{2}$ bonded carbon atoms, these allotropes possess exceptional mechanical, electrical and chemical properties that lead to energy conversion, storage devices, catalysts, carbon fibers and biosensors. ${ }^{40}$ Carbon allotropes are used as fillers to improve the durability and increase the electrical, thermal and electromagnetic properties of concrete. ${ }^{39}$ 


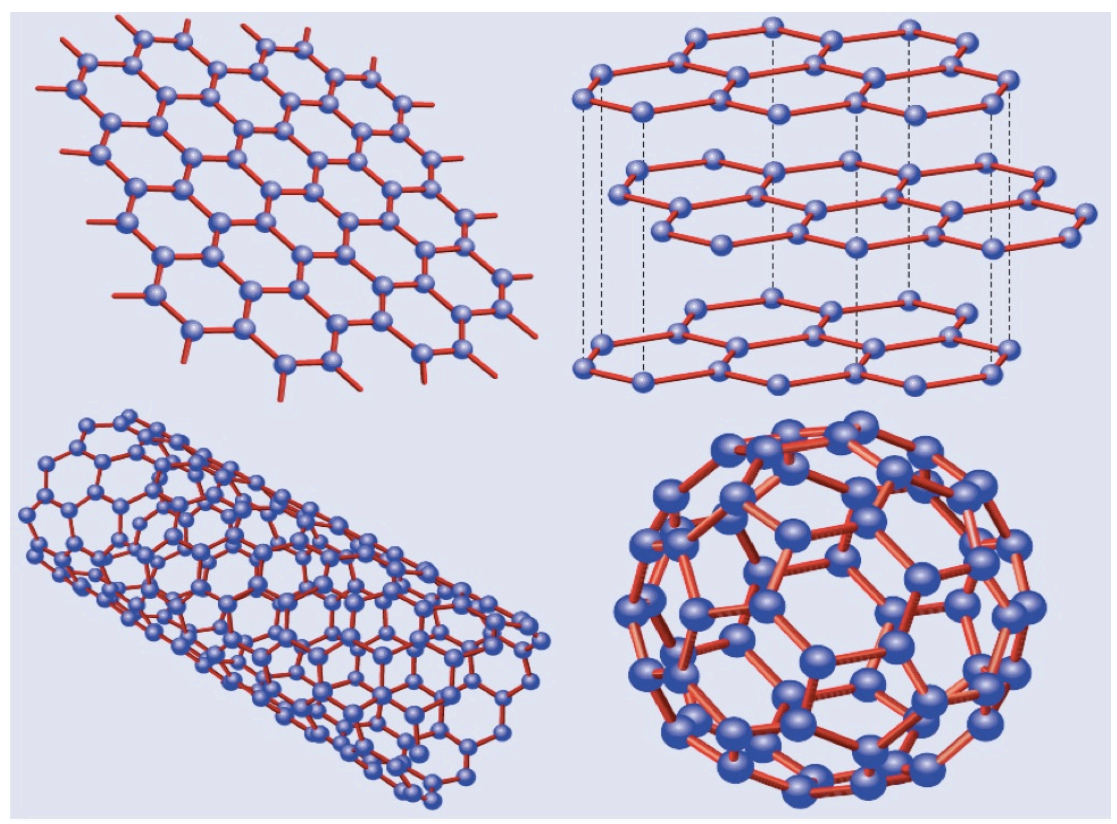

Figure 1. 7: Carbon allotropes - Graphene (left), graphite (right), carbon nanotube (bottom left) and fullerene (bottom right)

When considering the Koivisto's group core interests, carbon allotropes would be useful for the development of organic photovoltaic cells. Fullerenes are good candidates for electron acceptors with low reorientation energies for organic photovoltaic cells (OPVs). ${ }^{41}$ Lastly, a monolayer graphene sheet can be oxidized to form graphene oxide. It is a layered material oxidized from graphite and interspersed with oxygen molecule on its basal plane and edges. ${ }^{42}$ The most common method to chemically synthesize graphene sheets is Hummers method, in which graphite is oxidized using a strong acid and oxidation agent, so water molecules are able to intercalate between the graphene sheet. ${ }^{43}$ Graphene oxide has also become a popular nano-filler for cementious materials. Graphene sheets with hydrophilic functional groups like graphene oxide, have a large surface area with strong water absorbing capacity. ${ }^{39}$ The graphene market is increasing and is estimated to reach $\$ 552.3$ million by $2025 .{ }^{44}$ In Figure 1.8, you will notice what graphene market will increase in particular. Searching for graphene or other allotropes from the 
products generated from waste could be a low-cost source of carbaceous starting materials that may add in the market size, all while sequestering carbon dioxide from the atmosphere.

\section{U.S. graphene market size, by product, 2014 - 2025 (USD Million)}

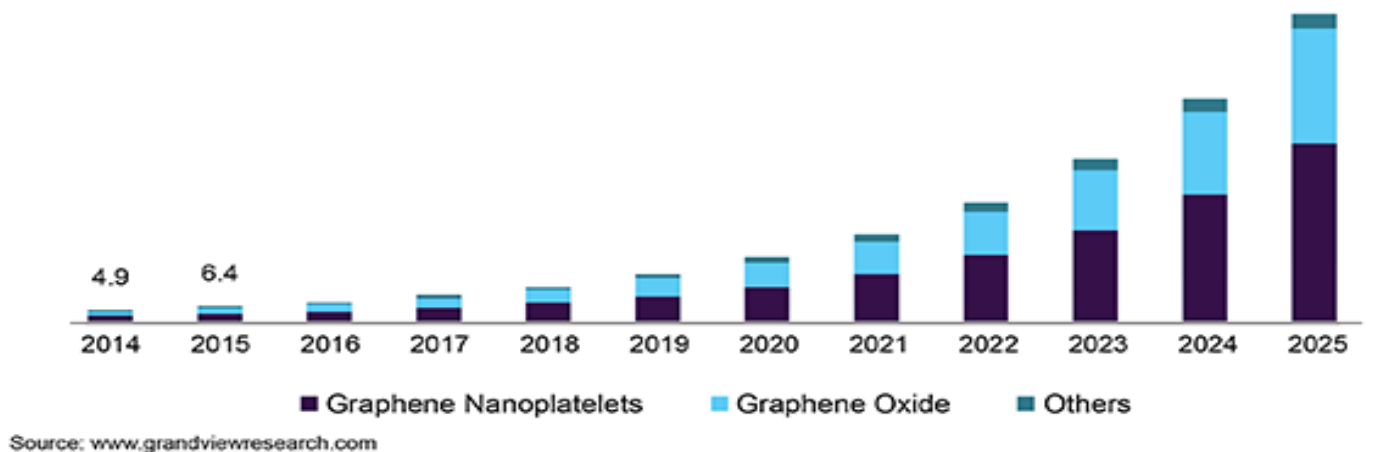

Figure 1. 8: Graphene and its other related materials are expected to increase by 2025

\subsection{Thesis Objectives}

As part of a series of industrial relevant projects this thesis will focus on the following nonproprietary projects although in some instance certain details have been omitted for proprietary reasons. Collectively, the following objectives seek to find further value from agricultural-derived food waste. The objectives are:

1. To determine if the digestate from anaerobic digestion can be used as a suitable soil amendment or fertilizer. To this end we will examine nitrogen, phosphorus and potassium (N:P: K) ratio, as well as other components of the digestate that may be relevant for plant growth.

2. To determine if the dewatered digestate solids can be used as a suitable pyrolysis feedstock for the development of advanced carbons. Briefly, advanced carbons are carbon allotropes found in coke that could have a myriad of potential applications. To this end we will examine 
the dewatered digestate as a feedstock for pyrolysis as well as the products that are formed (i.e. coke).

3. To determine the most effective and economical way to isolate and separate the sublime-able coke fraction (the carbon allotrope fraction) from the pyrolyzed digestate. To this end we will examine the coke fraction for graphene/graphite and explore exfoliation via methods to accomplish this goal. 


\section{Chapter 2: Methods and Materials}

\subsection{Anaerobic Digestion}

As discussed previously we sought to investigate the digestate as a fertilizer from 3 sources (Disco road, apple pomace, and grocery food waste). As such N, P, K analysis was undertaken but we also investigated other relevant minerals to anaerobic digestion and land-use application, which are described in the methods section.

The 5\% TS digestate samples $(750 \mathrm{~mL})$ were collected in sterile plastic bottles approximately every 3 weeks for 3 months (September to November). The samples were picked up from Disco road's compost site. In addition, CCI BioEnergy employees would provide the apple pomace and grocery food waste samples from the Biocube reactor. Each test below was performed in triplicate. The aqueous phase, after filtration was studied in all cases except total solids and volatile solids.

Both the City of Toronto Disco road and grocery food waste digestate mixtures were dark heterogeneous mixtures. Yard waste contains lignocellulose material, which does not readily degrade under anaerobic conditions; however, most residential waste (e.g. kitchen waste) degrades in anaerobic conditions. As a result, mechanical separation provides the organic fraction of waste and is usually more contaminated. Contamination affects the environmental quality (heavy metals) and acceptability (plastic content) of the final digestate end product. As a result, the $95 \%$ TS digestate contains more contamination from plastic than that of the $5 \%$ TS. ${ }^{32}$

Apple pomace is a by-product resulting from apple juice production. It contains a large amount of water and small amount of protein. ${ }^{33}$ Apple pomace is a rich source of pectin besides other nutrients such as carbohydrates, dietary fibres, minerals and vitamin-C. Apple pomace minerals such as potassium, calcium, sodium, magnesium, copper all exists in small weight 
percentage $\left(0.95 \%, 0.06 \%, 0.20 \%, 0.02 \%\right.$, respectively).$^{34}$ The apple pomace digestate analyzed was a merky liquid mixture with a low $\mathrm{pH}$.

\subsubsection{Metal Analysis using Flame Atomic Absorption Spectroscopy}

Elemental analysis was performed to determine the concentration of metals present in the aqueous phase of the digestate, specifically $\mathrm{K}, \mathrm{Na}, \mathrm{As}, \mathrm{Zn}, \mathrm{Fe}, \mathrm{Ca}$ and $\mathrm{Mg}$ were analyzed. The digestate was acidified with $5 \mathrm{~mL} / 100 \mathrm{~mL}$ nitric acid and sat for 10 minutes. It was then filtered through a $0.45 \mu \mathrm{m}$ and $5 \mathrm{~mL} / 100 \mathrm{~mL}$ was added again. $100 \mathrm{~mL}$ of well mixed sample was placed into a $250 \mathrm{~mL}$ beaker. In order to ensure the metals were in solution, the solution was heated with another addition of $2 \mathrm{~mL}$ concentrated nitric acid and hydrochloric acid. The solution was reduced to $15-20 \mathrm{~mL}$ and filtered again to remove any solids and the volume was adjusted and diluted to the $100 \mathrm{~mL}$ mark using deionized (DI) water. Depending on the element tested, there were different detection limits and dilutions needed to be carried out in order to ensure proper analysis. For $\mathrm{Ca}$, $\mathrm{Mg}, \mathrm{Na}$, and $\mathrm{K}$ it was a 1: 1000 dilution; $1 \mathrm{~mL}$ of sample to $100 \mathrm{~mL}$ DI and then $10 \mathrm{~mL}$ to 100 $\mathrm{mL}$. For Zn, it was a 1: 100 dilution and 1:5 dilution for As and Fe. Using Perkin Elmer flame atomic absorption spectroscopy, a blank was created using deionized water and then a set of standards was used to produce a calibration curve in order to determine the concentration present in the digestate. The standard concentrations used were 0 ppm, 1 ppm, 3 ppm, 5 ppm, 7 ppm, and $10 \mathrm{ppm}$. Depending on the element being tested, the corresponding lamp needed to be installed and set in the FAA parameters on the computer.

\subsubsection{Total Nitrogen (TN)}

TN was analyzed using the A303 method to determine the nitrogen content for the N, P, K ratio. $6 \mathrm{~mL}$ of sulphuric acid was mixed with $100 \mathrm{~mL}$ of digestate. The sample sat for 15 minutes 
and was then filtered. The filtrate was transferred to an Erlenmeyer flask and another $7 \mathrm{~mL}$ of sulphuric acid was added. At this point, the sample was transferred to smaller vials in order to test for total nitrogen using a Teledyne Tekmar Apollo 9000 TOC/TN Analyzer. The analyzer uses high temperature $\left(680{ }^{\circ} \mathrm{C}\right.$ to $\left.1000{ }^{\circ} \mathrm{C}\right)$ combustion and has a chemiluminescence detector. This analysis was done courtesy of another lab.

\subsubsection{Total Phosphorus (TP)}

TP was analyzed to determine the total phosphorus content for the $\mathrm{N}, \mathrm{P}, \mathrm{K}$ ratio using the persulfate digestion method. $15 \mathrm{~mL}$ of the filtered 5\% TS digestate was gently boiled for with the addition of phenolphthalein indicator ( 3 drops) and $0.5 \mathrm{~g}$ of potassium sulphate. The filtered solution was heated for 1.5 hours until the volume reduced to $10 \mathrm{~mL}$. The solution was diluted to $45 \mathrm{~mL}$. A NaOH titrant was created by adding $10.561 \mathrm{~g}$ to $50 \mathrm{~mL}$ of DI and then marked up to 200 $\mathrm{mL}$ in a $250 \mathrm{~mL}$ volumetric flask. 3 flasks were set up with $15 \mathrm{~mL}$ of the filtered solution with the phenolphthalein and then the $\mathrm{NaOH}$ was titrated into each flask until a light pink colour was reached. Once the colour was reached, it was diluted to $100 \mathrm{~mL}$ mark of the volumetric flask. Similar to the elemental analysis, a calibration curve was made with a set of phosphorus standards. The phosphorus standards used were 0 ppm, $0.2 \mathrm{ppm}, 0.4 \mathrm{ppm}, 0.6 \mathrm{ppm}, 0.8 \mathrm{ppm}$ and $1 \mathrm{ppm}$ in a $50 \mathrm{~mL}$ volumetric flask. The standards contained the corresponding volume that makes up the given ppm (i.e. $0.2 \mathrm{ppm}$ ) and added $1 \mathrm{~mL}$ of DI. The blank contained $2 \mathrm{~mL}$ of sample, $3 \mathrm{~mL}$ of DI, the samples contained $2 \mathrm{~mL}$ of sample, $2 \mathrm{~mL}$ DI and were spiked with $1 \mathrm{~mL}$ L-Ascorbic acid phosphorus reagent. An Agilent Cary $60 \mathrm{UV}-\mathrm{Vis}$ spectrophotometer was used under the Scan software at $420 \mathrm{~nm}$ to provide individual scans of absorption readings. 


\subsubsection{Total Solids (TS)}

Total solids were detected using the APHA 2540B method. A solution of digestate at a known volume $(100 \mathrm{~mL})$ was filtered and the determination of total solids present in the digestate was performed by heating approximately $200 \mathrm{~g}$ of the digestate in an oven at $105^{\circ} \mathrm{C}$ for 24 hours. The left-over dried solids were re-weighed.

\subsubsection{Volatile Solids (VS)}

Volatile solids are those solids that are lost on ignition of dry solids. Volatile solids typically represent the number of organic solids in the fraction. It is commonly used in assessing the amount of biologically inert organic matter, such as lignin in wastewater. VS were measure using APHA 2540E method. Similarly, the total solids were placed into a crucible and placed into the Vulcan 3-550 muffle furnace and ramped up to a set temperature of $550^{\circ} \mathrm{C}$ and left there for 15 minutes. Below is the calculation used to determine volatile solids, where $\mathrm{A}$ is the weight of the solid and dish prior to drying and B is the weight of solid and dish after drying.

\section{Equation 2:}

$$
\frac{V S}{L}=\frac{(A-B)}{\text { Sample vol }(m L)} \times 100
$$

\subsubsection{Total Organic Carbon (TOC)}

TOC analysis is important to know in order to gauge whether or not concentrations are safe enough for fertilization in case of leaching and runoff. The samples were filtered using vacuum 
filtration before brought to the instrument for analysis. TOC analysis was performed using a Shimadzu TOC-V Analyzer after the sample was prepared. $30 \mathrm{~mL}$ of the sample is placed into a vial and a small tube draws up $1 \mathrm{~mL}$ aliquots into the TOC-V analyzer. Carbon dioxide flows with the carrier gas via the dehumidifier into the sample cell. The area of the carbon dioxide peak signal is measured, and this peak area is converted to total carbon (TC) concentration using a calibration curve. The instrument draws up another $1 \mathrm{~mL}$ aliquot in order to measure the inorganic carbon (IC). The next few steps are done by the instrument itself and does not require the user to do it manually. The sample is acidified with phosphoric acid and sparged to convert the IC in the sample to carbon dioxide. This carbon dioxide is detected, and the sample IC concentration is measured in the same way as TC. The analyzer then subtracts the IC concentration from the TC concentration in order to determine the TOC concentration.

\subsubsection{Volatile Fatty Acid/ Total Alkalinity Content (VFA/TAC)}

$\mathrm{VFA} / \mathrm{TAC}$ is a ratio to indicate fermentation processing. The TAC value is an estimation of the buffer capacity of the sample and the VFA value corresponds to the volatile fatty acid contents. It is calculated empirically according to the Nordmann method (Equation 3). This analysis was performed using a manual titration. $20 \mathrm{~mL}$ sample was diluted with $180 \mathrm{~mL}$ of deionized water placed under agitation and connected to a $\mathrm{pH}$ meter. The sample was titrated with $0.05 \mathrm{M}$ of sulphuric acid $\left(\mathrm{H}_{2} \mathrm{SO}_{4}\right)$. The starting $\mathrm{pH}$ was noted and when the $\mathrm{pH}$ dropped to 5 , the volume was recorded as $\mathrm{V}_{1}$. When the $\mathrm{pH}$ passed 5 and dropped to 4.4 , the volume was recorded as $\mathrm{V}_{2}$. Equation 1 was used to calculate the quotient.

$$
\begin{gathered}
\text { Equation 3: } \quad V F A=\left(V_{2} \times 1.66-0.15\right) \times 500 \\
T A C=V_{1} \times 250
\end{gathered}
$$




$$
\frac{V F A}{T A C}=x
$$

\subsection{Pyrolysis}

While not the only pyrolysis feedstocks studied in this chapter (others include; Eucalyptus woodchips, bark, bark residue, walnut shells and cellulose), the 5\% TS digestate, is used herein as

a dried feedstock (the dried feedstock is a better option, as the wet fraction is impractical as a feedstock for a pyrolysis system). By using the digestate solid as feedstock for pyrolysis, the main components (lignin, cellulose, hemi-cellulose) are still identical to those found in the commonly employed lignocellulosic feedstocks. Based on previous studies, there was strong evidence to suggest that the digestate was comprised of mostly carbohydrates, therefore as a benchmark, cellulose (purchased from Aldrich) will also be pyrolyzed and coke output and allotrope presence was examined.

More specifically, this thesis seeks to investigate the presence of carbon allotropes in the pyrolysis products. However, the focus will only be on the two carbonaceous products; char and coke. The char production is the first solid product formed upon employed temperature and then sublimation occurs which results in coke production. To determine if the pyrolyzed solids can be sources of advanced carbons, spectroscopic analyses were undertaken, which are described in the methods section. Furthermore, this chapter also discusses the best way (most effective and economical) to separate the sublime-able coke fraction. To this end, the coke fraction was studied for graphene/graphite using the separation methods discussed previously.

Finally, owing to the first-generation nature of this industry sponsored prototype, another subsection is allocated to the challenges and limitations of the prototype instrument while exploring a variety of different feedstocks. 
This section details the tools used to produce biochar and coke from fast pyrolysis. The analyses that will be discussed in this section are moisture content for pre-treatment of feedstock as well as x-ray powder diffraction and Raman spectroscopy for understanding the composition of allotropes in char and coke.

\subsubsection{Isolation/ Exfoliation of Carbon Allotropes}

\section{Electrochemical Exfoliation}

Graphene exfoliation is typically the easiest way to isolate graphene and it represents a top down method to prepare it. Starting with graphite powder or coke, smaller graphene flakes are exfoliated from graphite sheets. Typically, inorganic solvents such as ammonium, sodium sulphate or sulphuric acid with concentrations around $0.1 \mathrm{M}$ or $1 \mathrm{M}$. However, the amount of exfoliated graphite depends on the electrolyte concentration. With an increase in the electrolyte concentration, the exfoliation ratio increases. ${ }^{35}$ To run the electrolysis reaction, a constant source of power needs to be supplied in the range of $9-12 \mathrm{~V}$. Figure 2.1 illustrates the electrochemical exfoliation, where the alligator clamps would connect to a platinum electrode cathode and anode, creating a current. The electricity in this reaction attracts charged ions to the coke and forces them in between the graphite layers, in a process known as intercalation. As they heat and gain more energy eventually forcing the sheets to separate leaving a suspension of graphene. ${ }^{36}$ 


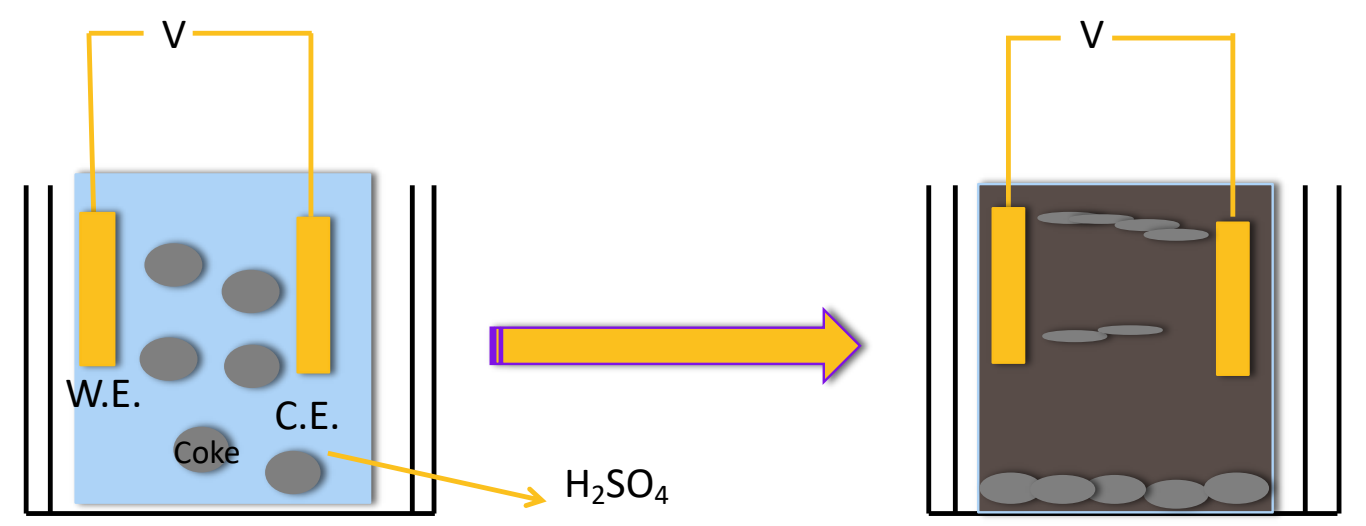

Figure 2.1:Diagram of electrochemical exfoliation using H2SO4 and how the coke (graphite) particles suspend ${ }^{37}$

\section{$\underline{\text { Black Tea Sonication }}$}

On an atomic level, graphite is layers of graphene sheets and therefore an ultrasonic method gently shakes apart the layers with the help of a certain solvent. ${ }^{42}$ Black tea contains tannins (polyphenolic biomolecule) commonly found in plants and bark. ${ }^{43}$ The tannins present in the black tea, along with the ongoing sonication can either create a (1) shear effect, (2) fragmentation, and (3) wedge effects, which can be shown in Figure 2.2. ${ }^{44}$ This polyphenolic biomolecule acts as a surfactant, which attaches to graphite layers inducing repulsive electric double layers, resulting in a stable colloidal graphene suspension. ${ }^{45}$

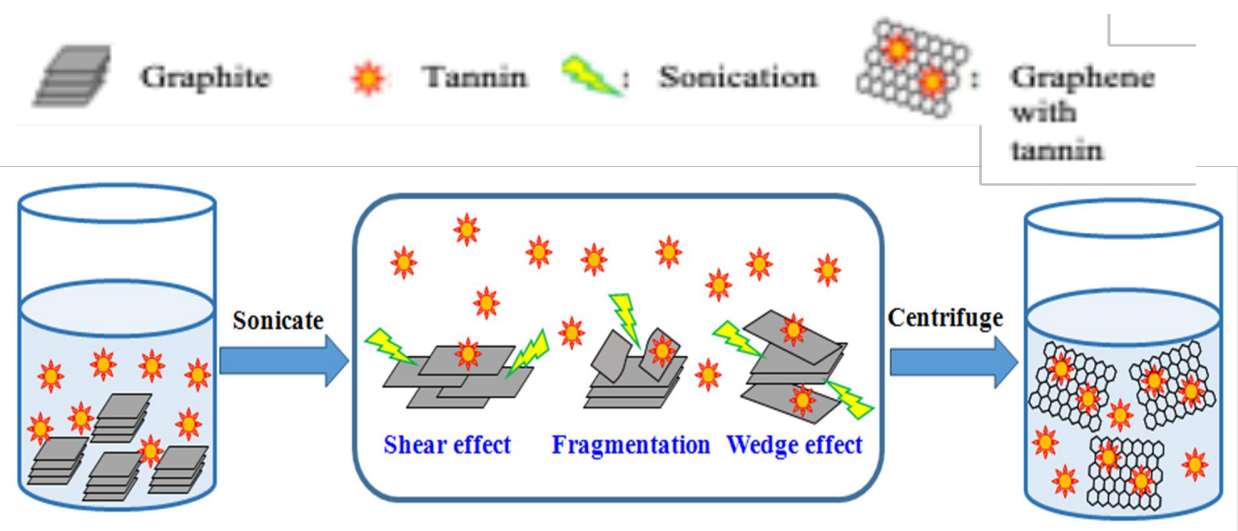

Figure 2. 2:Diagram of mechanism for graphene sonication 


\subsubsection{Characterization Techniques for Carbon Allotropes}

Gas Chromatography/Mass spectroscopy (GC/MS)

GC/MS is a form of analysis for smaller and volatile molecules. It can be applied to volatile solid, liquid and gaseous samples. GC/MS begins with gas chromatography, where the sample is volatized. This effectively vaporizes the sample (gas phase) and separates components using a capillary column packed with a solid stationary phase. The compounds are carried with an inert carrier gas such as argon, helium or nitrogen. As the components separate, they elute from the column at different times, which is referred to as retention time. Once the components leave the GC column, they are ionized by the mass spectrometer using electron or chemical ionization sources. The ionized molecules are then accelerated through the instruments mass analyzer, where the ions are separated based on their different mass-to-charge $(\mathrm{m} / \mathrm{z})$ ratios. $^{38}$

\section{$X$-ray Diffraction (XRD)}

$\mathrm{XRD}$ is the inelastic scattering of $\mathrm{x}$-ray photons and is based on constructive interference of monochromatic x-rays and a crystalline sample. The x-rays are generated by a cathode ray tube within the source, which is filtered to produce monochromatic radiation, directed at the sample. The x-rays bombard the sample with electrons (incident beam) and dislodge the inner shell electrons of the sample to produce constructive interference known as the diffracted beam. ${ }^{39}$ The Bragg's Law $(\eta \lambda=2 \mathrm{~d} \sin \theta)$ relates the wavelength of electromagnetic radiation to the diffraction angle and the lattice spacing in a crystalline sample. The diffracted x-rays are then detected, processed and counted. Conversion of the diffraction peaks to d-spacing's allows identification of the mineral because each mineral has a unique d-spacing. ${ }^{40}$ 


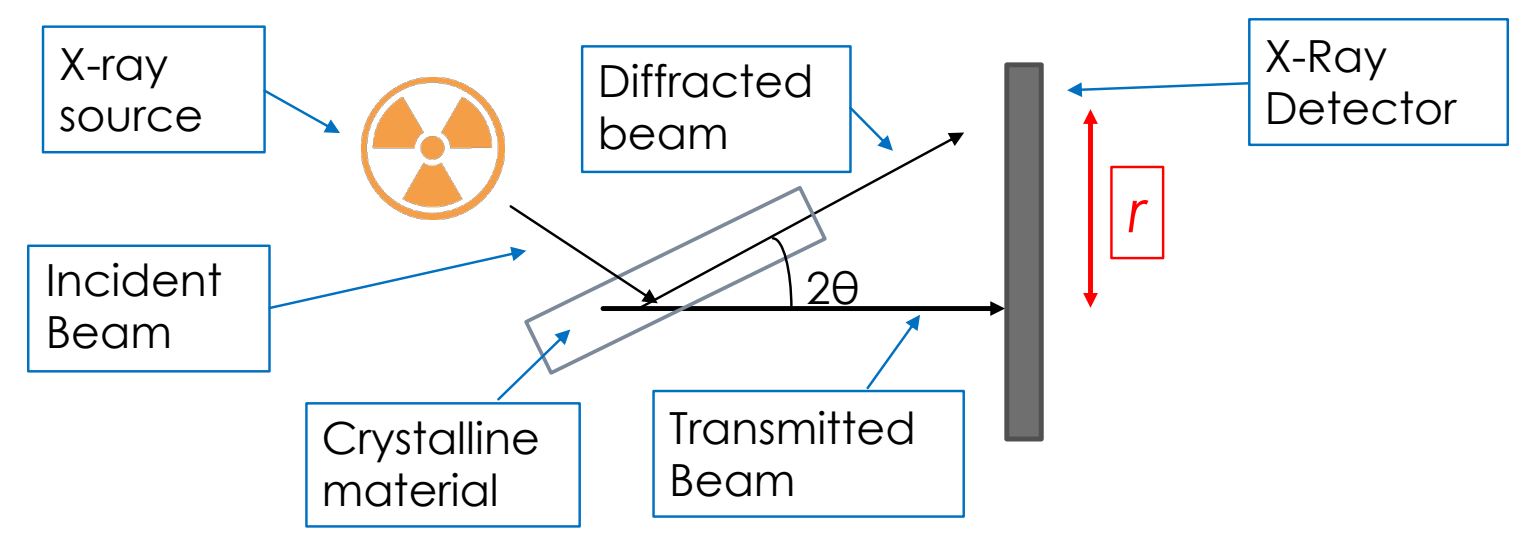

Figure 2. 3: X-ray diffraction illustration

\section{Raman Spectroscopy}

Raman spectroscopy is the technique based on inelastic scattering of monochromatic light from a laser source. Inelastic scattering is the frequency of photons in monochromatic light changing upon interaction with a sample. Photons of the laser light are absorbed by the sample and then remitted. The frequency of the remitted photons shift up or down in comparison with original monochromatic frequency, which is referred to Raman effect. The sample is illuminated with a laser beam and scattered light is collected with a lens and is sent through interference filter or spectrophotometer to obtain Raman spectrum of a sample. ${ }^{41}$ The most relevant signal found in Raman spectroscopy is the G-band, which refers to graphene and is also present in graphite. The G-band involves an optical phonon mode between the two dissimilar carbon atoms within the unit cell. In contrast to the graphite the Raman G-band at $1582 \mathrm{~cm}^{-1}$ is relative to the tangential mode vibrations of the $\mathrm{C}$ atoms. ${ }^{42}$ 


\subsubsection{Operating BT-Lab Prototype}

Pyrolysis is the decomposition of any product employed at high temperatures in complete absence of an oxidizing agent. It is typically employed at temperatures between $300{ }^{\circ} \mathrm{C}$ to 1000 ${ }^{\circ} \mathrm{C}$. The BT-lab bench-top model (Figure 2.4) has a maximum process control temperature of 800 ${ }^{\circ} \mathrm{C}$ due to safety issues, however temperature is most commonly employed at $700-750{ }^{\circ} \mathrm{C}$. Regardless of the temperatures being employed in the 300 to $1000{ }^{\circ} \mathrm{C}$ range by the prototype, pyrolysis still produces three main products; solid, liquid and gas. As mentioned above, solid product can be char, coke and pitch; liquid product can be seen as bio-oil or condensate; biogas (vented into the fume hood without collection) being produced can be carbon monoxide, carbon dioxide, nitrogen, water and hydrogen gas.

Due to the proprietary nature of the pyrolysis instrument, the cartoon in Figure 2.4 illustrates the components of the bench-top model. The feedstock or biomass will be fed into the hopper (Section 1), which allows the biomass to be brought into the reactor, via a screw auger. The reactor, which has a constant nitrogen gas flow carrier at 30 PSI (Section 2) has three different temperatures; bottom, wall and top. When the biomass enters the reactor, the biomass reaches a ceramic heating wall that is controlled by a process controller and carbonizes to produce char. The sublimation of char produces a coke product that creates a film on the lid of the reactor as well as clogs the main port leading to the quench (Section 3). The coke can be collected by removal of the lid when the prototype is cooled and not in use. Anything being further condensed will travel through the reactor port and along a hose line that is insulated and has a temperature of $500{ }^{\circ} \mathrm{C}$. The quench (Section 3) contains a heating tape to keep the unit at $100{ }^{\circ} \mathrm{C}$ so no polymerization occurs, and bio-oil is produced. In the quench unit, light water aerosol and nitrogen flows are pumped through a T-port on top of the quench to promote condensation. The products that are 
further condensed travel through another hose into the condenser unit (Section 4), collecting the condensate, which contains a large volume of water. Any vapours that travel and pass this unit are expelled via a tube into the fume hood. Amount of feedstock fed per run varied based on complications.

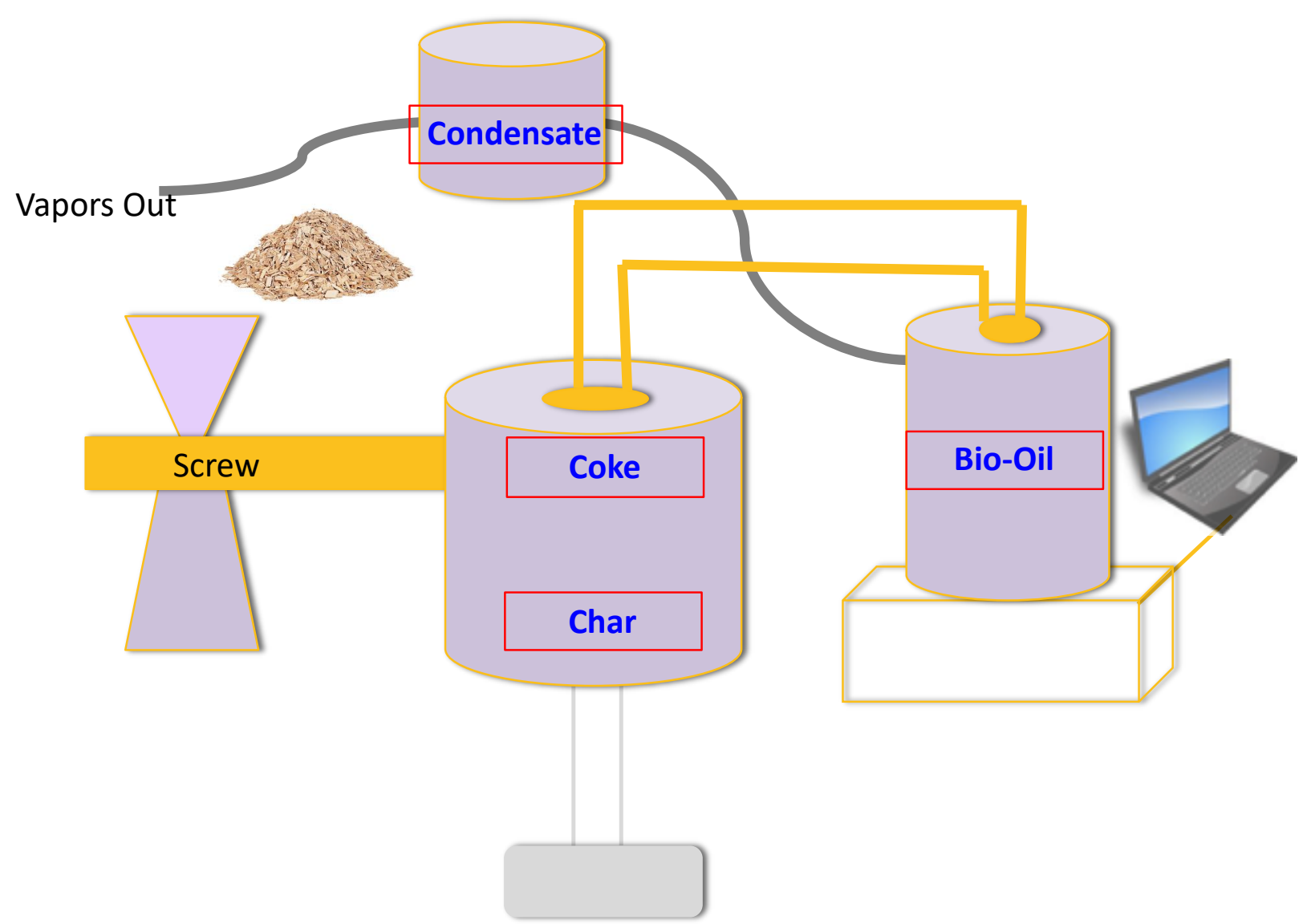

Figure 2. 4:BT-Lab prototype

\subsubsection{The Materials Pyrolyzed}

The materials discussed below that were used as feedstocks for this thesis were provided by the industry partner from their own clientele. Table 2.1 summarizes the different feedstocks ran using the pyrolysis instrument. The first feedstock studied was a fibrous material comprised of eucalyptus woodchips (EUC, Figure 2.5). EUC was ball milled and then further ground using a 
house blender. Regardless of pre-treatment, the fibrous nature of the made it difficult to feed into the screw. The second and third feedstocks used were tree bark and bark residue (DBA and DMR). Both were ball milled prior to processing. The bark residue contained more dust than the bark. Both bark-based feedstocks also had difficulties being fed into the screw feeder. Walnut shells (WAN) were the easiest feedstock to be fed into the screw feeder, as it did not require pre-treatment and the product was dried to begin with. The ease of feeding allowed for the walnut shells to possess the highest feedrate per hour. Cellulose (CUL) as seen in the figure below (Figure 2.6), is a fine powder that was easy to feed into the system, however, it created dust, clogging the system which halted the run early. Digestate from Disco road (VDI) was dried in a 1L beaker for 24 hours at room temperature in order to minimize any moisture in the pyrolysis instrument. The digestate mimicked the particle size of soil, and therefore, also created dust and halted the run early. Below in Figure 2.5 and 2.6, images of each feedstock used in pyrolysis is shown with a ruler to illustrate the particle size of feedstock.

Table 2.2 shows the temperatures employed at the bottom of the reactor, wall temperature (controlled by process controller) and top temperature which is the reactor line. The table also lists the duration of the run and how many grams of feedstock would have been fed in 1 hour. Last, the table records the dried wt $\%$ of coke and char produced from those corresponding runs. 
Table 2. 1:Summary of feedstock material, pre-treatment associated with it, how many runs and the abbreviation

\begin{tabular}{|c|c|c|c|}
\hline Material & Pre-treatment & $\begin{array}{c}\text { Period of Study (\# } \\
\text { of runs) }\end{array}$ & Code \\
\hline $\begin{array}{l}\text { Eucalyptus } \\
\text { Woodchips }\end{array}$ & $\begin{array}{c}\text { - Ball milled } \\
\text { - Blended } \\
\text { - Dried }\end{array}$ & 14 & EUC \\
\hline Bark & $\begin{array}{l}\text { - Ball milled } \\
\text { - Dried }\end{array}$ & 3 & DBA \\
\hline Bark Residue & $\begin{array}{l}\text { - Ball milled } \\
\text { - Dried }\end{array}$ & 2 & DMR \\
\hline Walnut Shells & - Blended & 3 & WAN \\
\hline Cellulose & - No treatment & 3 & CUL \\
\hline Digestate & - Dried & 3 & VDI \\
\hline
\end{tabular}

Below in Figure 2.5 and 2.6, images of each feedstock used in pyrolysis is shown with a ruler to illustrate the particle size of feedstock.

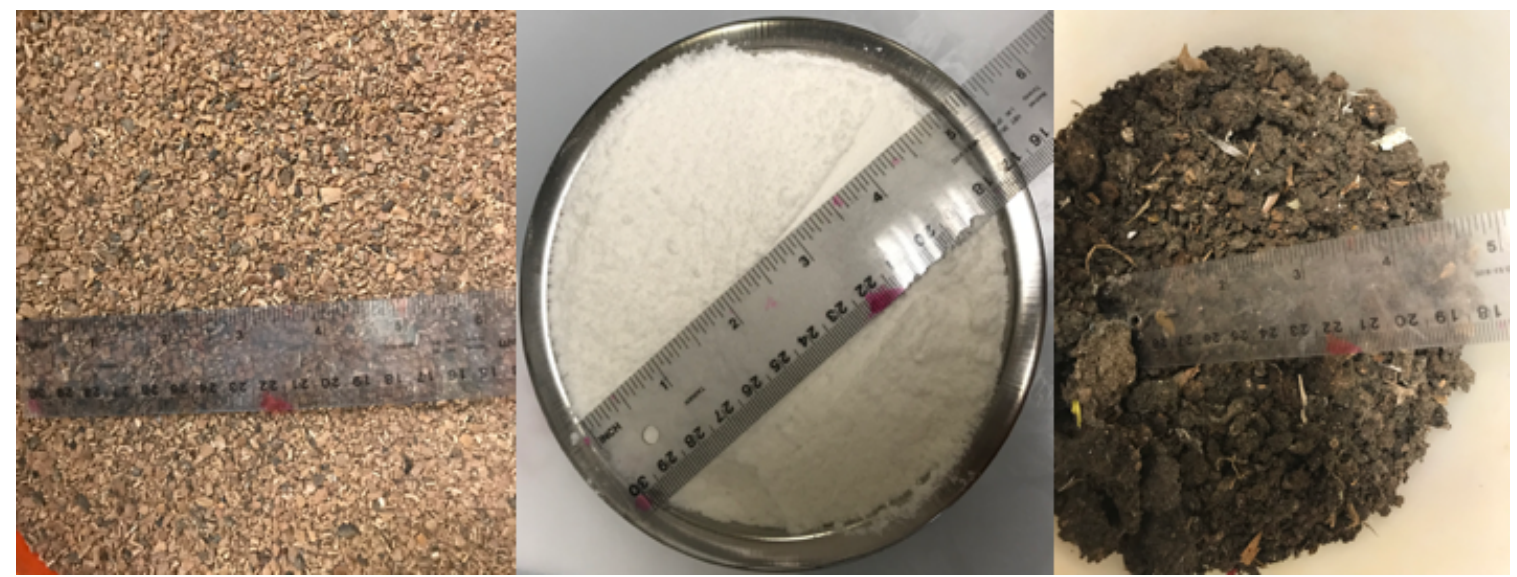

Figure 2 5:(Left to right); Eucalyptus (EUC) woodchips which were ball milled and then ground further using a blender. Bark (DBA) was previously ball milled and so was the bark residue (DMR) 


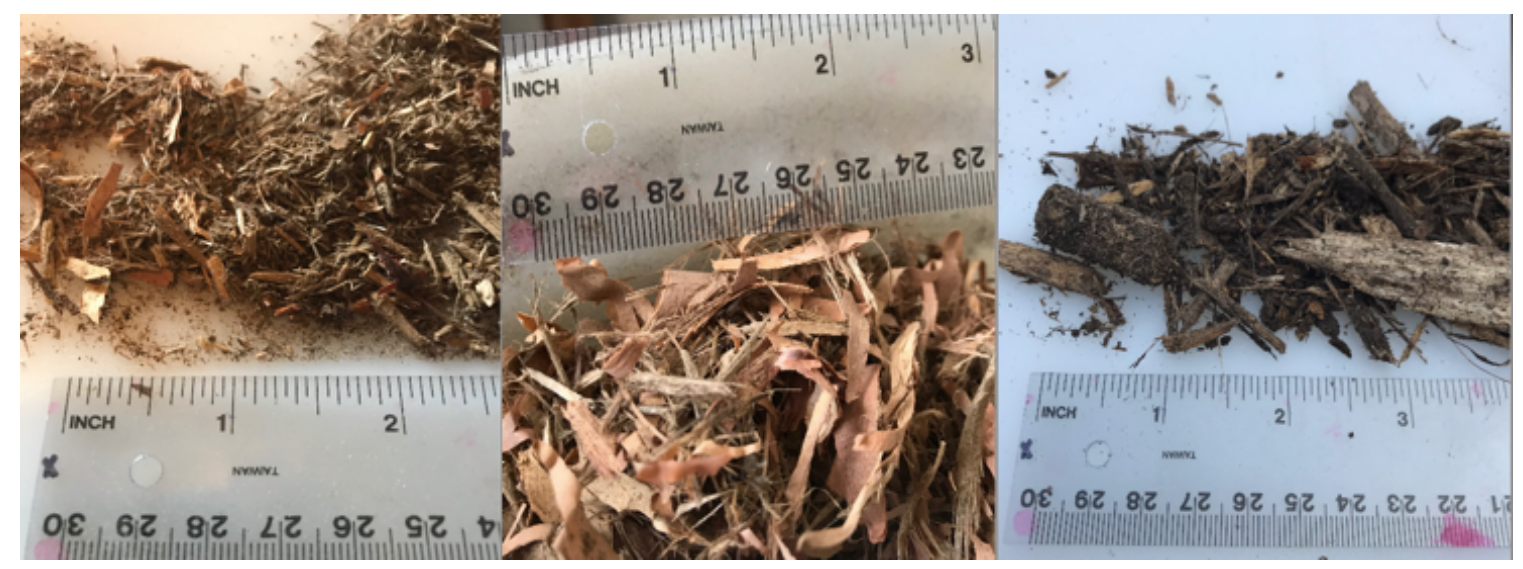

Figure 2. 6:(Left to right); Walnut (WAN) shells that have been ground. Cellulose (CUL) in a fine powder form. Disco road dewatered $30 \%$ digestate (VDI) dried

Table 2 2: Feedstock runs and corresponding parameters EUC= eucalyptus woodchips, WAN= walnut shells, DMR/DBA= bark. a) coke samples of specific runs with corresponding temperatures and weight percentage; b) char samples of specific runs with corresponding temperatures and weight percentage

\begin{tabular}{|l|l|l|l|l|l|l|}
\hline Feedstock & Temp Wall & Temp Top & $\begin{array}{l}\text { Temp } \\
\text { Botfom }\end{array}$ & g/hr & $\begin{array}{l}\text { Duration } \\
\text { (min) }\end{array}$ & wi\% \\
\hline EUC & 700 & 400 & 450 & 106 & 60 & 0.1 \\
\hline EUC & 750 & 437 & 505 & 100 & 97 & 0.2 \\
\hline EUC & 800 & 497 & 560 & 314 & 117 & 0.16 \\
\hline WAN & 700 & 390 & 440 & 1312 & 53 & 2.3 \\
\hline WAN & 700 & 430 & 490 & 1321 & 10 & 0.15 \\
\hline DMR & 700 & 395 & 442 & 198 & 8 & 1.1 \\
\hline DBA & 700 & 400 & 450 & 339.5 & 120 & 1.4 \\
\hline DBA & 700 & 400 & 450 & 594 & 72 & 1.5 \\
\hline
\end{tabular}

a)

\begin{tabular}{|l|l|l|l|l|l|l|}
\hline Feedstock & Temp Wall & Temp Top & $\begin{array}{l}\text { Temp } \\
\text { Bottom }\end{array}$ & g/hr & $\begin{array}{l}\text { Duration } \\
(\mathrm{min})\end{array}$ & wi\% \\
\hline EUC & 700 & 400 & 450 & 106 & 60 & 21 \\
\hline EUC & 750 & 437 & 505 & 100 & 97 & 15 \\
\hline WAN & 700 & 440 & 490 & 675 & 130 & 22.1 \\
\hline WAN & 700 & 390 & 440 & 1312 & 53 & 42.9 \\
\hline DMR & 700 & 395 & 442 & 198 & 8 & 31.5 \\
\hline DBA & 700 & 400 & 450 & 848 & 75 & 4 \\
\hline
\end{tabular}

b) 


\subsubsection{Characterization of Bio-Oil, Biochar and Coke}

\section{$\underline{\mathrm{GC} / \mathrm{MS}}$}

The oil/pitch/condensate was extracted from the pyrolysis machine and collected in the collection jars. In order to analyze using GC/MS, $1 \mathrm{~mL}$ of oil was mixed with $5 \mathrm{~mL}$ of acetone in order to be injected into the instrument without clogging the injection port. The GC/MS vials were filled to $1 \mathrm{~mL}$ and placed into the autosampler. The GC/MS oven was set to ramp up $10{ }^{\circ} \mathrm{C}$ every minute until $400{ }^{\circ} \mathrm{C}$ was reached, where it stayed for 10 minutes before venting. This temperature was set to allow most aromatic and phenolic compounds to be detected. Each GC/MS analysis took approximately 35 mins as the GC/MS needed to heat up to the given temperature and then vent and cool prior to the next run.

\section{X-ray Diffraction (XRD)}

After the biochar and coke was extracted from the pyrolysis benchtop, they were tested using XRD. Approximately 1-2 grams of biochar/coke was ground finely using a mortar and pestle until the powder showed some consistency. XRD sample prep consists of using tape inside the XRD frame, allowing your powder to stick once being applied using a scoopula. Once the frame window is packed with the powdered biochar, a yellow film known as Kapton is placed on top (Figure 2.7). The sides of the Kapton are secured in place with tape again, before placing the frame into the XRD. A standard quartz was run to calibrate the instrument prior to running the coke samples. In the XRD software, in General Measurements, the sample name is adjusted and 'Set Measurement Conditions' are changed to reflect the $2 \theta$ axis from the angles of 10 to $50^{\circ}$. However, it was recognized that particle size of the powder created for XRD would fluctuate the intensity 
and widen the area under the peak. Particle sieves with a 53 and $38 \mu \mathrm{m}$ sieve pore size was bought to improve the consistency and spectra analysis.

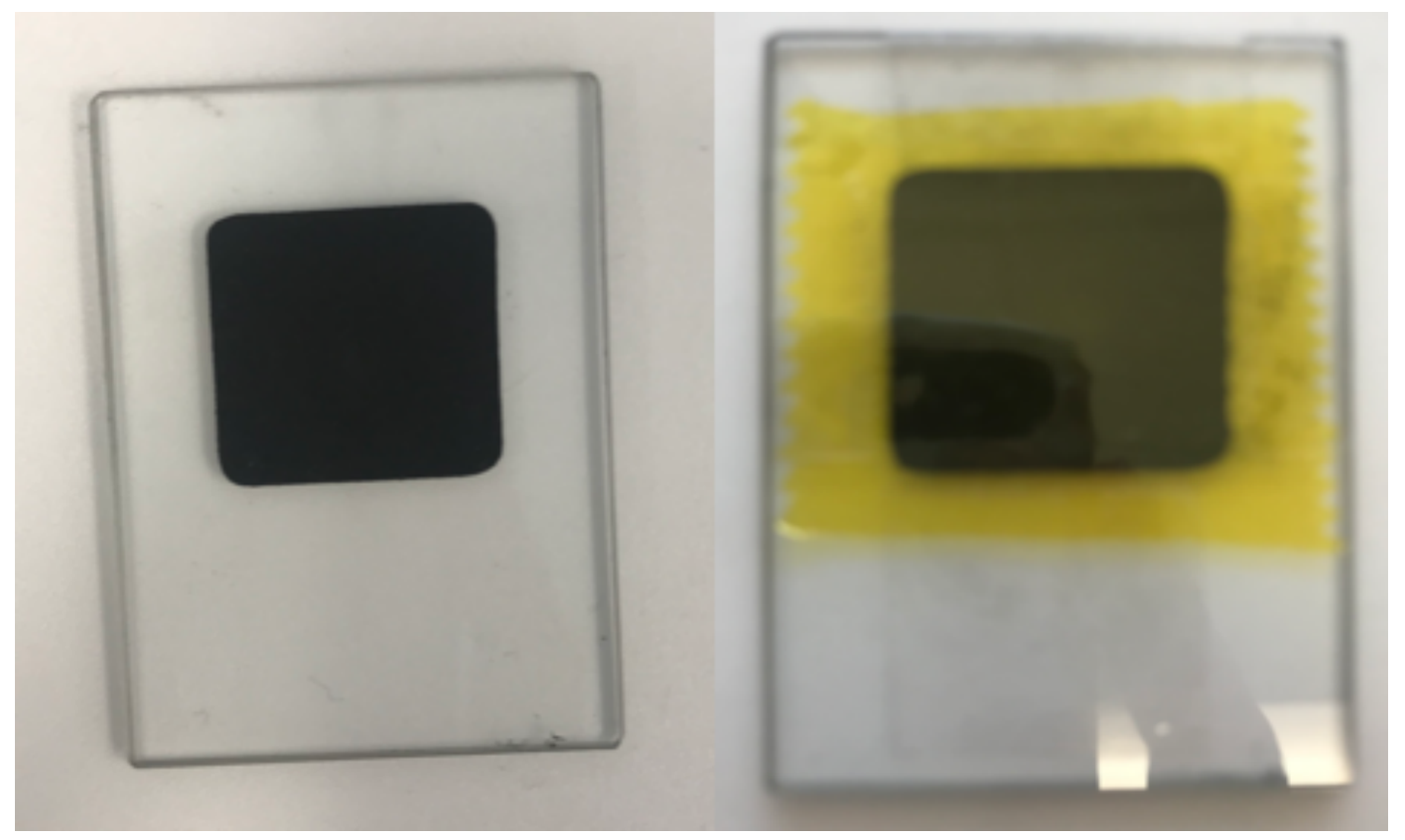

Figure 2. 7:XRD slide with and without Kapton film

\section{$\underline{\text { Raman Spectroscopy }}$}

A small amount $(\sim 0.5 \mathrm{~g})$ of sample is placed into the Raman for analysis of $\mathrm{G}$ band to determine whether or not graphene and carbon nanotubes are present. However, for fullerenes, they can be extracted with boiling toluene using a Soxhlet extractor. If fullerenes are present, the solution would become a brown/orange/pink colour depending on the composition. ${ }^{43}$ This analysis was done off campus by another individual so the specifications used are unknown.

\section{Electrochemical Exfoliation}

Variations of electrochemical exfoliation were attempted all using $9 \mathrm{~V}$ applied to the system overnight using an external power supply. $0.01 \mathrm{M}, 0.1 \mathrm{M}$ of sulphuric acid and ammonium sulphate were the three variations of exfoliation. All three variations contained approximately $0.500 \mathrm{~g}$ of 
coke to $175 \mathrm{~mL}$ of sulphuric acid, 2 platinum electrodes, were subjected to agitation and connected to a power supply of $9 \mathrm{~V}$. In both sulphuric acid exfoliations, there were three distinct layers; top, middle and bottom. Prior to having voltage and agitation applied, the sample was sonicated for 20 minutes. The ammonium sulphate electrochemical exfoliation was performed in a $0.5 \mathrm{M}$ solution with $0.5052 \mathrm{~g}$ of coke, that was sonicated for 40 mins. However, the sonication of ammonium sulphate and coke prevented a mixture of the coke with the solution and therefore the sulphuric acid exfoliation worked better. ${ }^{36}$ After supplying electricity to the reaction overnight, the reaction was filtered using vacuum filtration and the corresponding layers were analyzed using XRD.

\section{Black Tea Sonication}

A glass beaker was used as a vessel for the boiling of water and tea preparation. Using a hotplate, the tea bag was steeped in the beaker full of water, and after 5 minutes, the beaker cooled to room temperature. $0.8 \mathrm{~g}$ of coke was added to an Erlenmeyer flask and the $175 \mathrm{~mL}$ of steeped tea was added. The flask was covered with a septum and placed in a sonicator for 1 hour at $35^{\circ} \mathrm{C}$. After 1 hour, the flask was removed and then filtered using vacuum filtration. ${ }^{43}$ 


\section{Chapter 3: Results \& Discussion}

\subsection{Anaerobic Digestion}

\subsubsection{Metal Determination by Flame AA}

All elements were analyzed for effectiveness as a fertilizer or for safety precautions such as toxicity from leaching or runoff in an agricultural setting. For the importance of an effective fertilizer, potassium and sodium concentrations are the two main elemental concentrations that should be extrapolated from this table. Zinc concentrations in all digestates were low enough to not raise any concerns. Similarly, these digestate were collected from September to November, which can lead us to scientifically assume that the September batch could include more summer seasonal fruits and vegetables. October and November months would include typical fall fruits and vegetables. Concentrations influenced by seasonal change in produce can vary by increasing or decreasing, which would create the variability in the amounts calculated below as shown in Table 3.1. Disco road digestate on average had higher concentrations of calcium, sodium and potassium than the other two digestates due to the larger variety in the organic stream. Typically, for dry blended fertilizers available, the common ratios are 20-10-10, 20-20-10, 20-20-0 and 0-10-40.44 Based on these, the potassium analysis is higher than marketable fertilizers but can be reduced if the potassium component is diluted. Similarly, the full potassium value will not be the amount the soil or the plant will see upon fertilization. 
Table 3. 1: Each location of digestate over a 3-month period and the corresponding elemental analysis from flame atomic absorption. SD represents standard deviation

$\begin{array}{crrrrrr}\text { Location } & \text { Calcium } & \text { Iron } & \text { Magnesium } & \text { Potassium } & \text { Sodium } & \text { Zinc } \\ \text { Disco Road } & & & & & & \\ \text { AVG ppm } & 1175 & 13 & 2010 & 7432 & 10939 & 12 \\ \text { SD }( \pm) & 44 & 3 & 36 & 393 & 414 & 8 \\ \text { Apple } & & & & & & \\ \text { Pomace } & & & & & & 12 \\ \text { AVG ppm } & 603 & 5 & 2003 & 2165 & 4046 & 6 \\ \text { SD }( \pm) & 276 & 5 & 735 & 792 & 1547 & 10 \\ \text { Grocery } & & & & & & 3 \\ \text { AVG ppm } & 617 & 2 & 1446 & 4425 & 4715 & 779 \\ \text { SD }( \pm) & 520 & 3 & 962 & 1646 & & 3\end{array}$

\subsubsection{Salinity}

Salinity in soil amendments is important for plant growth as an increase in soil salinity levels can cause poor and spotty stands of crops as well as uneven and stunted growth and poor yields. The image below shows an example of increased salinity concentrations and the effect on fields. Primary effects of excess salinity is that it renders less water available to plants although some may still be present in the root zone.

Based on the concentrations presented in Table 3.1, a calculation was performed to determine the average salinity (Equation 4). The average salinities were $4.85 \mathrm{dS} / \mathrm{m}, 2.19 \mathrm{dS} / \mathrm{m}$, and $6.23 \mathrm{dS} / \mathrm{m}$ for Disco road, apple pomace and grocery food waste respectively. Given the average salinity, all three digestates fall within weakly to moderately saline given soil depth. Based on the saline tolerance, Table 3.2 shows what type of agriculture can be grown based on the salinity mentioned. ${ }^{45}$ However, important components for fertilization are the NPK values-nitrogen, phosphorus and potassium. The next section will discuss the importance of these components. Grocery food waste had the highest salinity content since it had a higher concentration in total solids and the likelihood that prepared foods were disposed. 
Equation 4:

$$
\begin{gathered}
T D S=E C\left(\frac{d S}{m}\right) \times 640 \\
E C=\frac{T D S}{640}
\end{gathered}
$$

\begin{tabular}{|c|c|c|c|c|}
\hline Salt Tolerance EC (dS/m) & Field Crops & Forages & Vegetables & Trees, Shrubs \\
\hline 4-8 (Moderate) & $\begin{array}{c}\text { Oats, } \\
\text { Yellow } \\
\text { mustard, } \\
\text { Meadow } \\
\text { fescue, Flax, } \\
\text { Canola }\end{array}$ & $\begin{array}{c}\text { Crested } \\
\text { wheatgrass, } \\
\text { Intermediate } \\
\text { wheatgrass, } \\
\text { Reed Canary } \\
\text { grass }\end{array}$ & $\begin{array}{c}\text { Tomatoes, } \\
\text { Broccoli, } \\
\text { Cabbage }\end{array}$ & $\begin{array}{c}\text { Spreading } \\
\text { juniper, } \\
\text { Poplar, } \\
\text { Ponderosa } \\
\text { pine, Apple,, } \\
\text { Mountain ash }\end{array}$ \\
\hline 4 & Corn & & $\begin{array}{c}\text { Sweet corn, } \\
\text { Potatoes }\end{array}$ & $\begin{array}{c}\text { Common } \\
\text { lilac, Siberian } \\
\text { Crab apple, } \\
\text { Manitoba } \\
\text { maple } \\
\end{array}$ \\
\hline $0-4$ & $\begin{array}{l}\text { Timothy, } \\
\text { Peas, Field } \\
\text { beans }\end{array}$ & $\begin{array}{c}\text { White dutch } \\
\text { clover, Aisike } \\
\text { clover, Red } \\
\text { clover, } \\
\text { Cannabis } \\
\end{array}$ & $\begin{array}{c}\text { Carrots, } \\
\text { Onions, } \\
\text { Strawberrie } \\
\text { s }\end{array}$ & $\begin{array}{c}\text { Rose, } \\
\text { Douglas fir, } \\
\text { Balsam fir, } \\
\text { Aspen, Birch, } \\
\text { Raspberry }\end{array}$ \\
\hline
\end{tabular}

Table 3. 2: Agriculture grown in specific salt tolerance 36

\subsubsection{N, P and K}

The table below (Table 3.3) shows the corresponding nitrogen, phosphorus and potassium concentrations for each digestate. The NPK ratio is essential for plant development as each component aids in a specific role of plant development. Nitrogen is important for healthy foliage, chlorophyll production and vegetative growth. Phosphorus is important for flower development, 
DNA/RNA synthesis and strong root development. Lastly, potassium is responsible for hearty growth, synthesis of proteins and carbohydrates. ${ }^{46}$ Based on the table below, indicates that for all digestates nitrogen will be low, phosphorus will be relatively non-existent compared with potassium in the digestate. Nitrogen is low due to the type offeedstocks being fed in AD. Since the feedstocks are more on the fibrous side, nitrogen concentrations are already low. Phosphorus is barely present in all three digestates because of the $\mathrm{pH}$ shifting the chemical equilibrium toward phosphate formation and potential precipitation, creating loss of phosphorus in the AD process. Potassium is present in the digestates as potassium concentrations are always present in terrestrial plants.

Table 3.3: Nitrogen, phosphorus and potassium concentrations of each digestate

\begin{tabular}{|cccc} 
Location & Nitrogen & Phosphorus & Potassium \\
Disco Road & & & \\
AVG ppm & 442 & 1.92 & 7432 \\
SD $( \pm)$ & 12 & 0.78 & 393 \\
Apple & & & \\
Pomace & & & \\
AVG ppm & 294 & 0.45 & 2165 \\
SD ( \pm ) & 87 & 0.24 & 792 \\
Grocery & & & \\
AVG ppm & 356 & 0.48 & 4425 \\
SD $( \pm)$ & 58 & 0.16 & 1646
\end{tabular}

\subsubsection{Total Solids (TS) and Volatile Solids (VS)}

Since the digestate analyzed was $5 \% \mathrm{TS}$, there were some amounts of solids and volatile solids in the samples (Table 3.4). The samples for Disco road and grocery digestate have higher values indicative of a seasonal change in compost and waste respectively. As briefly mentioned grocery food waste digestate contained more total solids in comparison to Disco and apple 
pomace leading to an increase in salinity. However, larger amount of volatile solids were noticed in the Disco road digestate. The larger amount of VS can still be contributed to the mass of seasonal fruits and vegetables Disco road disposes.

Table 3. 4: Total solids, volatile solid counts in parts per million for each digestate as well as total organic carbon, volatile fatty acids and total alkalinity content

\begin{tabular}{|ccccc|}
\hline Location & TS & VS (g/L) & TOC & VFA/TAC \\
Disco Road & & & & \\
AVG ppm & 2364 & 1.55 & 3750 & 0.26 \\
SD ( \pm ) & 887 & 1.16 & 784 & 0.15 \\
Apple & & & & \\
Pomace & & & & \\
AVG ppm & 1206 & 0.39 & 1337 & 0.29 \\
SD ( \pm ) & 406 & 0.15 & 114 & 0.07 \\
Grocery & & & & \\
AVG ppm & 1905 & 0.43 & 1579 & 0.14 \\
SD ( \pm ) & 1762 & 0.15 & 245 & 0.07 \\
\hline
\end{tabular}

\subsubsection{Total Organic Carbon (TOC)}

The total organic carbon for each digestate (Table 3.4), regardless of the time of sampling did not vary as much as the other analyses made. TOC concentration is larger in Disco road compost in comparison to the other digestates due to the variation of organic waste and contaminants present.

\subsubsection{Volatile Fatty Acid/ Total Alkalinity Content (VFA/TAC)}

Table 3.4 shows the volatile fatty acid and total alkalinity results for each digestate. Small changes were observed due to that fact that the digesters are kept at a specific $\mathrm{pH}$ to maintain the digestion process. The outlier seen in the analysis below; apple pomace can be explained through error as the sample was left stand still for a couple of days in room temperature before analysis affecting the fermentation process. The VFA/TAC content for the apple pomace and grocery food 
waste are comparable, indicative of similar vegetation and fruits along with the sample size. Disco Road sees more variety in its feedstock as it consumes all of the city's green bin waste.

Based on the results shown in the previous section and depicted below in Figure 3.1, the digestate at $5 \% \mathrm{TS}$ is not adequate for fertilization as is. The important components: N, P, K ratio was not ideal for immediate fertilization. Figure 3.1 depicts the relative ratio of the NPK levels for all 3 digestate. It is apparent that the nitrogen levels are extremely low, the phosphorus levels are not existent, and the potassium levels are extremely high. This is evidence that the digestate as is would not make an effective fertilizer given the ratios provided. In Canada, due to agricultural managements and other human activities, nitrogen is the most limiting nutrient for crop production and is usually applied in the largest quantities compared to other elements. ${ }^{47}$ Since nitrogen plays an important role in structure of protein, and chlorophyll production, additive of fertilizers is important for plant responsive growth. When soil available nitrogen is low, yield and protein content will also be low. However, marketable fertilizers do possess greater nitrogen values with no phosphorus or potassium (i.e. $46-0-0$ or $34-0-0$ ). These fertilizers contain ammonia or urea which can be lost through volatilization as ammonia gas to the atmosphere. For small seeded crops, $\mathrm{N}: \mathrm{P}: \mathrm{K}$ ratios can be $20-10-0$ and based on the ratios analyzed from the digestate, the nitrogen amount can fertilize approximately $10 \mathrm{ft}$ in depth. ${ }^{48}$ With respect to safety of fertilization via the digestates, there was no evidence of heavy metals present that could potentially lead to leaching, accumulation and water eutrophication. Based on that evidence, if soil and plant growth could grow based on the given ratio produced from anaerobic digestion, the safety for the surrounding environment would be more than adequate.

Additives to the digestates would need to be made in order to increase the nitrogen and phosphorus ratio but would need to decrease the potassium level. From the analysis, the salinity 
content is average and can work for certain crop growth and development. However, the NPK ratios need to be altered in order for the digestate to be used as a fertilizer. A potential additive that can be used to alter the ratios could be biochar. As previously discussed, biochar is a solid product comprised of carbon and is a by-product of biomass conversion using pyrolysis. Biochar is typically used for soil remediation processes for water retention and holding capacity. Biochar is porous and possesses large surface area allowing it to withhold more water than untreated soil. ${ }^{49}$ Biochar, depending on the feedstock used to produce it can more importantly assist in levelling out the NPK ratio. As an example, vegetable biochar would not be a proper additive as it yields low nitrogen concentrations as well as high potassium concentrations, both of which are not helpful. Hog manure-based biochar on the other hand is high in nitrogen and phosphorus which would help in increase two out of three main components for plant growth. A filtration/drying experiment showed that the solid component in the digestate is a carbohydrate of significant purity, which may be suitable/ ideal for pyrolysis and the conversion to advanced carbons.

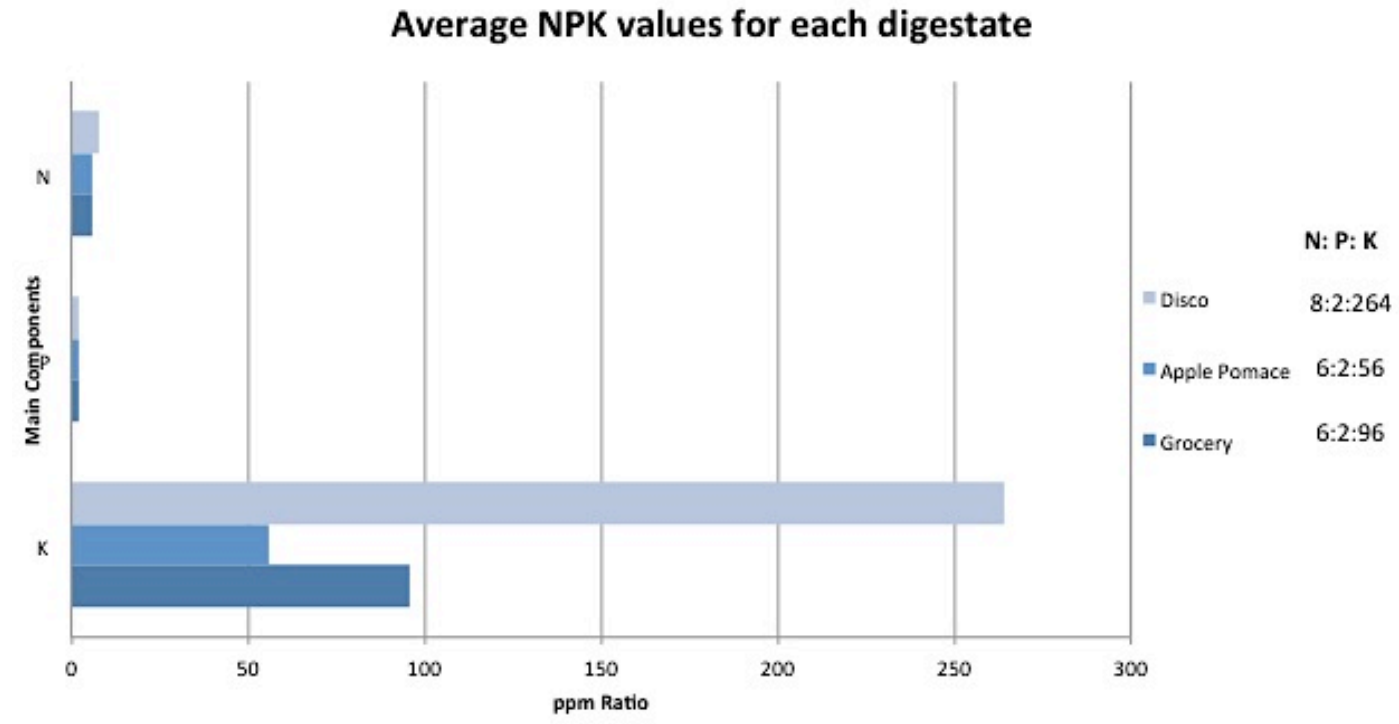

Figure 3. 1:NPK values for each digestate and the corresponding ratio on the right side of the legend. 


\subsection{Pyrolysis}

\subsubsection{Challenges with the Prototype}

A challenge that was insurmountable was the presence of oxygen within the pyrolysis system from small leaks. Since the prototype has metal to metal connections, and has been slightly modified throughout the project, the likelihood of leaks is quite common. The presence of oxygen in the system leads to combustion of organic material and inevitably leads to fuming (smoke). Broken down by section, the following outline the major limitation of the prototype.

Section 1: Feeding the hopper is a challenge, as the screw does not work efficiently for all feedstocks. When the pipe between the hopper and the reactor seem to be clogged, fumes immediately came back up the hopper and are hard to mitigate. This can be attributed to particle size depending on the feedstock (i.e., woodchips, cellulose, and digestate), if the particle size is too small and decomposition results in dust creation, the reactor lid can clog quickly, which results in coke production but halts run time as fumes are produced. The only control on feedrate is the speed at which the motor rotates the hopper screw. However, although the motor may be running at $50 \%$, the particle size of the feedstock can prohibit the desired feedrate as the material screws and cycles the material back up until it falls into another grove.

Section 2: Another challenge is the extraction of the sublimation product, coke. In order to collect the coke samples, the insulation on the reactor line is removed, exposing the bolts of the flange to disconnect the line and the reactor lid. The reactor lid is then lifted, and the coke is cleaned out. Since this is done every other day, there is variability of sealing and a well-insulated reactor line. Similarly, the char has an extractor port that has a smaller screw, ran in reverse to help empty out the bottom of the char bed in the reactor to allow for a longer feed time. However, due 
to the engineering and placement of the char extractor, the port that allows the screw to enter does not have an airtight seal, allowing any of the volatiles produced in the reactor to expel.

Since the char extractor was installed (February, 2019), leaks and unmanageable heating zones have prevented the production of bio-oil. The prevention of bio-oil production leads to the volatiles condensing later in the process, which means the condensate consists of oil and acetic acid mixture.

Yet another challenge in the general reactor design is that it is not easy to control the temperature in various zones. While we do know the temperature at various spots in system, the thermal couples that allow us to monitor the temperatures of each part of the reactor are not hard-wired back to the thermostat, which means temperature intervention is impossible. Owing to the reactor wall temperature being ceramic and electronically controlled, the process controller in which it is connected to, is the only temperature that can be controlled and set. Heating tapes that easily fluctuate in temperature controls the reactor line and inside quench. The temperature set on the process controller is roughly $200{ }^{\circ} \mathrm{C}$ more than the reactor wall temperature. The temperatures mentioned in Table 2.2 ( $\mathrm{a}$ and $\mathrm{b}$ ) are the temperatures recorded from the software at the initial time of running. Table 2.2 showcases the temperatures of the reactor wall, top and bottom as well as the grams of feedstock fed in 1 hour, estimated as some runs were only 8 minutes long due to challenges with the prototype, and the last column is the weight percentage of the solid product based on the corresponding run.

\subsubsection{GC/MS results for Oil/Pitch/Condensate}

Although not the focus of this thesis, the following analysis was carried out on the more volatile fractions for eucalyptus woodchips. Table 3.5 and 3.6 lists the type of liquid component, either pitch, oil, and condensate the compound and the percentage of that found compound. Based 
on literature, hard woods such as beech wood and eucalyptus contain similar compounds which result in similar compounds found within the bio-oil produced during pyrolysis. ${ }^{50}$ Depending on the temperatures employed during pyrolysis, some aromatic compounds would be degraded and not analyzed using GC/MS. Lignins may be pyrolyzed to produce a mixture of relatively simple phenols which result in the cleavage of ether and certain C-C linkages. ${ }^{50}$ The common compounds can be separated into 6 categories; (1) major carbohydrates, (2) minor carbohydrates, (3) furans, (4) phenols, (5) guaiacols, and (6) syringols. The typical pyrolysis liquid compounds found in wood based feedstocks are hydroxyacetaldehyde, acetic acid, hydroxyproanone, hydroxy propanal, butanedial, phenol, catechol, 2-furaldehyde, benzaldehyde, guaiacol, 4-methyl guaiacol, syringol, 4-methyl syringol, furanone, and levoglucosan. ${ }^{51}$ Increase in furans yield can be attributed to low temperatures and mainly to the decomposition of hemicellulose. Together with these compounds, other compounds with low molecular weight are formed such as carboxylic acids and ketones (i.e. hydroxy-2-cyclopentenone). ${ }^{52}$ Normally, natural lignin contains no catechol unit, which leads to the idea that catechols are associated with secondary pyrolysis at high temperatures. Guaiacol is an intermediate compound and the decomposition of guaiacol to catechol is favoured at high temperatures and long holding time. ${ }^{53}$ During a one-step pyrolysis, phenolic compounds tend to polymerize with aldehydes under acidic conditions whereas during multistep pyrolysis, cellulose and hemicellulose are removed prior to the decomposition of lignin. In the temperature range 350 to $450^{\circ} \mathrm{C}$, secondary compounds, mainly catechols, increased with a longer holding time due to demethylation of methoxy phenols rather than dehydration reactions. ${ }^{54} \mathrm{By}$ adding water to the bio-oil through an aerosol spray in the quench, a viscous oligomeric ligninderived fraction settles at the bottom while carbohydrates-derived compounds that are water soluble form a top layer. $25-30 \%$ of the bio-oil is the water-insoluble fraction, often called 
pyrolytic lignin due to the fact that it is composed of oligomeric fragments originating from the degradation of lignin. ${ }^{55}$ Cyclopentanedione, butanedioic acid, and octadecanoic acid are cellulose and hemicellulose decomposition products respectively. Similarly, 2,6-dimethoxy-4-(2-propenyl)phenol is a syringyl, which is a lignin decomposition product. ${ }^{56}$ As well, furfural, furanmethanol, 2-methyl-2-cyclopentene-1-one, 2-furancarboxyaldehyde-5-methyl, levoglucosan and acetic acid are degradation products of cellulose and hemicelluloses. ${ }^{57}$ Depending on the needs of the end user, certain compounds found will be more beneficial than others. Some users find the need of phenols important for resin applications. 
Table 3.5: Compound list found in eucalyptus oil and pitch

\begin{tabular}{|c|c|c|}
\hline Liquid Component & Compound & $\%$ \\
\hline EUC Pitch & Agaric Acid & $11 \%$ \\
\hline EUC Oil & Acetic Acid & $10 \%$ \\
\hline EUC Oil & Propanone & $8 \%$ \\
\hline EUC Oil & " " & $4 \%$ \\
\hline EUC Oil & Hexadeconoic Acid & $5 \%$ \\
\hline EUC Pitch & Ethyl iso- allocholate & $3 \%$ \\
\hline EUC Oil & Phenol & $3 \%$ \\
\hline EUC Oil & " " & $2 \%$ \\
\hline EUC Oil & phenol, 3-methyl-4-(methythiol) & $4 \%$ \\
\hline EUC Oil & 2-6-dimethoxy-4-(propenyl)phenol & $3 \%$ \\
\hline EUC Oil & phenol, 3- (1-1-dimethylethyl)-4-methoxy & $2 \%$ \\
\hline EUC Oil & phenol, 2-methoxy-4-(1-propenyl) & $2 \%$ \\
\hline EUC Oil & phenol, 2-methoxy & $2 \%$ \\
\hline EUC Oil & phenol, 1,2,6-dimethoxy & $1 \%$ \\
\hline EUC Pitch & phenol-dimethoxy & $1 \%$ \\
\hline EUC Pitch & dimethoxy-propenyl phenol & $1 \%$ \\
\hline EUC Oil & Phenol,2,4-dimethyl & $1 \%$ \\
\hline EUC Oil & hydroxy-2-butanone & $2 \%$ \\
\hline EUC Oil & " " & $1 \%$ \\
\hline EUC Oil & Catechol & $3 \%$ \\
\hline EUC Oil & " " & $2 \%$ \\
\hline EUC Oil & Cresol & $3 \%$ \\
\hline EUC Oil & " " & $1 \%$ \\
\hline EUC Oil & " " & $1 \%$ \\
\hline EUC Oil & 3,5-dimethoxy-4-hydroxytoluene & $3 \%$ \\
\hline EUC Pitch & dimethoxy-4-hydroxytoluene & $2 \%$ \\
\hline EUC Oil & cyclopentenone, 2-hydroxy-3-methyl & $2 \%$ \\
\hline EUC Oil & cyclopentanedione & $1 \%$ \\
\hline EUC Oil & Furfural & $2 \%$ \\
\hline EUC Oil & " " & $1 \%$ \\
\hline EUC Oil & Furanmethanol & $2 \%$ \\
\hline EUC Oil & 2-furancarboxyaldehyde, 5-methyl & $1 \%$ \\
\hline EUC Oil & Desaspidinol & $2 \%$ \\
\hline EUC Pitch & " " & $1 \%$ \\
\hline EUC Pitch & methoxy methyl octahydro-pryanol chromenedione & $1 \%$ \\
\hline EUC Pitch & acetyl dimethoxy phenyl acetate & $1 \%$ \\
\hline EUC Pitch & cyclohexadienone, trihydroxy-isovaleryl, bis (3-methyl-2-butenyl) & $3 \%$ \\
\hline EUC Oil & 1,2-benzenediol, 3-methoxy & $4 \%$ \\
\hline EUC Oil & benzenediol,3-methyl & $1 \%$ \\
\hline EUC Oil & 5-tert-butylpyrogallol & $2 \%$ \\
\hline EUC Oil & limethyl-2pyridone, 3- (4,6-dibromo)-2-hydroxyphenylmethylamin & $1 \%$ \\
\hline EUC Oil & " " & $1 \%$ \\
\hline EUC Oil & ethanol & $2 \%$ \\
\hline EUC Oil & cyclobutane & $1 \%$ \\
\hline EUC Oil & 1,2-epoxy-3-propyl acetate & $2 \%$ \\
\hline EUC Oil & 2,6-napthalenediol & $1 \%$ \\
\hline EUC Oil & 9-octadecenoic acid & $1 \%$ \\
\hline EUC Oil & butanoic acid & $1 \%$ \\
\hline
\end{tabular}

$\underline{\text { Condensate Analysis }}$

Table 3.6 lists the compounds found in eucalyptus woodchips condensate and the relative percentage of the compound in the given condensate. These compounds are present due to the 
decomposition of intermediate functional groups as mentioned above. Depending on the potential use of the bio-oil, some of these compounds will be useful.

Table 3. 6: List of compounds found in eucalyptus condensate and corresponding percentage

\begin{tabular}{|l|c|c|}
\hline Liquid Component & Compound & $\%$ \\
\hline EUC Condensate & Propanone & $5 \%$ \\
\hline EUC Condensate & Phenol & $3 \%$ \\
\hline EUC Condensate & phenol, 2-methyl & $2 \%$ \\
\hline EUC Condensate & phenol, 3-methyl & $3 \%$ \\
\hline EUC Condensate & Catechol & $7 \%$ \\
\hline EUC Condensate & Furfural & $5 \%$ \\
\hline EUC Condensate & phenol, 2,6-dimethoxy & $2 \%$ \\
\hline EUC Condensate & phenol, 4-methoxy-3-(methoxymethyl) & $1 \%$ \\
\hline EUC Condensate & melezitose & $3 \%$ \\
\hline EUC Condensate & D-glucopyranose & $10 \%$ \\
\hline EUC Condensate & cyclopentenone, 2-hydroxy-3-methyl & $1 \%$ \\
\hline
\end{tabular}

\subsubsection{C, H, and N Analysis}

Samples were sent out to Chemisar Laboratories Inc., to determine the $\mathrm{C}, \mathrm{H}, \mathrm{N}$ percentages and are shown below in Table 3.7. Based on this table, it is evident that the coke product contains more carbon than char, but more importantly, it contains a higher percentage than the other elements. This analysis proves that the sublimation product of pyrolysis is the more promising product for carbon allotrope discovery. Based on this analysis, the coke from any feedstock is still not fully carbonized as approximately $10 \%$ consists of another element. The char on the other hand contains a large amount of unpyrolyzed organic matter, resulting in a lower percentage of carbon. The remaining weight of the total percentage is likely made up of oxygen, which was not measured.

Table 3.7: $C, H$, and $N$ analysis of coke and char for different feedstocks

\begin{tabular}{|l|r|r|r|r|}
\hline Sample & Carbon \% & Hydrogen \% & Nitrogen \% & Total \% \\
\hline VDI Raw & 56.24 & 12.68 & 3.49 & 72.41 \\
\hline VDI Coke & 84.94 & 3.87 & 0.42 & 89.23 \\
\hline VDI Char & 63.19 & 5.29 & 1.97 & 70.45 \\
\hline EUC Coke & 85.12 & 2.35 & 0.56 & 88.03 \\
\hline EUC Char & 67.11 & 6.29 & 2.25 & 75.65 \\
\hline DBA Coke & 85.22 & 2.64 & 0.73 & 88.59 \\
\hline DBA Char & 70.73 & 5.88 & 1.79 & 78.40 \\
\hline
\end{tabular}




\subsubsection{XRD Results of Coke Samples}

\section{Literature Comparison for Carbon Allotropes}

Based on literature, XRD diffraction angles of graphite and graphene are shown at $27^{\circ}$ and $44^{\circ}$ whereas the oxidized version of graphite (graphene oxide) has an angle of $11^{\circ}$ and $44^{\circ}$ (Figure 3.2). In the XRD shown, the graphene oxide (GO) increases interplanar distance due to the introduction of oxygen-containing groups on the edge of each layer. ${ }^{58}$ Since carbon nanotubes and fullerenes $\left(\right.$ e.g. $\left.\mathrm{C}_{60}\right)$ are made up of multiple carbon sheets or atoms, the complexity of the XRD also changes. Figure 3.3 shows the angle diffraction pattern of fullerene powder, and the numbers above the peaks are the reflection indices (faced centered cubic and hexagonal close packed) with the hexagonal close packed (hcp) lattice shown in parentheses. ${ }^{59}$

In order to compare the carbon allotropes based in the coke and char samples, the simplistic standard to use is the graphite found in $\mathrm{HB}$ pencils (Figure 3.4). The intense signal at $27^{\circ}$ is indicative of the purity and crystallinity of the sample. Low-temperature produced carbon allotropes are different from well-crystallized graphite because it consists of random stacking of small layers, as shown by the following coke XRD patterns. 


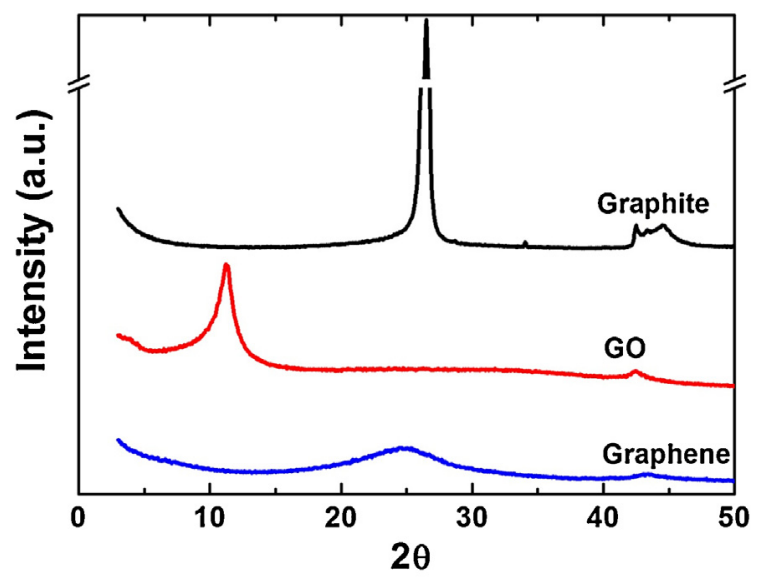

Figure 3. 2: XRD patterns of graphite, graphene oxide, and graphene

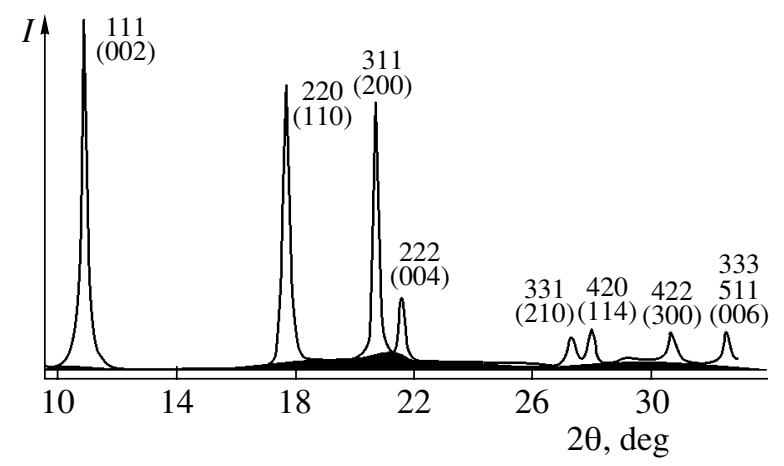

Figure 3. 3: XRD pattern for fullerene powder

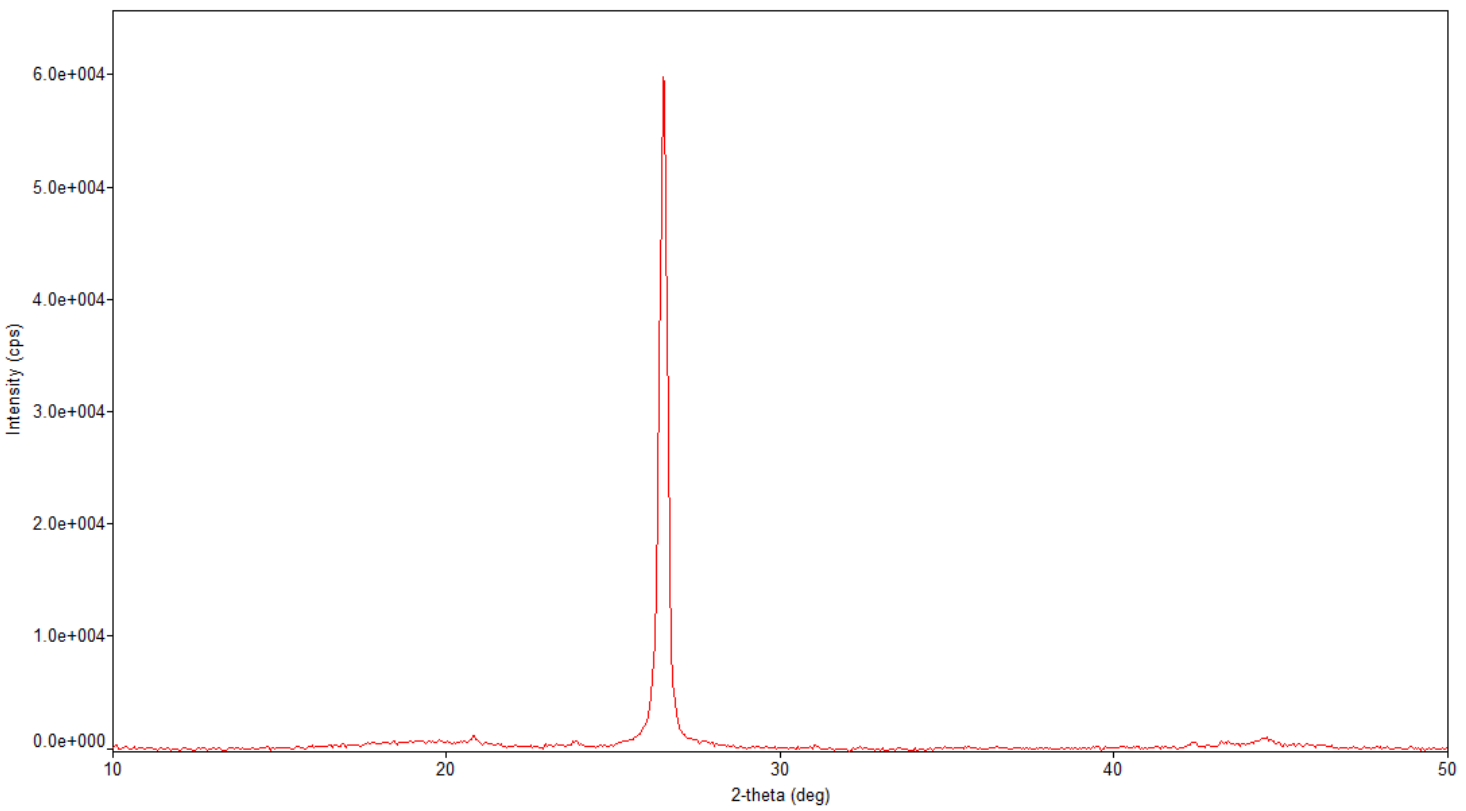

Figure 3. 4: Graphite standard from HB pencil 
In Figure 3.5, eucalyptus char (blue) and coke (red) are compared from similar runs with similar pyrolyzed temperatures. It can be seen that the char XRD patterns do not show any evidence of graphite at this particular temperature, however if the temperature was greater than $540{ }^{\circ} \mathrm{C}$ in the reactor, observed peaks at $26^{\circ}$ and $44^{\circ}$ would be expected based on literature precedent (prototype wall temperature was capped at $500{ }^{\circ} \mathrm{C}$ ).$^{60}$

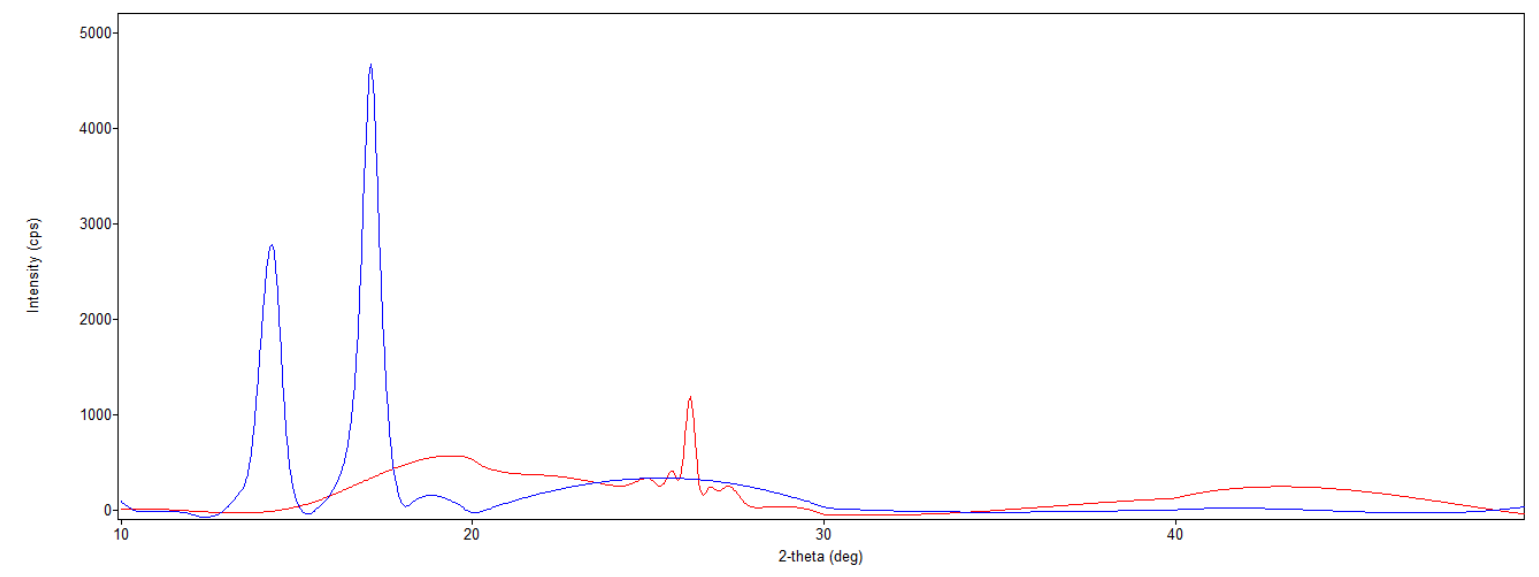

Figure 3. 5: EUC char (blue) and coke (red) sieved

In attempt to rationalize digestate pyrolysis a cellulose feedstock was pyrolyzed as a benchmark. Figure 3.6 shows $\alpha$-cellulose prior to carbonization, with peaks at 15 and $22^{\circ}$ (red). After pyrolysis, the carbonization of the cellulose matter degrades and peaks visible in the raw cellulose are replaced with the peaks associated with graphite (blue; difficult to see based on the relative intensity). The cellulose coke (blue) XRD patterns mimic the graphite peaks, however, due to impurities in the coke in comparison to pure graphite, the intensity is lower. This XRD spectrum illustrates the evidence that carbonization does produce the carbon allotrope graphite. 


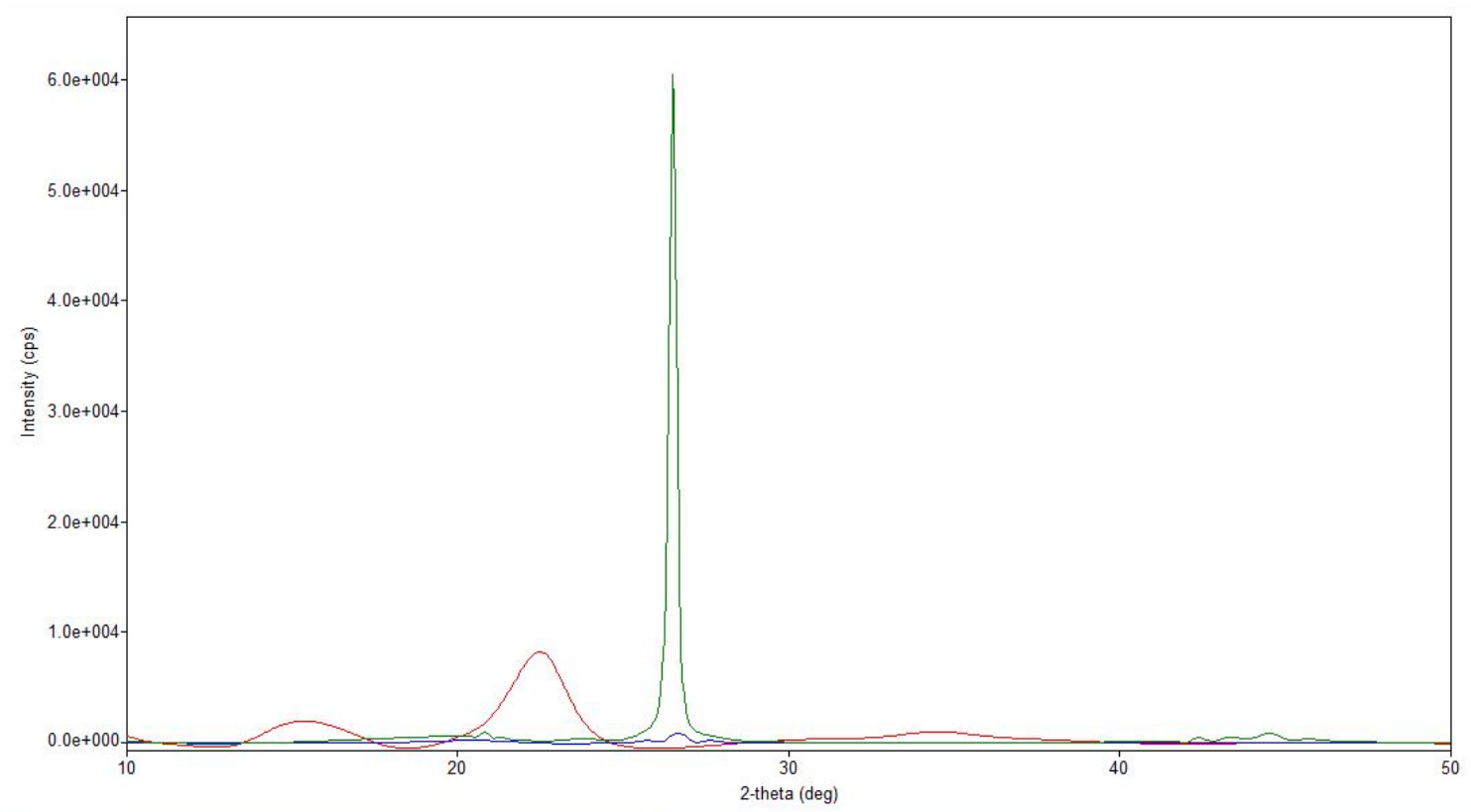

Figure 3. 6: Raw cellulose prior to pyrolysis (red), CUL coke-1 (blue), graphite (green)

\section{$\underline{\text { Sieved vs Non-sieved }}$}

Figure 3.7 compares the difference between XRD spectra with and without sieving. Sieving the ground coke or char samples allows for homogenous particle size in order to achieve reproducibility with the XRD analysis. After sieving with a $53 \mu \mathrm{m}$ mesh size, broad peaks that existed prior to sieving become more defined because more convoluted peaks are a result of particle broadening. ${ }^{61}$ This can be seen when comparing the below diffraction patterns, as peaks become sharper at $37^{\circ}$. Similarly, the graphite peak of $26^{\circ}$ has multiple peaks prior to sieving but is sharper after sieving. Literature has recommended that particle size of carbon samples should be less than $100 \mu \mathrm{m} .{ }^{62}$ As mentioned in 2.2.6, the sample is pulverized and by hard grinding, the crystalline structure of the allotrope deteriorates allowing the proper size to pass through the given sieve. ${ }^{63}$ 


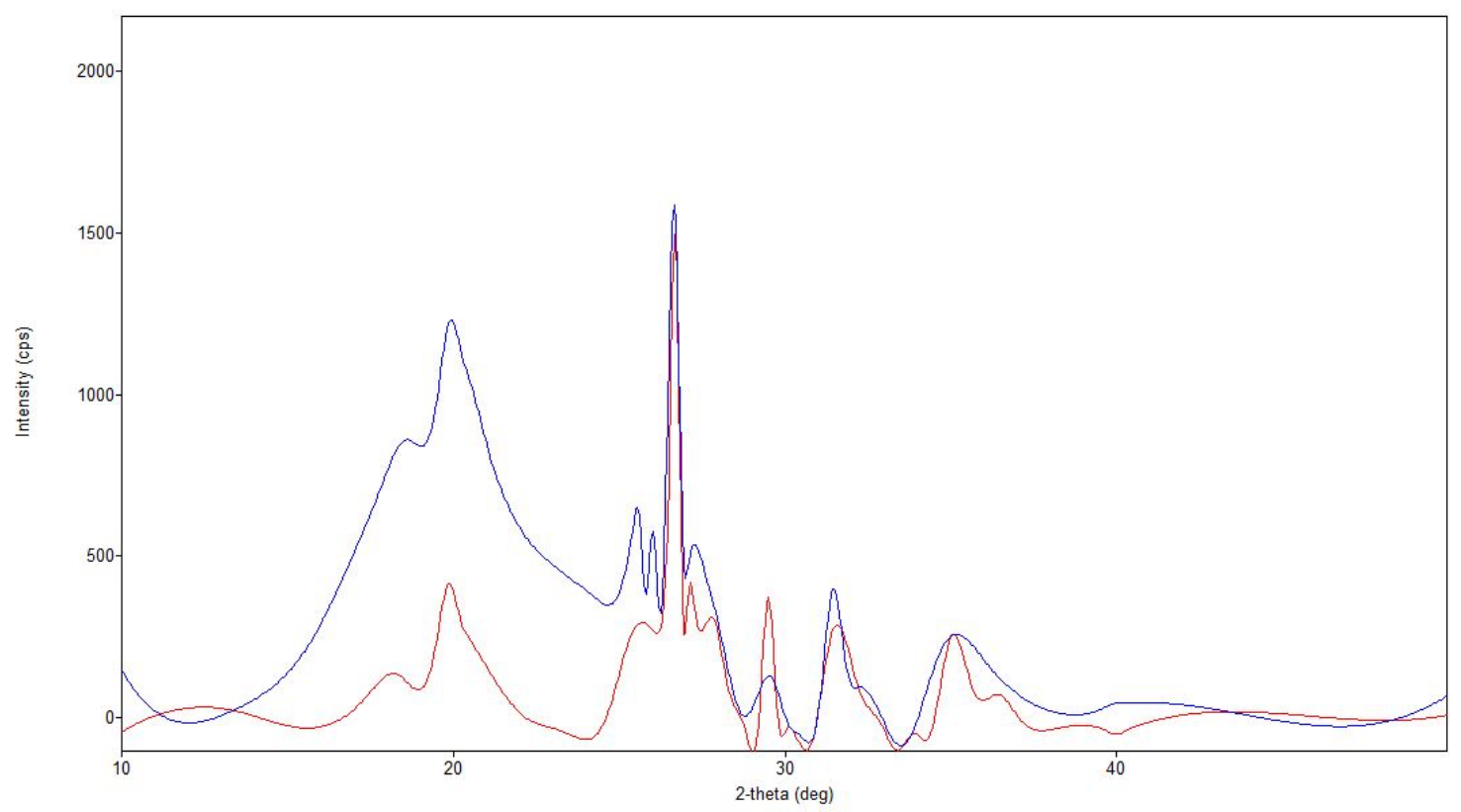

Figure 3. 7: Digestate coke (2), prior to sieving (blue) and digestate (2) after sieving using 53 m (red)

\section{Exfoliation and Sonication}

As shown in Figure 3.8, it is evident that the electrochemical exfoliation using $0.1 \mathrm{M}$ of sulfuric acid $\left(\mathrm{H}_{2} \mathrm{SO}_{4}\right)$ was more successful in reducing broad peaks and removing peaks associated with other organic matter. Similarly, electrochemical exfoliation, which was applied overnight with $9 \mathrm{~V}$ resulted in greater intercalation between the coke layers than the vibration using a sonicator for 1 hour. Although both processes were able to stabilize and prevent reaggregation, the intensity of the $26^{\circ}$ peak in Figure 3.7 corresponds to literature, which states that graphite has a interlayer spacing of approximately $0.35 \mathrm{~nm} .{ }^{64 ; 65}$ Moreover, coke displays the graphite (100) band approximately around $44^{\circ}$. Exfoliation using $\mathrm{H}_{2} \mathrm{SO}_{4}$ and applying an electricity source overnight, was able to purify the crude coke (Figure 3.8). In comparing the diffraction patterns, the broad peak between 10 and $20^{\circ}$ as well as any peaks visible from $30^{\circ}$ onwards are mitigated. Based on this evidence, the exfoliation process was successful. 


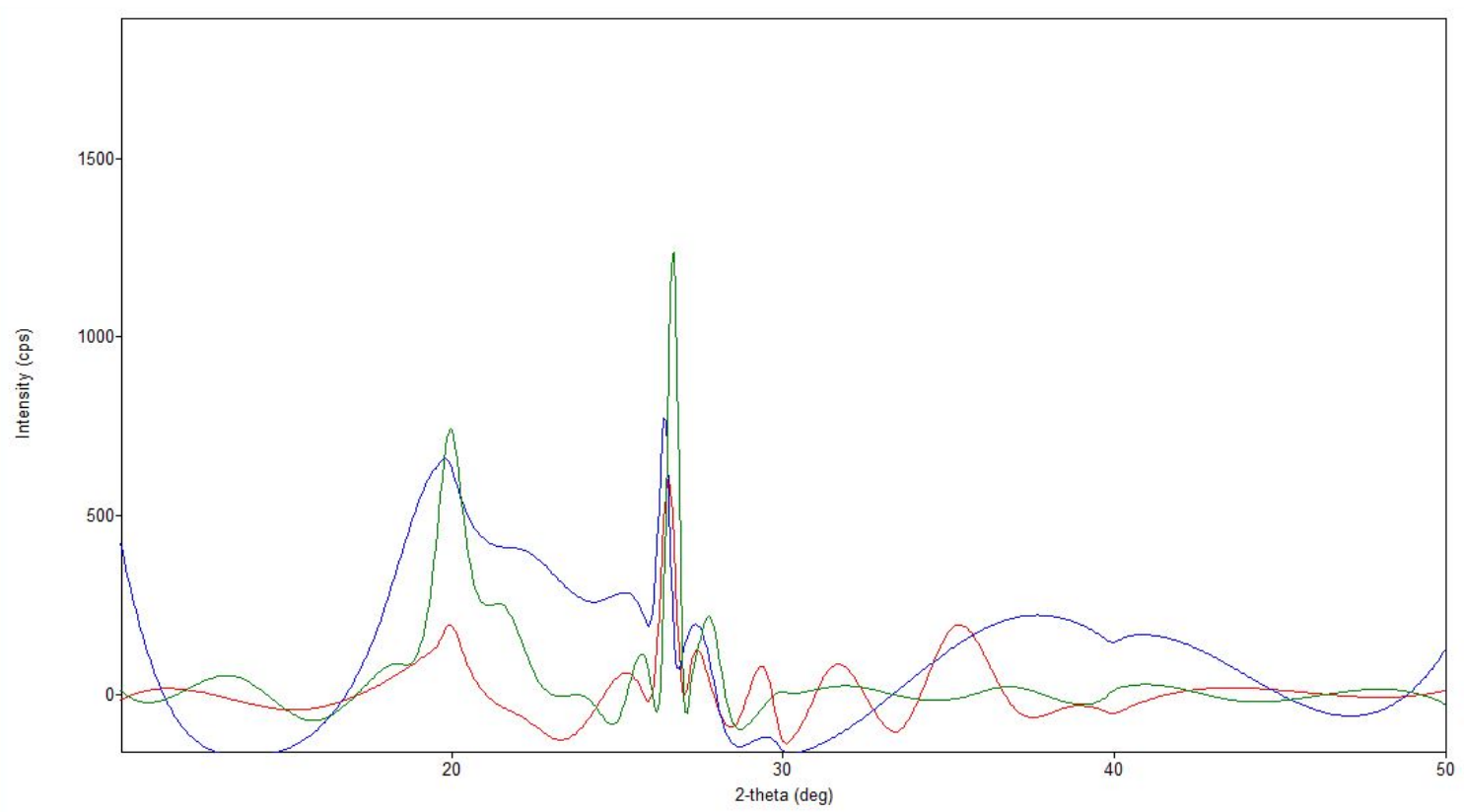

Figure 3. 8:Digestate (1) coke after sonication in black tea (blue), digestate (1) coke after 0.1 M H2SO4 electrochemical exfoliation (green) compared to digestate sieved prior to exfoliation (red)

\subsubsection{Raman Results}

Single walled nanotubes (SWNT) or bundles, can be analyzed using Raman analysis, because the direction of the optical electric field is relative to the nanotube axis. Similarly, changing the diameter and chirality of SWNTs, results in different resonance in the Raman spectra. The characteristic signal found in Raman spectroscopy is the G-band. The G-band refers to graphene and is also present in graphite. The G-band involves an optical phonon mode between the two dissimilar carbon atoms within the unit cell. In contrast to the graphite the Raman G-band at $1582 \mathrm{~cm}^{-1}$ is relative to the tangential mode vibrations of the C atoms. The SWNT G-band is composed of several peaks due to the phonon wave vector confinement along the SWNT circumferential direction and due to symmetry-breaking effects associated with the curvature (Figure 3.9). ${ }^{42}$ The coke and char samples were sent out for analysis and none of the samples contained CNT or fullerenes. 


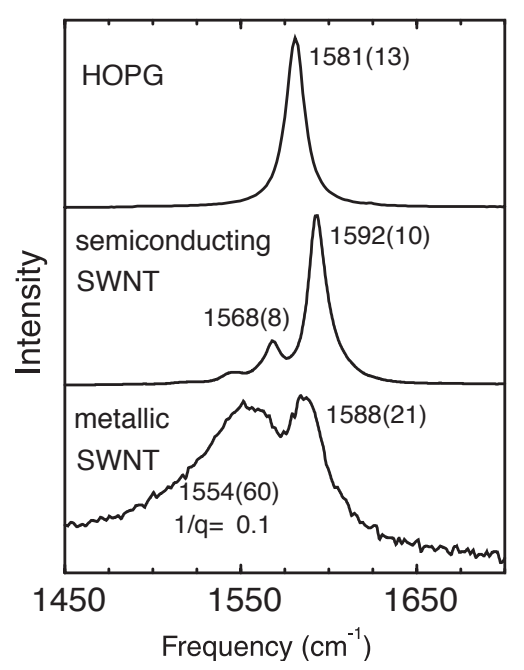

Figure 3. 9: G-band for graphite and SWNTs

Chapter 3 of this thesis was designed to determine whether or not the dewatered digestate would serve as a suitable feedstock for pyrolysis with the production of carbon allotropes from solid products. In hopes of finding more complex carbon allotropes used for optoelectronic applications, the solid by-products of pyrolysis with digestate feedstock were examined for the presence of graphenes. Char and coke products from the digestate feedstock has shown that graphite is present. Although, it is difficult to optimize the production of pyrolysis owing to a lack of temperature control, the presence of graphite is reassuring as it showed that this thermal conversion process is able to close the loop on waste, which could provide value for other applications.. While in the process of attaining the main goal of this thesis, particle size was noticed to be a variable of concern when it came to validating XRD as a characterization technique and. the intensities of this carbon allotrope vary based on the purity of the coke. With that being said, upon proper exfoliation techniques, the products can be exfoliated to extract graphite to graphene, given that graphite is made up of multiple layers of graphene. As shown in the previous section, the two types of exfoliations changed the given XRD patterns, however, the electrochemical exfoliation using sulfuric acid had shown to be the better choice due to eliminating impurities. 


\section{Chapter 4: Conclusions and Future Work}

\subsection{Overall Summary}

To summarize, the first objective of this thesis was CCI Bioenergy's motivation to determine whether or not the digestate converted from 3 different sources via anaerobic digestion process would produce an effective fertilizer: based on the components analyzed, the ratios of nitrogen could make for an effective fertilizer, however, the potassium component is extremely high. After analyzing the digestate using elemental analysis along with total nitrogen and total phosphorus, the important $\mathrm{N}, \mathrm{P}$ and $\mathrm{K}$ ratios were discovered to not be in range with an effective source of fertilization. Nitrogen and phosphorus were low, whereas the potassium ratio was extremely high, leading to other potential concerns. However, digestate is still a liability for anaerobic digestion and the city of Toronto pays $\$ 126$ per tonne (15,000 tonnes per year) to dispose of their digestate. Nonetheless, during the filtration process, it was recognized that the dewatered digestate could make for suitable pyrolysis feedstock.

The second objective of this thesis was to use the dewatered digestate as a pyrolysis feedstock. The coke and char samples were analyzed for XRD, C, H, N and Raman spectroscopy providing evidence that graphite is the present allotrope in the coke production. Further observations were made when the cokes particle size was sieved to provide a more homogenous sample size prior to XRD analysis. The sieved sample provided sharper and more defined peaks.

The last objective of this thesis was to purify the crude coke and exfoliate the graphite in order to see if graphene is present. An electrochemical exfoliation using $\mathrm{H}_{2} \mathrm{SO}_{4}$ and a black tea sonication were compared. The electrochemical exfoliation provided more intercalation between the crude coke and resulted in a purer XRD pattern than the black tea sonication. However, there may not be an economical value associated with exfoliating the coke if there is no evidence of high 
value nano-carbons. Having said that though, there are numerous applications that the pyrolyzed products can be used for (vide infra).

\subsection{Improvements to Prototypes}

As mentioned in 3.3.3, there were multiple challenges with the prototype disallowing similarities between every run. In order to provide controlled experiments, the prototype would need improvements. First, the biomass feeding system would need to be altered in order to create a smooth feeding system for any type of feedstock. As shown in Figure 3.17 the feed would move on a conveyor belt directly above the reactor, where the biomass would dry from the latent heat of the reactor lid. The dried biomass would then drop into a hopper and another conveyor belt system enables any feedstock with any particle size to smoothly transition from the hopper to the reactor. Second, inert gas such as nitrogen gas will be entering the hopper, the reactor and the quench, keeping a positive pressure flowing in the system. By adding nitrogen gas to the hopper, the hopper can remain closed and does not require manual labour. Third, the instrument would need to contain ceramic walls and hard-wired thermocouples in necessary spots such as reactor, reactor lid, reactor line, and quench to control temperatures that alter each run and product yield. Another improvement to the instrument would be adding a coke removal pan similar to a filter present in a furnace, however this pan will be made of mesh. This pan allows the coke to be collected as well as prevent clogging during the run. Similarly, beneath the quench unit and prior to bio-oil collection, a filter will be added to filter out particulate that may have travelled from the reactor line. By filtering out these particulates, the bio-oil will strictly be liquid. In order to remove char from the reactor without causing too much fume exposure, the char extraction will be a valve in a port system. The char extraction pan will be an inert, airtight system, however, similar to a glove box, it will allow the user to extract the char and prevent the inert gas from seeping out through 
the antechamber. Another improvement is the addition of cyclones in the quench system. These would be three steel cyclonic condensers in series, that contain the cold aerosol water and nitrogen. The mixture of vapours and gases enter each condenser and are immediately cooled. This causes tangential entry forces the vapours and gases to spin, providing good agitation and heat transfer, driving the condensed liquid droplets to the wall through cyclonic action. ${ }^{66}$

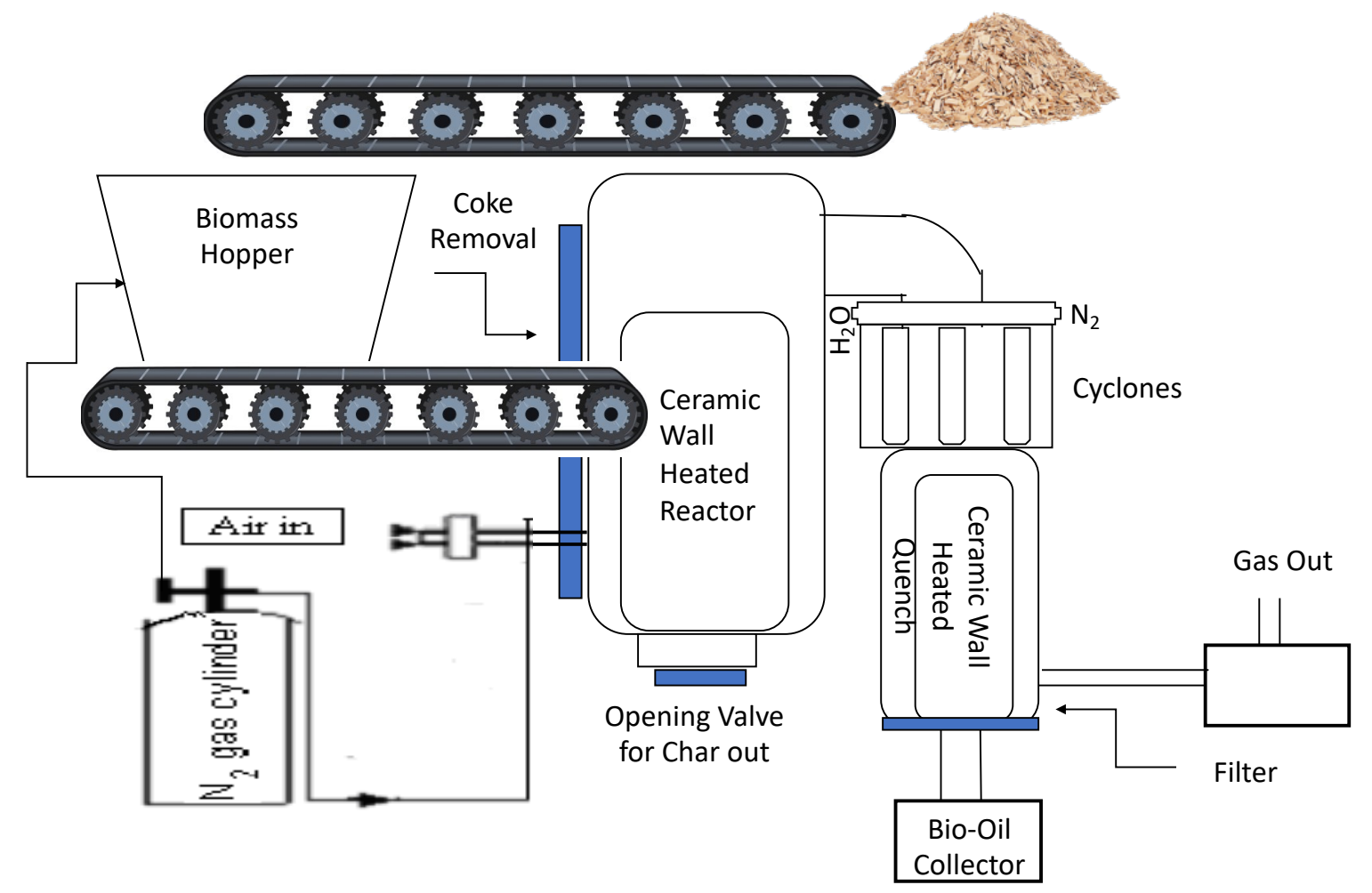

Figure 4.1:New design of pyrolysis benchtop prototype

\subsection{Future Work with the Carbon Allotropes from Pyrolysis}

Since this thesis focused on converting waste to create value and close the loop on this waste product, the actual applications for this graphitic product was not fully explore. However, creating carbon allotropes from digestate, is possible, but difficult to scale up with based on current 
prototype. As shown in Table 3.2, the wt \% based on how much has been fed is quite low in comparison to the other by-products produced. Although, pyrolyzed coke and char do produce carbon allotropes, the quality needed for optoelectronic purposes not where it needs to be to become cost effective. Therefore, other environmentally friendly purposes should be considered.

The current imbalance of carbon in the atmosphere is stimulating the search for carbon sequestration opportunities and for alternative products with a reduced carbon footprint. Concrete is one of the materials with the highest potential for reductions in its environmental impact and the related GHG emissions. ${ }^{67}$ Concrete is an anthropogenic material, with low-cost and high compressive strength and is the most commonly used building material with annual production of over 14 billion tonnes. ${ }^{68}$ With large quantities being produced, concrete industry accounts for $7 \%$ of global $\mathrm{CO}_{2}$ emissions. ${ }^{69}$ Graphene has been explored in cementitious materials and has shown to exhibit unique mechanical, electrical, and thermal transport properties. ${ }^{70}$ Another possibility is the use of biochar as an additive for concrete, due to its ability to sequester atmospheric $\mathrm{CO}_{2}$. Biochar, as previously mentioned, is a porous carbon-based material, incorporating the majority of the mineral content of the original feedstock. Biochar has high fixed carbon levels, high specific surface areas and pore volumes, and good absorptive capacity. ${ }^{71}$ Biochar has several properties that have been identified to improve various performance characteristics of the concrete to which it has been added. The low bulk density of biochar, the low thermal conductivity, and the porous nature of the material all presents different advantages for this as an additive to building materials. ${ }^{72}$ The low density allows for lighter concrete and can help displace the larger volume fraction taken up by denser materials, such as cement powder. The low thermal conductivity of the biochar, along with the pores that are present in the material increases the thermal insulation of the material by breaking up the thermal bridging. ${ }^{73}$ In addition to insulation properties, the 
biochar creates voids and networks of interconnected pores in the concrete, providing porous structure, increasing sound absorption. ${ }^{74}$ It is also known that the pores can promote water retention during the mixing stage. The water is then released as the available moisture is used up for hydration reactions, promoting secondary hydration reactions and additional curing, resulting in improved mechanical properties. ${ }^{75}$ Graphene oxide is currently used in cement paste and mortar matrix, improving mechanical properties. Similarly, graphite powder has been proven to increase damping ability and improvement of self-heating. ${ }^{76}$ As such the use of the pyrolyzed solid waste from biomass represents an exciting material to create green building materials, and a rather charming method to sequester carbon from the atmosphere, after we have already paid for transportation and extracted the value from human food consumption. Future studies (although already ongoing) will be to incorporate biochar and coke into concrete mixer and testing for its ability to absorb the microwave radiation and the other properties listed above. 


\section{References}

(1) Clark, J. H. Green Chemistry: Today (and Tomorrow). Green Chem. 2006, 8 (1), 17-21.

(2) BEC. Biomass Energy Centre http://www.biomassenergycentre.org.uk/ (accessed Mar 23, 2019).

(3) World Bioenergy Association. Global Biomass Potential Towards 2035. 2016, 1-6.

(4) Gadonneix, P.; Pacific, A.; Asia, S.; Frei, C. 2010 Survey of Energy Resources. World Energy Council. 2010.

(5) Berg, J., Tymoczko, J. \& Stryer, L. Biochemistry, 5th ed.; W.H. Freeman, 2002.

(6) Byrne, C.E. and Nagle, D. C. Wood Monoliths-Characterization. Carbon N. Y. 1997, 35 (2), 267-273.

(7) Alberts, B., Johnson, A., Lewis, J., Raff, M., Roberts, K. \& Walter, P. Molecular Biology of the Cell. Garl. Sci. 2002.

(8) Grabber, J. H. How Do Lignin Composition, Structure, and Cross-Linking Affect Degradability? A Review of Cell Wall Model Studies. Crop Sci. 2005, 820-831.

(9) Rowell, R. M., Pettersen, R., Han, J. S., Rowell, J. S. \& Tshabalala, M. A. Cell Wall Chemistry, Wisconsin. 2005. 35-45.

(10) Bruijnincx, P. C. A.; Rinaldi, R.; Weckhuysen, B. M. Unlocking the potential of a sleeping giant: Lignins as Sustainable Raw Materials for Renewable Fuels, chemicals and materials. Royal Society of Chem. 2015. DOI: 10.1039/c5gc90055g

(11) Mohan, D.; Pittman, C. U.; Steele, P. H. Pyrolysis of Wood / Biomass for Bio-Oil : A Critical Review. 2006, No. 4, 848-889.

(12) Ontario Ministry of Agriculture, Food and Rural Affairs (OMAFRA). Soil Health in Ontario. 2019. Retrieved July 18, 2019.

(13) Robertson, G. P.; Vitousek, P. M. Nitrogen in Agriculture : Balancing the Cost of an Essential Resource. Annual Review of Environment and Resources. 2009. 34: 97-125.

(14) Eghball, B., Binford, G., \& Baltensperger, D. Phosphorus Movement and Adsorption in a Soil Receiving and Fertilizer Application Long-Term Manure. Int. Adsorpt. Soc. 1968.

(15) Schjonning, P. Christensen, B. T. and Carstensen, B. Physical and Chemical Properties of a Sandy Loam Receiving Animal Manure, Mineral Fertilizer or No Fertilizer for 90 Years. Eur. J. Soil Sci. 1994, 45 (3), 257-268.

(16) Mandal, A.; Patra, A. K.; Singh, D.; Swarup, A.; Ebhin Masto, R. Effect of Long-Term Application of Manure and Fertilizer on Biological and Biochemical Activities in Soil during Crop Development Stages. Bioresour. Technol. 2007, 98 (18), 3585-3592.

(17) Jongloed, A. W.; Lenis, N. P. Environmental Concerns about Livestock Manure. J. Anim. Sci. 1998, 76 (May), 2641-2648.

(18) Trenkel, M.E. Slow and Controlled-Release and Stabilized Fertilizers. International Fertilizer Industry Association. 2013. 53, 17-69.

(19) Kizilkaya, R., Bayraki, F., Surucu, A. Relationship between Phsphatase Activity and Phosphorus Fractions in Agricultural Soils. Int. J. Soil Sci. 2007, 2 (2), 107-118.

(20) Kirschner, E. Fertilizer Makers Gear up to Grow. Chemical \& Engineering. 1997, 1315.

(21) Luis, A., Teixeira, P., Almeida, S., Matos, J., and Da Silva, E. Chemical and Diatom Characterization of Metal-Contaminated Stream Sediments and Surface Water of 
Corona Stream. Sci. Total Environ. 2011, 409 (20), 4312-4325.

(22) Ubi, W.; Ubi, M. W.; Akpanidiok, A. U. Effect of NPK Fertilizer and Interval Management on the Chemical Properties of Coastal Plain Sands of Akpabuyo, Nigeria. Glob. J. Agric. Sci. 2013, 12 (1), 73-79.

(23) Romero-Aranda, R.; Soria, T.; Cuartero, J. Tomato Plant-Water Uptake and PlantWater Relationships under Saline Growth Conditions. 2001, 160, 265-272.

(24) Paetsch, L.; Mueller, C. W.; Kögel-Knabner, I.; Von Lützow, M.; Girardin, C.; Rumpel, C. Effect of In-Situ Aged and Fresh Biochar on Soil Hydraulic Conditions and Microbial C Use under Drought Conditions. Sci. Rep. 2018, 8 (1), 1-11.

(25) Locatelli, G.; Boarin, S.; Fiordaliso, A.; Ricotti, M. Cogeneration: An option to facilitate load following in Small Modular Reactors. Progress in Nuclear Energy. 2017, (97) 110. DOI: $10.1016 /$ j.pnucene.2016.12.012

(26) Hanief, A. Phosphorus Fractions in Biosolids, Biosolid- Amended Soils , Runoffs and Its Impact on Primary Productivity in Aquatic Ecosystems. 2011.

(27) Cobaugh, K. L.; Schaeffer, S. M.; Debruyn, J. M. Functional and Structural Succession of Soil Microbial Communities below Decomposing Human Cadavers. 2015, 1-20.

(28) CCI BioEnergy https://www.ccibioenergy.com/ (accessed Apr 8, 2019).

(29) Möller, K. Effects of Anaerobic Digestion on Digestate Nutrient Availability and Crop Growth : A Review. 2012, No. 3, 242-257.

(30) Cherubini, F. The Biorefinery Concept : Using Biomass Instead of Oil for Producing Energy and Chemicals. Energy Convers. Manag. 2010, 51 (7), 1412-1421.

(31) Theapparat, Y.; Chandumpai, A.; Faroongsarng, D. Physiochemistry and Utilization of Wood Vinegar from Carbonization of Tropical Biomass Waste; 2018.

(32) Braber, K.; Novem, B. V. Anaerobic Digestion of Municipal Solid Waste: A Modern Waste Disposal Option on the verge of Breakthrough. 1995, 9 (95), 365-376.

(33) Jewell, J. Apple Pomace Energy and Solids Recovery. 1979, 407-410.

(34) Joshi, V. K. Optimization of Apple Pomace Based Medium and Fermentation Conditions for Pigment Production by Micrococcus Species. 2005, 64 (August), 598601.

(35) Hashimoto, H.; Muramatsu, Y.; Nishina, Y.; Asoh, H. Bipolar Anodic Electrochemical Exfoliation of Graphite Powders. Electrochem. commun. 2019.

(36) Low, C. T. J. Electrochemical Approaches to the Production of Graphene Flakes and Their Potential Applications. Carbon N. Y. 2012, 54, 1-21.

(37) Yu, P.; Lowe, S. E.; Simon, G. P.; Zhong, Y. L. Current Opinion in Colloid \& Interface Science Electrochemical Exfoliation of Graphite and Production of Functional Graphene. Curr. Opin. Colloid Interface Sci. 2015, 20 (5-6), 329-338.

(38) ThermoFischer Scientific https://www.thermofisher.com/ca/en/home/industrial/mass-spectrometry/massspectrometry-learning-center/gas-chromatography-mass-spectrometry-gc-msinformation.html (accessed Jun 26, 2019).

(39) Foneii, H. A. The Characterization of Papers by X-Ray Diffraction ( XRD ) : Measurement of Cellulose Crystallinity and Determination of Mineral Composition.

(40) Moore, D. M. and Ryenolds, R. C. J. X-Ray Diffraction and the Identification and Analysis of Clay Materials, 2nd ed.; Oxford, 1997.

(41) Princeton Instruments. Raman Spectroscopy. 2019. https://www.princetoninstruments.com/spectroscopy/Raman 
(42) Dresselhaus, M.S., Dresselhaus, G., Saito, R., and Jorio, A. Raman Spectroscopy of Carbon Nanotubes.Pdf. Phys. Rev. 2005, 409, 47-99.

(43) Dresselhaus, M.S., Dresselhaus, G., and Saito, R. Carbon Fibres Based on C60 and Their Symmetry. Phys. Rev. 1992, 45 (11), 6234-6242.

(44) Maguire, R.; Alley, M. Fertilizer Types and Calculating Application Rates. Crop and Soil Environmental Sciences. 2009, 1-3.

(45) She, D.; Sun, X.; Gamareldawla, A. H. D.; Nazar, E. A.; Hu, W.; Edith, K.; Yu, S. Benefits of Soil Biochar Amendments to Tomato Growth under Saline Water Irrigation. Sci. Rep. 2018, 8 (1), 1-10.

(46) Anai, J. Y.; Akata, S. N.; Unakawa, S. F.; Awata, E. N. Effect of NPK Application on Growth , Yield and Nutrient Uptake by Sugarcane on a Sandy Soil in Northeast Thailand. Trop. Agric. Dev. 2010, 54 (4), 113-118.

(47) Khakbazan, Mohammad ; Grant, Cynthia ; Huang, Jianzhong ; Zhong, Colin ; Smith, Elwin ; O’Donovan, John ; Mohr,Ramona ; Blackshaw, Robert ; Lafond, Guy ; Johnson, Eric ; Gan,Yantai ; Lupwayi,Newton ; St. Luce, M. Economic Impact of Residual Nitrogen and Preceding Crops on Wheat and Canola. Agron. J. 2018, 110 (1), 339348.

(48) Alberta Government. Wheat Nutrition and Fertilizer Requirements-nitrogen https://www.alberta.ca/wheat-nutrition-and-fertilizer-requirements-nitrogen.aspx (accessed Aug 21, 2019).

(49) Ulyett, J.; Sakrabani, R.; Kibblewhite, M.; Hann, M. Impact of Biochar Addition on Water Retention, Nitrification and Carbon Dioxide Evolution from Two Sandy Loam Soils. 2014, January, 96-104.

(50) Ralph, J., and Hatfield, R. D. Pyrolysis GC:MS Characterization of Forage Materials.Pdf. J. Agric. 1991, 39, 1426-1437.

(51) Branca, C.; Giudicianni, P.; Di Blasi, C. GC / MS Characterization of Liquids Generated from Low-Temperature Pyrolysis of Wood. 2003, 3190-3202.

(52) Chiaramonti D, Oasmaa A, Solantausta Y. Power generation using fast pyrolysis liquids from biomass. Renewable and Sustainable Energy Reviews. 2007, (11) 10561086.

(53) Ne, J. Step-Wise and One-Step Vacuum Pyrolysis of Birch-Derived Biomass to Monitor the Evolution of Phenols. 2001, 60, 219-231.

(54) Czernik, S.; Bridgwater, A. V. Overview of Applications of Biomass Fast Pyrolysis Oil. 2004, 12, 590-598.

(55) Scott, S., Piskorz, J., and Radlein, D. Lignin Derived Oils from the Fast Pyrolysis of Poplar Wood. Journal of Analytical and Applied Pyrolysis. 1987, (12)51-59.

(56) Moldoveanu, S. Pyrolysis of Organic Molecules, 1st ed.; Elsevier: Netherlands, 2010.

(57) Hassan, E. M.; Steele, P. H.; Ingram, L. Characterization of Fast Pyrolysis Bio-Oils Produced from Pretreated Pine Wood. Applied Biochem Biotechnol. 2009, 182-192.

(58) Johra, F. T.; Lee, J.; Jung, W. Facile and Safe Graphene Preparation on Solution Based Platform. J. Ind. Eng. Chem. 2014, 20 (5), 2883-2887.

(59) Ginzburg, B. M.; Tu, S.; Tabarov, S. K.; Shepelevski, A. A.; Shibaev, L. A. X-Ray Diffraction Analysis of C 60 Fullerene Powder and Fullerene Soot. Technical Physics. 2005, 50 (11), 1458-1461.

(60) Azargohar, R.; Dalai, A. K. Biochar As a Precursor of Activated Carbon. Applied Biochemistry and Biotechnology. 2006, 129 (6), 762-773. 
(61) Warren, B. E. X-Ray Diffraction; Dover: New York, 1990.

(62) Kang, J. C., Chen, P. H. and Johnson, W. R. Thermal Uses and Properties of Carbohydrates and Lignins. Ketene Formation for the Pyrolysis of Carbohydrates. 1976, 261.

(63) Iwashita, N. Chapter 2 - X-Ray Powder Diffraction. Materials Science and Engineering of Carbon. 2016, 7-25.

(64) Lotya, M.; Hernandez, Y.; King, P. J.; Smith, R. J.; Nicolosi, V.; Karlsson, L. S.; Blighe, F. M.; De, S.; Wang, Z.; Mcgovern, I. T.; et al. Liquid Phase Production of Graphene by Exfoliation of Graphite in Surfactant / Water Solutions. J. Am. Chem. Soc. 2009, 131 (10), 3611-3620. DOI: 10.1021/ja807449u

(65) He, M.; Guo, X.; Huang, J.; Shen, H.; Zeng, Q.; Wang, L. Mass Production of Tunable Multicolour Graphene Quantum Dots from an Energy Resource of Coke by a One-Step Electrochemical Exfoliation. Carbon N. Y. 2018.

(66) Xu, R.; Ferrante, L.; Briens, C.; Berruti, F. Flash Pyrolysis of Grape Residues into Biofuel in a Bubbling Fluid Bed. J. Anal. Appl. Pyrolysis 2009, 86, 58-65.

(67) Cuthbertson, D.; Berardi, U.; Briens, C.; Berruti, F. Biomass and Bioenergy Biochar from Residual Biomass as a Concrete Filler for Improved Thermal and Acoustic Properties. Biomass and Bioenergy 2019, 120 (February 2018), 77-83.

(68) Li, Z. Advanced Concrete Technology. John Wiley \& Sons (Editors). 2011, 1-22.

(69) Meyer, C. The Greening of the Concrete Industry. Cem. Concr. Compos. 2009, 31 (8), 601-605.

(70) Zheng, Q.; Han, B.; Cui, X.; Yu, X.; Ou, J. Graphene-Engineered Cementitious Composites: Small Makes a Big Impact. Nanomater. Nanotechnol. 2017, 7, 1-18.

(71) Kloss, S.; Zehetner, F.; Dellantonio, A.; Hamid, R.; Ottner, F.; Liedtke, V.; Schwanninger, M.; Gerzabek, M. H.; Soja, G. Characterization of Slow Pyrolysis Biochars: Effects of Feedstocks and Pyrolysis Temperature on Biochar Properties. J. Environ. Qual. 2012, 41(4), 990-1000. DOI: 10.2134/jeq2011.0070.

(72) Gupta, S.; Kua, H. W. Factors Determining the Potential of Biochar As a Carbon Capturing and Sequestering Construction Material : Critical Review. 2017, 29 (9). DOI: 10.1061/(ASCE)MT.1943-5533.0001924

(73) Berardi, U.; Naldi, M. The Impact of the Temperature Dependent Thermal Conductivity of Insulating Materials on the Effective Building Envelope Performance. Energy Build. 2017, 3-42 DOI: 10.1016/j.enbuild.2017.03.052

(74) Berardi, U.; Iannace, G. Acoustic Characterization of Natural Fibers for Sound Absorption Applications. Build. Environ. 2015, 1-42.

DOI: 10.1016/j.buildenv.2015.05.029

(75) Yeon Lee, J., Do Yun, H., and Chang Choi, W. Mechanical Properties of Mortar Containing Bio-Char from Pyrolysis. Journal of Korea Institute for Structural Maintenance and Inspection. 2012, 67-74. DOI: 10.11112/jksmi.2012.16.3.067

(76) Han, B.; Wang, Y.; Dong, S.; Zhang, L.; Ding, S. Smart Concretes and Structures : A Review. Journal of Intelligent Material Systems and Structures. 2015, 1-43. DOI: $10.1177 / 1045389 X 15586452$ 